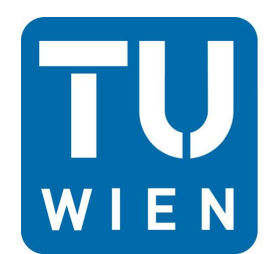

TECHNISCHE UNIVERSITÄT WIEN

Vienna University of Technology

D I P L O M A R B E I T

\title{
Financing the Reduction of Emissions from Deforestation: A Differential Game Approach
}

Ausgeführt am Institut für

Stochastik und Wirtschaftsmathematik

der Technischen Universität Wien

unter Anleitung von Ao.Univ.Prof. Dipl.-Ing. Dr.techn. Gernot Tragler

durch

Bernadette Riesner

Breinberg Nord 24

5202 Neumarkt

Wien, am 13. Mai 2015

(Unterschrift) 



\section{Kurzfassung}

In dieser Diplomarbeit werden zwei Varianten eines Klimaschutzmechanismus, der weltweite Emissionen vor allem durch eine Verringerung der Abholzung des Regenwaldes senken will, analysiert und miteinander verglichen. Im Rahmen dieses Mechanismus zahlen Industrieländer Entschädigungen an Regenwaldländer, wenn diese ihre Abholzung reduzieren, da dies kostengünstiger ist als die heimische Produktion zu beschränken. Die Ausgangsfrage für diese Arbeit ist dabei, welche Finanzierungsoption die besten Ergebnisse für das Klima, den Regenwald und den Wohlstand der Teilnehmerstaaten mit sich bringt. Weiters werden zwei kritische Aspekte des Mechanismus in beiden Optionen behandelt. Dafür werden hauptsächlich Differentialspiele mit zwei Spielern (Industrieländer und Regenwaldländer) entwickelt. Diese Spiele werden durch Anwendung von Pontryagins Maximumsprinzip und mit dem Konzept von Nash- bzw. Stackelberg-Gleichgewichten gelöst. Durch die linear-quadratische Form der Spiele können in den meisten Fällen analytische Lösungen gefunden werden. Es stellt sich heraus, dass beide Varianten des Mechanismus einen wertvollen Beitrag zum Klimaschutz leisten können, und dass die meisten jeweiligen Vor- und Nachteile der Varianten invariant gegenüber Parameteränderungen und kleineren Modifikationen des Modells sind. 



\begin{abstract}
This thesis analyzes and compares two versions of a mechanism that aims at mitigating climate change through reducing emissions from rainforest-deforestation. In this mechanism, industrialized countries pay compensations to countries with rainforests if they reduce their deforestation, because it is more cost-efficient than restricting domestic production. The initial question is, which funding possibility yields the best environmental results and is most beneficial for the involved parties. Furthermore, two critical issues of the mechanism are addressed more closely in both scenarios. For this purpose, differential games are developed, in which industrialized countries and countries with rainforests denote the two players. Solutions are obtained by applying Pontryagin's Maximum Principle and the concepts of Nash or Stackelberg Equilibria. Due to the model assumptions, analytical solutions can be found for most of the considered games. It turns out that both versions of the mechanism can be a valuable contribution in the battle against climate change. Moreover, most advantages and disadvantages of the two variants turn out to be robust with respect to parameter changes and small modifications of the model.
\end{abstract}





\section{Contents}

1 Introduction to REDD 1

1.1 What is REDD? . . . . . . . . . . . . . . . . . . . . 1

1.2 Market-based versus fund-based approach $\ldots \ldots \ldots \ldots \ldots$

\begin{tabular}{|lll}
2 & Literature related to the modelling of REDD & 7
\end{tabular}

$2.1 \quad$ Large Computational models . . . . . . . . . . . . . . . . . 7

2.2 Models in the tradition of Ehui et al. . . . . . . . . . . . . . . 8

2.3 Other game-theoretic models $\ldots \ldots \ldots \ldots \ldots$

3 Market-Based vs. Fund-Based REDD 13

$3.1 \quad$ Modelling . . . . . . . . . . . . . . . . . . . . . 13

3.2 Parametrisation . . . . . . . . . . . . . . . . . . 20

3.3 Results . . . . . . . . . . . . . . . . . . . . . . . . . . . . 22

3.4 Sensitivity Analysis $\ldots \ldots \ldots \ldots \ldots \ldots$

\begin{tabular}{|lll}
4 & Fairness Aspects & 43
\end{tabular}

4.1 Differing parameters $\ldots \ldots \ldots \ldots \ldots \ldots \ldots$

4.2 Stackelberg Competition . . . . . . . . . . . . . . . . . . . . 46

4.3 Separate markets $\ldots \ldots \ldots \ldots \ldots$

5 Sustainability Aspects $\quad 55$

5.1 The adapted model $\ldots \ldots \ldots \ldots \ldots \ldots \ldots$

5.2 Solving the adapted model $\ldots \ldots \ldots \ldots \ldots \ldots$. . . . . . . . . . 57

5.3 Parametrisation . . . . . . . . . . . . . . . . . . . . . . . . . . 59

5.4 Results . . . . . . . . . . . . . . . . . . . . . 60

5.5 Sensitivity Analysis $\ldots \ldots \ldots \ldots \ldots$

\begin{tabular}{lll}
\hline 6 Conclusion & 67
\end{tabular} 



\section{Chapter 1}

\section{Introduction to REDD}

\subsection{What is REDD?}

In search of promising strategies to combat climate change, REDD is one of the most debated proposals. REDD is an abbreviation for 'reduced emissions from deforestation and forest degradation' (Fatheuer 2008). The basic idea is to pay money to forest owners so that they do not cut down their forest and hence avoid greenhouse gas emissions (Dooley et al. 2008]). Forests (especially rainforests) are important $\mathrm{CO}_{2}$-sinks and deforestation causes approximately $20 \%$ of global $\mathrm{CO}_{2}$-emissions (Stern 2007).

Therefore, the preservation of rainforests within the scope of a REDD-mechanism can play a vital role in the battle against climate change. Nicholas Stern (2007) emphasises that in the following way:

'Reducing deforestation is the single largest opportunity for cost-effective and immediate reductions of carbon emissions.'

This potential was already seen in the negotiations that led to the Kyoto Protocol in 1997. But no agreement on the precise design could be found and only afforestation became eligible under the Clean Development Mechanism.

In 2005 at the COP-11 in Montreal the Coalition for Rainforest Nations, headed by Costa Rica and Papua New Guinea, put REDD back on the agenda.

In the Bali Roadmap 2007 the fundamental decision for the implementation of a REDD mechanism was written down. 
Since the United Nations Climate Change Conference on Bali the term REDD+ instead of $R E D D$ has been widely used. The plus suggests a broader approach that also incorporates poverty reduction and preservation of biodiversity. However, the main idea remains the same and therefore the notation $R E D D$ will be maintained here in this thesis.

2010 at the COP-16 in Cancun it was decided that at first national reference emissions respectively reference deforestation rates have to be determined. Furthermore, robust and transparent monitoring systems have to be implemented. This is, because if a forest owner is payed for reduced deforestation, it has to be known how much she would have cut down in absence of a compensation scheme, and the actual deforestation activities have to be verifiable.

First guidelines for the determination of reference rates were agreed upon in 2011 at the COP-17 in Durban. Furthermore, the funding of REDD was discussed, however without any concrete result.

The major points for discussion at the COP-18 in Doha were again the funding of REDD and the monitoring of deforestation, but again no resolution could be adopted.

Finally, 2013 at the United Nations Climate Change Conference in Warsaw, some monitoring issues could be solved. This agreement cleared the way for result-based payments. The financing discussion now focused on the choice between a market-based and a fundbased approach, but no agreement could be achieved.

The historical information about REDD is taken from Holloway and Giandomenico 2009 and theredddesk].

\subsection{Market-based versus fund-based approach}

In both scenarios the forest owners receive money if their deforestation is below a certain reference rate. The reference rate should describe how much they would have deforested in absence of a REDD mechanism. In reality it is not easy to determine that rate because the forest owners tend to exaggerate the planned future deforestation in order to raise more money. In a theoretical setting we do not have to face this problem because their behaviour can be modelled as the solution of an optimisation problem.

In a market-based scenario, forest owners can generate certificates if their deforestation 
rate is below the reference rate. That means that reduced deforestation is converted into reduced carbon emissions, and this certificate can be sold on an international certificate market. Buyers, who have a reduction obligation, imposed by the Kyoto Protocol or a succeeding agreement, can use these certificates towards their emissions reductions compliance targets. That means, if the price of the certificate is lower than the domestic carbon avoidance costs, the buyer can comply with her reduction target in a cheaper way.

A fund-based solution implies that a fund is implemented into which everybody, mainly industrial countries though, can pay money. The thus arising sum will be distributed among rainforest countries, according to their reduced deforestation. Donors with reduction obligations are not allowed to count the emission reduction they financed as their own reduction.

The strongest advocate of a market-based solution is the Coalition for Rainforest Nations, an organisation of 41 rainforest countries in Latin America, Africa and Asia. They argue that only in a market-solution with certificate trading, industrial countries have a monetary incentive to invest into the preservation of the rainforest, and thus only in this approach sufficient money can be raised. Furthermore, this proposal is economically efficient, meaning that a fixed reduction obligation can be fulfilled with the least possible cost.

On the other hand, the largest rainforest country Brasil and the insular state Tuvalu belong to the most vehement opponents of a market-based approach. Their main point is that a market-solution only helps industrial countries to cheaply comply with their reduction obligations but that it does not lead to additional emission reduction (Dooley et al. 2008).

However, both reasonings fall short, as REDD cannot be analysed independently from the negotiations for new reduction obligations in the scope of a successive treaty of the Kyoto Protocol. It can be assumed that industrial countries will be willing to accept more stringent reduction targets, if they are able to fulfil them relatively cheaply with the help of certificate trading as part of REDD.

Which effect prevails, either the increased willingness to transfer money to the south if emission certificates are thereby generated and to accept low emission caps in a marketbased approach or the additional reductions beyond the obligations in a fund-based solution, is the starting point for this thesis. 
This thesis is organised as follows: Chapter 2 gives an overview of literature dealing with the modelling of incentives for reduced deforestation and emissions trading. In Chapter 3 , a model that is based on models from Chapter 2 but deals more specifically with the above question of fund-based vs. market based REDD, is developed and closely analysed. In Chapters 4 and 5 criticism towards REDD is presented and the model is adapted to analyse or improve the criticised aspects. Chapter 6 summarises the most important results and highlights possible extensions of the model. 




\section{Chapter 2}

\section{Literature related to the modelling of REDD}

\subsection{Large Computational models}

A strong strain in literature is the assessment of REDD-like scenarios within the frame of a large integrated assessment model.

A widely known example is the WITCH (World Induced Technical Change Hybrid) model (Bosetti et al. [2007]). It is a Ramsey-type neoclassical optimal growth hybrid model. It differentiates between twelve world regions that each optimise investments in different capital stocks, R\&D, energy technologies and consumption of fossil fuels. The gametheoretic frame accounts for interdependencies and spillovers across world regions and allows the analysis of fully cooperative equilibria as well as regional coalitional equilibria. Analyses of mechanisms to reduce deforestation and mitigate climate change within the framework of WITCH can e.g. be found in Bosetti et al. 2009] and Tavoni et al. [2007].

Another often-cited integrated assessment approach are the RICE/DICE models developed at Yale University by William Nordhaus et al. (Nordhaus and Boyer [2000]). An example for the use of RICE/DICE in the context of reduced deforestation can be found in Eriksson 2013.

In Kindermann et al. 2008 even three different very detailed global forestry and land-use models are used to show that programmes for avoided deforestation can lead to substantial emission reductions. The three models used there are DIMA (Dynamic Integrated Model of Forestry and Alternative Land Use), GCOMAP (Generalized Comprehensive 
Mitigation Assessment Process Model), and GTM (Global Timber Model). DIMA assesses land-use options in agriculture and forestry in 0.5-degree-grid cells across the globe. GCOMAP is a dynamic partial equilibrium model that analyses afforestation and deforestation in 10 world regions. GTM optimises management of forestlands for 250 timber types.

Due to the high level of detail, these models might be quite realistic, but they are also untransparent. It is hard to keep track of assumptions, policy specifications and underlying data. Therefore it seems not to be the best choice to adapt one of the above models for the analysis of the initial question of this thesis.

\subsection{Models in the tradition of Ehui et al.}

Many models with varying frame and aim can be seen in the tradition of Ehui et al. [1990], in the sense that the utility function of forest-owners is derived from the intuitively accessible description of the driving factors of deforestation there. Examples are Andrés-Domenech et al. [2008], Karima et al. [2008], Martín-Herrán et al. [2006] and Van Soest and Lensink 2000.

Roughly speaking, in all of these models the south faces the following optimisation problem:

$$
\begin{gathered}
\max _{D(t)} \int_{0}^{\infty} e^{-r t}\left\{[\bar{P}-\theta q(t)] q(t)+p(t)\left[F_{0}-F(t)\right]+T(t)\right\} d t \\
q(t)=\gamma F(t)+D(t) \\
\text { s.t. } \quad \dot{F}(t)=-D(t), \quad F(0)=F_{0}
\end{gathered}
$$

Firstly, it is important to note that two kinds of deforestation activities are regarded here: clear felling and selective logging for precious timber. Let $D(t)$ denote the amount of timber from clear felling. Selective logging is assumed to consist of a very small constant fraction $(\gamma)$ of the total stock of forest $F(t)$. Both activities together lead to the total amount of felled timber $q(t)$ at time $t$.

It is furthermore assumed that deforestation yields two kinds of income. Firstly, timber can be sold at a price that is linearly decreasing in the amount sold. Then revenues through timber sale in $t$ amount to $[\bar{P}-\theta q(t)] q(t)$, where $\bar{P}$ is the maximal market price obtained when $q(t)$ tends towards zero and $\theta$ is a positive parameter that determines the 
steepness of the demand curve.

Secondly, the deforested areas can be used for agricultural production. Agricultural yield is denoted by $p(t)$. Only clear-felled areas can be used for this purpose, thus agricultural income can be modelled as $p(t)\left[F_{0}-F(t)\right]$, where $F_{0}$ denotes the initial size of the rainforest and $F(t)$ is the size of the rainforest at time $t$.

Furthermore it is assumed that selective logging has a negligible influence on the size of the rainforest, therefore only $D(t)$ appears in the differential equation for the stock variable $F(t)$.

Finally, $T(t)$ denotes transfer payments that are somehow dependent on deforestation rates or forest stocks, and $r$ is the discount rate.

Simplifications of this base model can e.g. be found in Karima et al. [2008], where the time horizon is finite, selective logging is not regarded and agricultural yield is set to a fixed value. On the other hand e.g. in Andrés-Domenech et al. [2008] also afforestation activities and natural grow back of forests are considered.

Modelling of non-forest owners and the game-theoretic framework differ more widely, as described in what follows.

In Van Soest and Lensink [2000] a donor exogenously offers a compensation function $T(t)$ that depends only on the stock of the forest (positively) and large-scale deforestation (negatively). The authors conclude that it is important that per-unit compensation is fixed and does not increase with decreasing forest size, as this may lead to an extra incentive to deforest rather than that it becomes less attractive.

In Martín-Herrán et al. [2006] non-forest countries are modelled explicitly as deriving (linear-quadratic) utility from forest stocks and negative utility from compensation payments. A differential game à la Stackelberg with Markovian information structure is considered, where non-forest-owners act as leaders and announce the general form of their transfer strategy. Forest-owners take this information into account and choose an optimal deforestation rate response. After that, the donor community decides the absolute amount of transfer. The authors show that the utility of both players can be improved through this Stackelberg differential game.

In Karima et al. 2008] the transfer function is specified more clearly as $T(t)=s(t)$. 
$\max (0, F(t)-\nu D(t))$. Non-forest countries want to maximise the forest stock at the end of the regarded period. Again, non-forest owners act as leaders in a Stackelberg differential game (but here with an open loop information structure) and first propose a subsidy rate $s(t)$. Afterwards the forest owner optimises her deforestation rate, taking into account the leader's announcement. Once this reaction is known to the leader, she chooses her control path. It can be shown that this set-up - making the transfer function directly dependent on the deforestation rate in addition to be dependent on the forest stock - has a clear impact on slowing deforestation.

In Andrés-Domenech et al. 2008 non-forest owners derive concavely increasing utility from emissions, as emissions are closely linked to production. Negative utility comes from increased $\mathrm{CO}_{2}$ concentrations in the atmosphere. It is also assumed that forests are carbon sinks and therefore non-forest countries are indirectly interested in high forest stocks. In this paper individual optimisation and joint optimisation (optimisation of the sum of both utilities) are compared with each other. It is found that joint optimisation can lead to economic as well as environmental gains.

\subsection{Other game-theoretic models}

Furthermore, there are many interesting papers that cannot easily be attributed to a large strain of literature.

The aim of Ollivier 2012 is to determine whether REDD on national or individual level is preferable. For that purpose a two-sector growth model with Cobb-Douglas production functions that contains land and capital is developed. An international institution exogenously offers a transfer that (positively) depends on the difference between a reference deforestation rate and actual deforestation, and also on forest stock. Comparison of the social-planner optimisation and the decentralised solution leads to the conclusion that REDD is more efficient on a national level.

In Chiroleu-Assouline et al. 2013 the REDD mechanism is modelled as a principal-agent problem. The principal (a developed country or a supranational funding institution) wants to reduce deforestation in order to mitigate climate change and is ready to transfer money to forest-owners. The agent (a developing country with rainforest) is solely interested in its economic growth and controls her deforestation depending on her commitment with the principal. The focus in this paper is on the challenges that arise from incomplete information about reference deforestation rates and opportunity costs of reduced deforestation. 
Another totally different aspect is highlighted in Figuières and Midler [2011]. The authors model $m$ developing countries with rain forests and a block of developed countries with a preference for low tropical deforestation. The aim is to design a REDD-frame such that the Nash Subgame Perfect Equilibrium between the $m+1$ players is also a Pareto optimum, fulfils a non-envy criterion between developing countries, and can be seen as environmentally responsible.

Although not directly dealing with incentives for reduced deforestation, the work of Helm 2003 and Amato and Valentini 2011] is also worth mentioning here. Helm 2003 analyses which emission caps countries choose with or without international emissions trading. To do so, a three-stage game is regarded. In the first stage, countries decide whether or not they want to establish a trading system. Only unanimous consent leads to the implementation of such a system. In the second stage, countries optimise their emissions caps. In the third case (in the case of unanimous approval), emission allowances are traded on an international emission permit market. The game is solved using backwards induction. The author concludes that the effects of allowance trading are ambiguous, welfare as well as total global emissions may or may not increase, dependent on specifications of countries' benefit and damage functions.

Amato and Valentini 2011 extend the analysis in Helm 2003 by also considering a cooperative assignment of emission caps. It is shown that this centralisation leads to higher welfare and lower total global emissions than in the non-cooperative case. 



\section{Chapter 3}

\section{Market-Based vs. Fund-Based REDD}

\subsection{Modelling}

The goal of this section is to develop models that reproduce the main ideas of a marketbased and a fund-based approach, respectively, and allow to compare the outcomes in both scenarios. The aim is to keep the models as simple as possible in order to focus on the defining differences between the two approaches.

Although there is a lot of literature about the modelling of REDD (see chapter 2) to the best of my knowledge there are no mathematical papers that focus on this specific topic. The strategy of the following chapter is therefore to use components of models from above-cited papers and put them into a game-theoretic frame that accounts for the differences in the two REDD-scenarios.

To be more specific, that game-theoretic frame should not only describe the functioning of the two REDD mechanisms themselves but also the willingness of industrialised countries to reduce their own emissions, depending on which REDD mechanism is installed. As described in Section 1.2., only the joint analysis of those two effects can lead to a reasonable comparison between the two REDD approaches.

As in large parts of the literature and for reasons of simplicity, only two agents will be considered that interact in a finite period $[0, T]$. The first agent will be called north and represents industrial countries that do not own forest. The second one, south, represents developing countries with rainforests. 


\subsubsection{The baseline scenario}

\section{Modelling of the south}

The modelling of the south is chosen to follow the tradition of Ehui, Hertel and Preckel [1990], as this approach, although already 25 years old, seems to be widely acknowledged, is still being reused and describes the driving factors of deforestation in an intuitively accessible way.

Here, however, only one kind of deforestation is regarded: $D(t)$ represents clear-felling deforestation at time $t$. Selective logging is ignored, as it is only a constant rate in (2.1), and therefore not alterable by a REDD mechanism.

As in all models in Section 2.2, it is assumed that deforestation in the south yields two kinds of income. Firstly, timber can be sold at a price that is linearly decreasing in the amount sold. Then revenues through timber sale in $t$ amount to $[\bar{P}-\theta D(t)] D(t)$, where $\bar{P}$ is the maximal market price obtained when $D(t)$ tends towards zero and $\theta$ is a positive parameter that determines the steepness of the demand curve.

Secondly, the deforested areas can be used for agricultural production. Here, like in Karima et al. 2008], it is assumed that the yield per cultivated land is constant. As a short and finite horizon is regarded, this does not seem to be a severe assumption. Thereby, agricultural income can be modelled as $Y\left[F_{0}-F(t)\right]$, where $F_{0}$ denotes the initial size of the rainforest and $F(t)$ is the size of the rainforest at time $t$.

Similarly to (2.1), in the absence of an international agreement, the south faces the following optimisation problem:

$$
\begin{gathered}
\max _{D(t)} \int_{0}^{T} e^{-r_{s} t}\left\{[\bar{P}-\theta D(t)] D(t)+Y\left[F_{0}-F(t)\right]\right\} d t+e^{-r_{s} T} \phi F(T) \\
\text { s.t. } \quad \dot{F}(t)=-D(t), \quad F(0)=F_{0}
\end{gathered}
$$

The salvage value function $\phi F(T)$, which is also taken from Karima et al. [2008], should prevent complete deforestation at the end of the period considered.

Let $\bar{D}(t)$ be the function that optimises this problem and serves as a reference rate for the definition of reduced deforestation. 


\section{Modelling of the north}

The economic utility of the north is modelled in a more schematic way. It is important here to reflect the two-edged role of greenhouse gas emissions for the north. On the one hand, emissions are closely linked to production and thereby economic welfare. On the other hand, excessive emissions of greenhouse gases lead to climate change and all the negative impacts related to it.

One could now argue that climate change also impacts the south and should therefore also be represented in the south's objective function. While it is undoubtable that the south will also suffer from climate change, it is reasonable to assume that economic growth has a much higher priority for many developing countries than climate protection and that therefore no "climate-change-term" appears in the south's subjective utility function.

Analogously to Andrés-Domenech et al. [2008] (see Section 2.2), Breton et al. [2005] and Dockner and Long [1993 (there in a slightly different context), it is assumed that production and greenhouse gas emissions grow proportionally and that the utility derived from production is concave. The following specification of utility fulfils both requirements:

$$
\text { Economic utility of the north }(t)=a E_{n}(t)-b E_{n}(t)^{2} \text {, }
$$

where $E_{n}(t)$ denotes the greenhouse gas emissions of the north.

However, not only industrial activities of the north lead to greenhouse gas emissions, as mentioned before. According to Stern [2007] approximately $20 \%$ of global $\mathrm{CO}_{2}$ emissions stem from deforestation activities. Due to the game-theoretic frame that will be developed in the following sections, it is crucial to be able to compare emissions of the north and the south. In the above cited papers on REDD this is not necessary, as the donor is either assumed to have a preference for rainforests and low deforestation rates or the transfer is exogenously provided.

Therefore, in this model deforestation has to be converted into corresponding greenhouse gas emissions. The most natural way to do so is to assume that a certain area of rainforest stores on average a certain amount of $\mathrm{CO}_{2}$, which will be released after logging. This leads to

$$
E_{s}(t)=\gamma D(t)
$$


the emissions of the south $E_{s}(t)$ are thus proportional to deforestation. Here it is ignored that the cleared areas are often used for cattle breeding, which leads to increased methane production and therefore also to global warming.

It is important to note that it is not the emissions $E_{n}(t)+E_{s}(t)$ at a certain point in time, but rather the accumulated stock of greenhouse gases in the atmosphere $S(t)$, that leads to climate change and the damages associated with it. It is clear that the concentration of greenhouse gases in the atmosphere increases with emissions,

$$
\dot{S}(t)=E_{n}(t)+E_{s}(t)
$$

but one could also argue that, e.g., $\mathrm{CO}_{2}$ vanishes from the atmosphere after some time and the differential equation should thus rather look like $\dot{S}(t)=E_{n}(t)+E_{s}(t)-\delta(t) S(t)$, which is used in Dockner and Long [1993]. However, Solomon et al. 2009] compute a half-life period of $\mathrm{CO} 2$ of up to 800 years. Taking into a account a maximal time horizon of 10-20 years for political decisions, the natural decay of greenhouse gases can be neglected here.

A truly realistic modelling of the stock of greenhouse gases would be much more complex and would for instance also incorporate the carbon uptake by the oceans, which varies from year to year due to el Niño effects (see Le Quéré et al. 2009]). But as these details are irrelevant for highlighting the differences of the basic mechanisms of the two different REDD scenarios, they are neglected as well.

Andrés-Domenech et al. 2008, Benchekroun and Long 2002, Dockner and Long 1993 and Breton et al. 2005] state that the damage caused by a certain concentration of greenhouse gases is convex in the stock $\left(L^{\prime \prime}(S)>0\right)$. However, as there has always been $\mathrm{CO}_{2}$ in the atmosphere, it is not the existence but the concentration over a threshold $\underline{S}$ that causes damage. The following damage function, which is widely used in the literature, reflects those two observations:

$$
\text { Damage caused by climate change }(t)=c_{n}[S(t)-\underline{S}]^{2}
$$

In this model, $c_{n}$ weights the damages, in comparison to economic utility. The level of $c_{n}$ can also be interpreted as environmental awareness of the north. The higher $c_{n}$ is, the more the north considers environmental aspects when it chooses its optimal emissions path. 
In absence of an international agreement, the north faces the following optimisation problem:

$$
\max _{E_{n}(t)} \int_{0}^{T} e^{-r_{n} t}\left\{a E_{n}(t)-b E_{n}(t)^{2}-c_{n}[S(t)-\underline{S}]^{2}\right\} d t-e^{-r_{n} T} \psi S(T)
$$

The dynamic constraint results from plugging (3.3) into (3.4):

$$
\dot{S}(t)=E_{n}(t)+\gamma \bar{D}(t), \quad S(0)=S_{0}
$$

\subsubsection{Preliminaries on modelling a REDD-mechanism}

After the introduction of a REDD mechanism, the south receives money, if its deforestation is below a certain reference rate. In reality, this reference rate will presumably be an extrapolated trend from historic emissions (Dooley et al. 2008). Here it is easier to determine how much the south would have deforested in absence of a REDD mechanism, i.e. $\bar{D}(t)$, the solution of problem 3.1). Thus, reduced deforestation amounts to $\bar{D}(t)-D(t)$, and reduced emissions of the south are given by $\gamma(\bar{D}(t)-D(t))$, where $D(t)$ denotes deforestation under a REDD mechanism. Furthermore, this leads to a transfer

$$
T(t)=p(t) \gamma(\bar{D}(t)-D(t))
$$

where $p(t)$ is the price assigned to a certain quantity of avoided emissions. In order to be

able to compare the two different REDD scenarios, in the style of Helm 2003 and Amato and Valentini [2011] (see Section 2.3), a two-stage game will be considered. The model there applies more to the market-based approach, but the basic idea of it - modelling a two-stage game - can be adjusted to also describe a fund-based approach.

\subsubsection{A market-based approach}

As just mentioned, a two-stage game is considered:

- In the first stage, the north agrees on emission caps.

- In the second stage, emission certificates are traded, or more specifically, the north will buy emission certificates from the south in order to fulfil its emission caps with less restrictions for domestic production. 
As this problem will be solved using backwards induction, it is more intuitive to start the detailed description at the second stage.

For that purpose let $O_{n}(t)$ denote the emission cap of the north at time $t$ that results from the first stage. The north can emit more than the cap $O_{n}(t)$, but the transgression has to be compensated through the purchase of emission certificates, thus $E_{n}(t)=O_{n}(t)+Z_{n}(t)$. Increasing emissions $E(t)$ result according to 3.2 in increasing domestic production, but the corresponding certificates (denoted by $Z_{n}(t)$ ) have to be bought at market price $p_{z}(t)$. To comply with the caps in the cheapest possible way the north faces the following optimisation problem:

$$
\max _{Z_{n}(t)} \int_{0}^{T} e^{-r_{n} t}\left\{a\left[O_{n}(t)+Z_{n}(t)\right]-b\left[O_{n}(t)+Z_{n}(t)\right]^{2}-p_{z}(t) Z_{n}(t)\right\} d t
$$

Here, no terms for the damages caused by excessive pollution appear, as the trading of emission certificates only redistributes emissions between traders but does not change the sum of them.

The south can sell certificates, if it emits less than in the baseline scenario:

$$
Z_{s}(t)=\gamma(\bar{D}(t)-D(t))
$$

The south now has to balance the utility derived from deforestation and the income from selling certificates (see (3.1) and (3.7)):

$$
\begin{gathered}
\max _{D(t)} \int_{0}^{T} e^{-r_{s} t}\left\{[\bar{P}-\theta D(t)] D(t)+Y\left[F_{0}-F(t)\right]+p_{z}(t) \gamma[\bar{D}(t)-D(t)]\right\} d t+e^{-r_{s} T} \phi F(T) \\
\text { s.t. } \dot{F}(t)=-D(t), \quad F(0)=F_{0}
\end{gathered}
$$

The equilibrium market price is the price that leads to $Z_{n}(t)=Z_{s}(t) \forall t \in[0, T]$.

Let $Z_{n}^{*}\left[O_{n}(t), t\right], D^{*}\left[O_{n}(t), t\right]$ be the (Nash-Equilibrium-)solutions of this game.

For further convenience, the following short notation is introduced:

$$
\begin{array}{r}
R_{n}\left[O_{n}(t), t\right]:=a\left\{O_{n}(t)+Z_{n}^{*}\left[O_{n}(t), t\right]\right\}-b\left\{O_{n}(t)+Z_{n}^{*}\left[O_{n}(t), t\right]\right\}^{2} \\
-p_{z}(t) Z_{n}^{*}\left[O_{n}(t), t\right]
\end{array}
$$


Now the first stage can be considered. At the first stage, the trade-off between economic utility 3.10 and damage through emissions 3.5 is optimised.

The north faces:

$$
\begin{gathered}
\max _{O_{n}(t)} \int_{0}^{T} e^{-r_{n} t}\left\{R_{n}\left[O_{n}(t), t\right]-c_{n}[S(t)-\underline{S}]^{2}\right\} d t-e^{-r_{n} T} \psi S(T) \\
\text { s.t. } \quad \dot{S}(t)=O_{n}(t)+\gamma \bar{D}(t), \quad S(0)=S_{0}
\end{gathered}
$$

The constraint results from (3.4) and the observation that trade only redistributes the emissions between regions but does not directly change overall emissions, thus $E_{n}(t)+$ $E_{s}(t)=$

$O_{n}(t)+Z_{n}(t)+\gamma \bar{D}(t)-Z_{s}(t)=O_{n}(t)+\gamma \bar{D}(t)$.

\subsubsection{A fund-based approach}

For the modelling of a fund-based approach again two stages will be required.

- In the first stage, the north agrees on emission caps and also determines how much it is willing to pay into the fund for the preservation of the rainforest and which price it assigns to a certain area of saved rainforest.

- In the second stage the south optimises deforestation according to the money in the fund and the assigned price.

Because the north is able to foresee the reactions of the south, it suffices to determine the price, the required budget then results from the reaction of the south.

In this specification the north acts as a leader and the south as a follower. This seems quite natural, because a situation in which the north offers a voluntary donation and the south is a recipient of aid, is quite asymmetric.

Just like in the market-based approach, it is more intuitive to start the detailed description in the second stage, in which the emission caps $O_{n}(t)$ and the prices offered by the north $p_{f}(t)$, are already set. According to (3.1) and (3.7) the south considers the following optimisation problem:

$$
\max _{D(t)} \int_{0}^{T} e^{-r_{s} t}\left\{[\bar{P}-\theta D(t)] D(t)+Y\left[F_{0}-F(t)\right]+p_{f}(t) \gamma[\bar{D}(t)-D(t)]\right\} d t+e^{-r_{s} T} \phi F(T)
$$

$$
\text { s.t. } \dot{F}(t)=-D(t), \quad F(0)=F_{0}
$$


Let $D^{*}\left[O_{n}(t), p_{f}(t), t\right]$ be the optimal path of deforestation.

For the first stage, again an abbreviation for the economic utility of the north will be introduced, but in the fund-based approach, transferring money to the south only has a negative impact on the economic utility of the north:

$$
R_{n}\left[O_{n}(t), p_{f}(t), t\right]:=a O_{n}(t)-b O_{n}(t)^{2}-p_{f}(t) \gamma\left\{\bar{D}(t)-D^{*}\left[O_{n}(t), p_{f}(t), t\right]\right\}
$$

Now, at the first stage, the north optimally chooses the emission caps and the price offers. As in the market-based scenario, economic interests 3.13 and the avoidance of damages (3.5) have to be balanced:

$$
\max _{O_{n}(t), p_{f}(t)} \int_{0}^{T} e^{-r_{n} t}\left\{R_{n}\left[O_{n}(t), p_{f}(t), t\right]-c_{n}[S(t)-\underline{S}]^{2}\right\} d t-e^{-r_{n} T} \psi S(T)
$$

In contrast to the market-based scenario, reduced emissions from reduced deforestation directly lead to decreased overall emissions as there is no carbon trading. Thus (3.4) and $E_{n}(t)+E_{s}(t)=O_{n}(t)+\gamma D(t)$ lead to the following constraint:

$$
\dot{S}(t)=O_{n}(t)+\gamma D^{*}\left[O_{n}(t), p_{f}(t), t\right], \quad S(0)=S_{0}
$$

\subsection{Parametrisation}

The goal of this section is to find parameters for the above developed model that fulfil the following criteria:

- As many parameters as possible should represent a real price or quantity.

- In the baseline scenario, north and south should emit 27,600 respectively 6,900 million tonnes of $\mathrm{CO}_{2}$.

- The behaviour of both players in the two REDD-scenarios should be interpretable.

The second criterion results from Olivier et al. [2013], where the authors state that global emissions in 2013 amounted to 34,500 million tonnes $\mathrm{CO}_{2}$, and from Stern 2007], where it is postulated that approximately $20 \%$ of global emissions are due to deforestation. 
The following parameters are chosen according to actual prices or quantities:

$F_{0}$ :

The world's forest surface area in 2005 amounted to 3, 952, 000, 000 times $100 \mathrm{~m}^{2}$ AndrésDomenech et al. [2008]).

$Y:$

Andrés-Domenech et al. [2008] state that cotton is a representative commodity related to deforestation and yields a revenue of $11 \$$ per $100 \mathrm{~m}^{2}$.

$\bar{P}$ and $\theta$ :

According to Andrés-Domenech et al. [2008], the average yield of timber per $100 \mathrm{~m}^{2}$ is approximately twice the agricultural yield on the deforested area. Therefore $\bar{P}$ and $\theta$ are set to obtain a timber price of approximately $20 \$$ per $100 \mathrm{~m}^{2}$ in the beginning of the observed period $(\bar{P}=120, \theta=0.1)$.

$\underline{S}$ and $S_{0}$ :

In Andrés-Domenech et al. 2008, parameter $\underline{S}$ is set to match the pre-industrial $C \mathrm{O}_{2^{-}}$ concentration level of 2,201,000 million metric tons of $\mathrm{CO}_{2} . S_{0}$ denotes the cumulated quantity of $\mathrm{CO}_{2}$ in the atmosphere in 2007, which amounts approximately to 3,000,000 million metric tons.

The remaining parameters are mainly chosen to satisfy the second condition:

$\gamma:$

Parameter $\gamma$ is chosen 6.661 in order to convert deforestation into the, according to criterion 2, right amount of emissions of the south.

$a, b$, and $c_{n}$ :

Similarly $a, b$, and $c_{n}$ are chosen to yield the desired amount of emissions of the north. However, many combinations of these parameters fulfil that criterion. The challenge here is to find the right balance between economic interest $(a, b)$ and environmental concern $\left(c_{n}\right)$. If the north were modelled as too environmentally friendly, it would stop all deforestation activities in the REDD scenario. On the other hand, if $c_{n}$ is too small, relatively to $a$ and $b$, then the introduction of a REDD mechanism has no effect on deforestation at all. Finally, $a=300, b=0.05$, and $c_{n}=0.0000005$ seems to be a balanced choice. 
$r_{n}, r_{s}:$

The discount rates $r_{n}$ and $r_{s}$ are set to the standard value of 0.05 .

$\phi, \psi:$

Medium range salvage values $\phi$ and $\psi$ do not critically influence the solutions. In lack of theoretical foundation, they are set to the round number of 10 .

Table 3.1 sums up the set of parameters used for the subsequent analysis.

\begin{tabular}{|ccccccc|}
\hline$T$ & $\bar{P}$ & $\theta$ & $F_{0}$ & $Y$ & $r_{n}$ & $r_{s}$ \\
\hline 10 & 120 & 0.1 & $3,952,000,000$ & 11 & 0.05 & 0.05 \\
\hline
\end{tabular}

\begin{tabular}{|cccccccc|}
\hline$\gamma$ & $\phi$ & $\psi$ & $\underline{S}$ & $S_{0}$ & $a$ & $b$ & $c_{n}$ \\
\hline 6.661 & 10 & 10 & $2,201,000$ & $3,000,000$ & 300 & 0.05 & 0.0000005 \\
\hline
\end{tabular}

Table 3.1: Parameters used for the analysis in the following sections

\section{$3.3 \quad$ Results}

To keep the notation simple, in the following section $H$ denotes the current value Hamiltonian function of the respective optimisation problem. $H_{x}$ indicates the first partial derivative of the Hamiltionian with respect to $x$, and $H_{x, y}$ the second derivative with respect to $x$ and $y$.

The costate variable is represented by $\lambda$ and the scrap value function by $S C R$.

More detailed nomination of these terms will be forgone, as it will be given through context what they refer to.

\subsubsection{The baseline scenario}

In the baseline scenario the actions of the north do not influence the welfare and thus the actions of the south.

The necessary optimality conditions for the south's problem as stated in (3.1) are:

$$
\begin{aligned}
H_{D}=\bar{P}-2 \theta D(t)- & \lambda(t) \stackrel{!}{=} 0 \\
\dot{\lambda}(t) & \stackrel{!}{=} r_{s} \lambda(t)-H_{F}=r_{s} \lambda(t)+Y \\
\lambda(T) & \stackrel{!}{=} S C R_{F}(F(T))=\phi
\end{aligned}
$$


A solution that fulfils the necessary optimality conditions maximises the optimal control problem (3.1), because the Hamiltionian is concave in $(D, F)$ :

$$
\left(\begin{array}{ll}
H_{D, D} & H_{D, F} \\
H_{F, D} & H_{F, F}
\end{array}\right)=\left(\begin{array}{cc}
-2 \theta & 0 \\
0 & 0
\end{array}\right)
$$

The linear differential equation for $\lambda(t)$ is straightforward to solve, and the resulting optimal control is given by

$$
\bar{D}(t)=\frac{1}{2 \theta}\left(\bar{P}+\frac{Y-e^{r_{s}(t-T)}\left(Y+\phi r_{s}\right)}{r_{s}}\right) .
$$

The north takes into account the pollution generated from the south's deforestation. Its necessary optimality conditions are given by:

$$
\begin{aligned}
H_{O_{n}}=a-2 b O_{n}+\lambda(t) & \stackrel{!}{=} 0 \\
& \dot{\lambda}(t) \stackrel{!}{=} r_{n} \lambda(t)-H_{S}=r_{n} \lambda(t)+2 c_{n}(S(t)-\underline{S}) \\
\lambda(T) & \stackrel{!}{=} S C R_{S}(S(T))=-\psi \\
& \dot{S}(t) \stackrel{!}{=} H_{\lambda}=O_{n}(t)+\gamma \frac{1}{2 \theta}\left(\bar{P}+\frac{Y-e^{r_{s}(t-T)}\left(Y+\phi r_{s}\right)}{r_{s}}\right) \\
S(0) & \stackrel{!}{=} S_{0}
\end{aligned}
$$

Since this is a system of two linked differential equations, the solving gets slightly trickier. However the system is still linear and therefore analytically solvable (e.g. using the Matlab toolbox Symbolic). As the display of the closed-form solution would require more than 25, 000 characters, it is therefore omitted.

The Hessian matrix of the Hamiltionian, in turn, can be displayed easily:

$$
\left(\begin{array}{cc}
H_{O_{n}, O_{n}} & H_{O_{n}, S} \\
H_{S, O_{n}} & H_{S, S}
\end{array}\right)=\left(\begin{array}{cc}
-2 b & 0 \\
0 & -2 c_{n}
\end{array}\right)
$$

As this matrix is negative definite, the above optimality conditions are not only necessary but also sufficient.

Figure 3.1 shows the optimal emission paths for both regions. Emissions in the first year are sufficiently close to the levels required in the section about parametrisation. $(6,559$ 


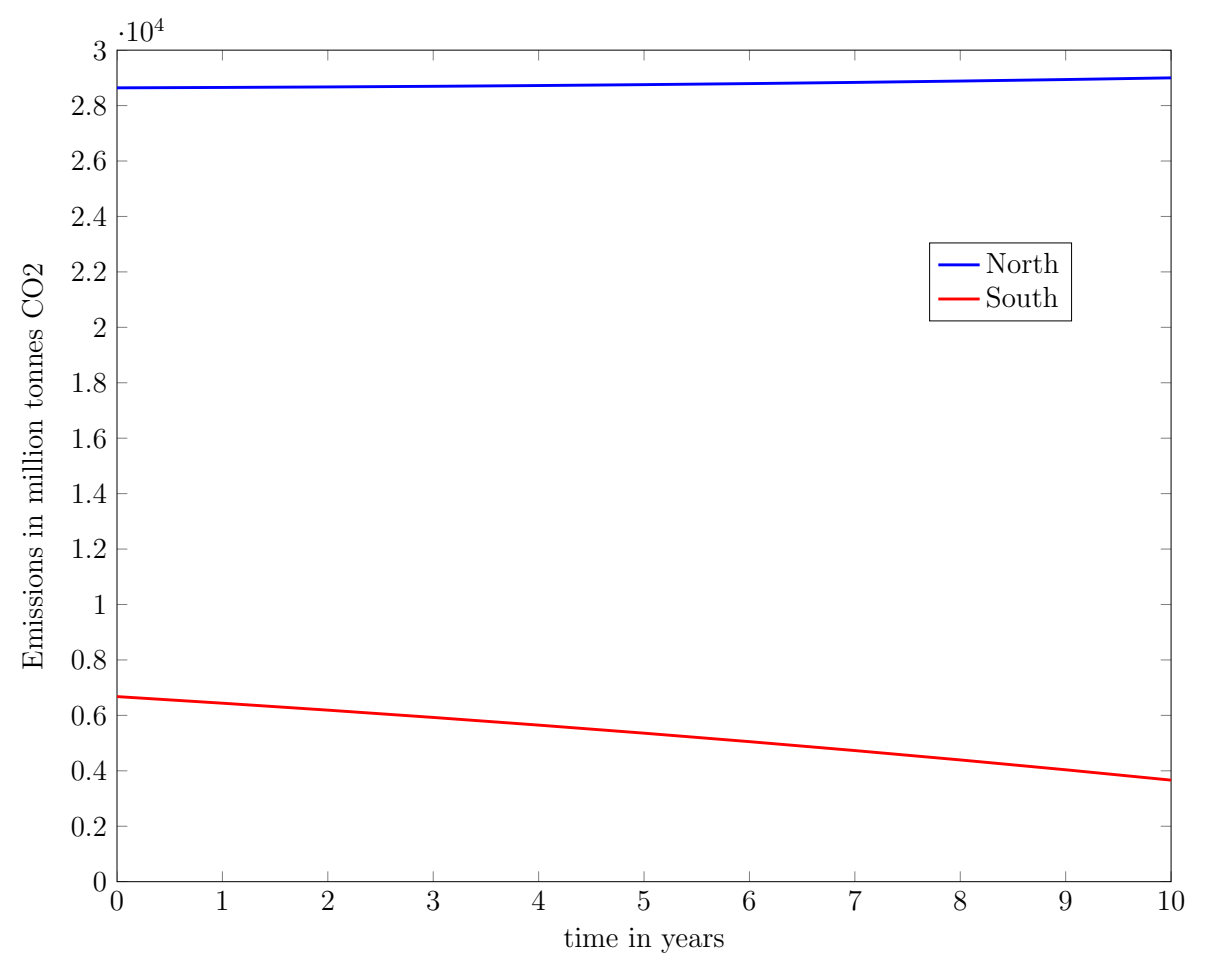

Figure 3.1: Emissions in the baseline scenario

instead of 6,900 million tonnes for the south and 28,650 instead of 27,600 million tonnes for the north.)

Furthermore, Figure 3.1 indicates a slight increase in emissions for the north and a decline in emissions from deforestation over the time horizon of ten years. The second observation is in line with FAO 2010], stating that the rate of deforestation shows signs of decreasing in Asia, South America, Oceania and Africa.

\subsubsection{Market-based REDD}

In the second stage, global total emissions are already set and emission certificate trading takes place. For the north, there are no dynamic constraints to consider and it simply maximises the (concave) utility in (3.8). Thus the optimal amount of certificates bought is

$$
Z_{n}(t)=\frac{a-p_{z}(t)}{2 b}-O_{n}(t)
$$


The south has to solve the following system of equations:

$$
\begin{aligned}
H_{D}=\bar{P}-2 \theta D(t)-p_{z}(t) \gamma-\lambda(t) & \stackrel{!}{=} 0 \\
\dot{\lambda}(t) & \stackrel{!}{=} r_{s} \lambda(t)-H_{F}=r_{s} \lambda(t)+Y \\
\lambda(T) & \stackrel{!}{=} S C R_{F}(F(T))=\phi
\end{aligned}
$$

These conditions are sufficient for optimality as the Hessian matrix of the Hamiltonian does not differ from the one in the baseline scenario (see (3.15)).

Optimal deforestation is given by

$$
D\left(p_{z}(t), t\right)=\frac{1}{2 \theta}\left(\bar{P}-\gamma p_{z}(t)+\frac{Y-e^{r_{s}(t-T)}\left(Y+\phi r_{s}\right)}{r_{s}}\right)=\bar{D}(t)-\frac{\gamma}{2 \theta} p_{z}(t)
$$

Plugging solution $D\left(p_{z}(t), t\right)$ into $Z_{s}(t)=\gamma(\bar{D}(t)-D(t))$ yields:

$$
Z_{s}(t)=\frac{\gamma^{2} p_{z}(t)}{2 \theta}
$$

Therefore in market equilibrium a price for certificates of

$$
p_{z}(t)=\frac{a \theta-2 b \theta O_{n}(t)}{b \gamma^{2}+\theta}
$$

arises.

In the first stage, the north optimises its emission caps. After plugging in $p_{z}(t)$ and $D\left(p_{z}(t), t\right)$, the necessary optimality conditions for 3.11 are:

$$
\begin{aligned}
H_{O_{n}} & =\frac{a \theta^{2}+\lambda(t) \theta^{2}+b^{2} \gamma^{4} \lambda(t)-2 O_{n}(t) b \theta^{2}+2 a b \gamma^{2} \theta+2 b \gamma^{2} \lambda(t) \theta-4 O_{n}(t) b^{2} \gamma^{2} \theta}{\left(b \gamma^{2}+\theta\right)^{2}} \\
& \stackrel{!}{=} 0 \\
\dot{\lambda}(t) & \stackrel{!}{=} r_{n} \lambda(t)-H_{S}=r_{n} \lambda(t)+2 c_{n}(S(t)-\underline{S}) \\
\lambda(T) & \stackrel{!}{=} S C R_{S}(S(T))=-\psi \\
\dot{S}(t) & \stackrel{!}{=} H_{\lambda}=O_{n}(t)+\gamma \frac{1}{2 \theta}\left(\bar{P}+\frac{Y-e^{r_{s}(t-T)}\left(Y+\phi r_{s}\right)}{r_{s}}\right) \\
S(0) & \stackrel{!}{=} S_{0}
\end{aligned}
$$

These conditions are sufficient for optimality as the Hamiltonian is again concave in $\left(O_{n}, S\right)$ : 


$$
\left(\begin{array}{cc}
H_{O_{n}, O_{n}} & H_{O_{n}, S} \\
H_{S, O_{n}} & H_{S, S}
\end{array}\right)=\left(\begin{array}{cc}
-\frac{2 b \theta^{2}+4 b^{2} \gamma^{2} \theta}{\left(b \gamma^{2}+\theta\right)^{2}} & 0 \\
0 & -2 c_{n}
\end{array}\right)
$$

The solution can be obtained using the Matlab toolbox Symbolic. It is again nowhere near a reasonable length to display it here, but Figure 3.2 reveals the most important information.

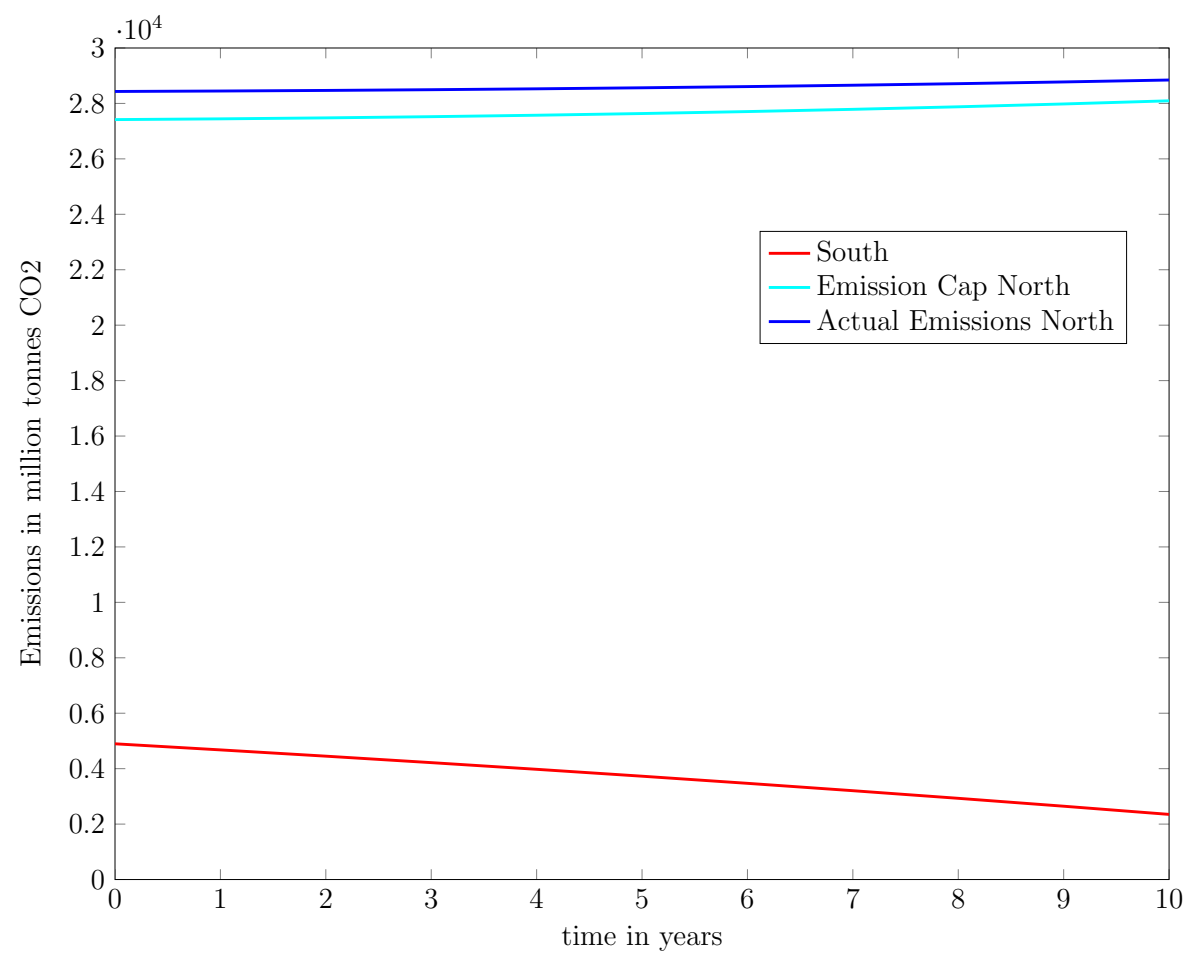

Figure 3.2: Emissions in the market-based REDD scenario

The shape of the graphs in Figure 3.2 looks similar to those in Figure 3.1, but now two lines are required to describe the behaviour of the north. The cyan line shows optimal emissions caps $\left(O_{n}(t)\right)$, while the dark blue line describes the actual emissions $\left(O_{n}(t)+Z_{n}(t)\right)$, which are higher than the cap as emission certificates can be bought.

Figure 3.3 shows that the amount of certificates traded as well as the price payed for emission allowances decline by approximately $25 \%$ during the 10 years considered. This decrease can be explained in the following way:

- According to 3.11 total global emissions in $t$ only depend on $O_{n}(t)$.

- Acoording to (3.17) and (3.18) market price and amount of certificates traded vary 

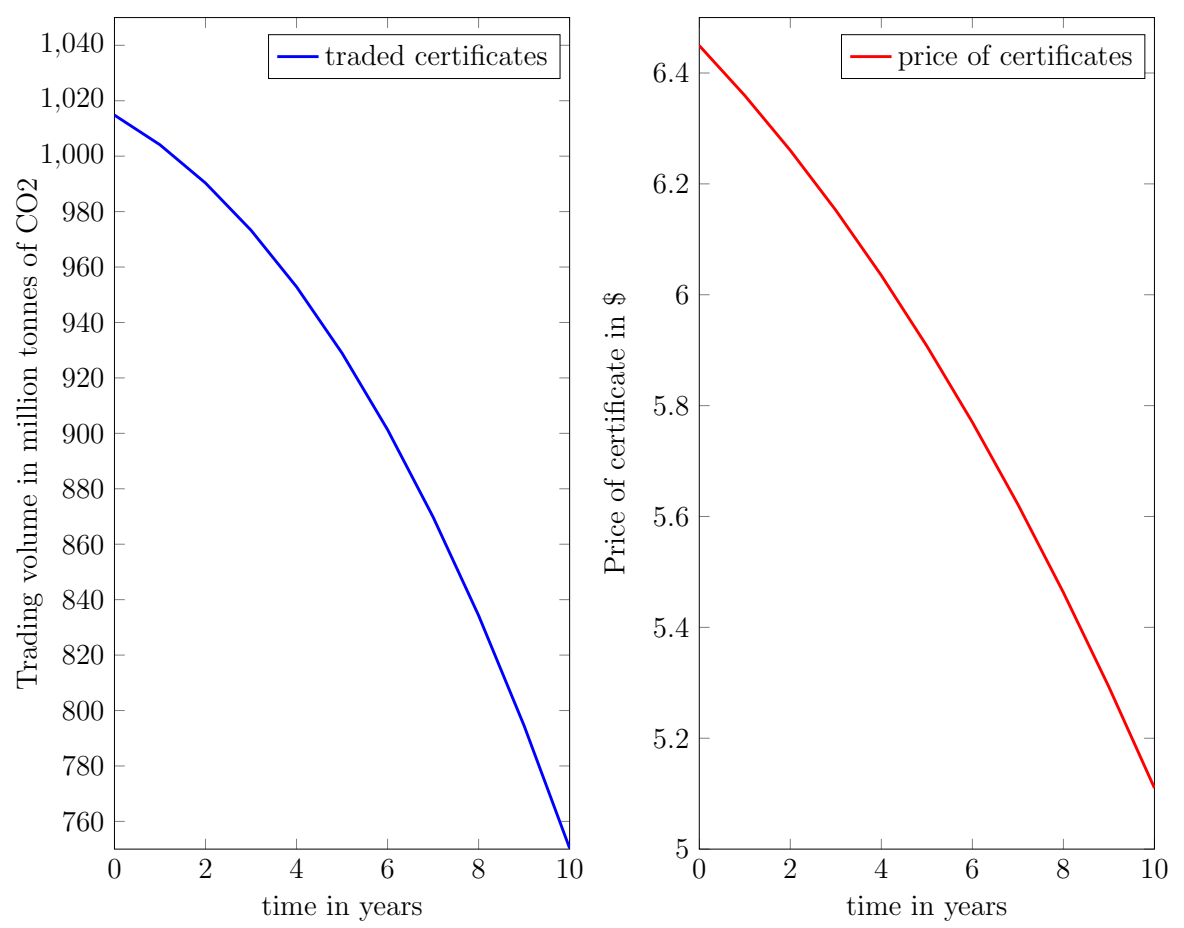

Figure 3.3: Traded volume of certificates (left) and price of certificates (right) in the market-based REDD scenario

in time only due to changes in $O_{n}(t)$. To be more specific, increases in $O_{n}(t)$ lead to a decrease in the other two variables.

Emissions $O_{n}(t)$ grow over time, because the damage of climate change here depends on cumulative emissions. Therefore, the earlier emissions occur, the longer they raise the damage function and the more harmful they are for the north.

\subsubsection{Fund-based REDD}

At the second stage, the emissions from the north and the price offered from the north for reduced deforestation are already set. For the south only the price offered for reduced deforestation is of interest. Therefore, $D\left(p_{f}(t), t\right)$ can be taken from the first step in the market based approach (see (3.16) ) and

$$
D\left(p_{f}(t), t\right)=\frac{1}{2 \theta}\left(\bar{P}-\gamma p_{f}(t)+\frac{Y-e^{r_{s}(t-T)}\left(Y+\phi r_{s}\right)}{r_{s}}\right)=\bar{D}(t)-\frac{\gamma}{2 \theta} p_{f}(t) .
$$

In the first stage, the north optimally chooses $O_{n}(t)$ and $p_{f}(t)$, therefore the optimality conditions consist of more equations than before: 


$$
\begin{aligned}
H_{O_{n}}=a-2 b O_{n}(t)+\lambda(t) & \stackrel{!}{=} 0 \\
H_{p_{f}}=-\frac{\gamma\left(\lambda(t)+2 \gamma p_{f}(t)\right)}{2 \theta} & \stackrel{!}{=} 0 \\
\dot{\lambda}(t) & \stackrel{!}{=} r_{n} \lambda(t)-H_{S}=r_{n} \lambda(t)+2 c_{n}(S(t)-\underline{S}) \\
\lambda(T) & \stackrel{!}{=} S C R_{S}(S(T))=-\psi \\
\dot{S}(t) & \stackrel{!}{=} H_{\lambda}=O_{n}(t)+\frac{\gamma}{2 \theta}\left(\bar{P}-\gamma p_{f}(t)+\frac{Y-e^{r_{s}(t-T)}\left(Y+\phi r_{s}\right)}{r_{s}}\right) \\
S(0) & \stackrel{!}{=} S_{0}
\end{aligned}
$$

As in the previous cases these conditions are sufficient, because the Hamiltonian is jointly concave in $\left(O_{n}, p_{f}, S\right)$ :

$$
\left(\begin{array}{ccc}
H_{O_{n}, O_{n}} & H_{O_{n}, p_{f}} & H_{O_{n}, S} \\
H_{p_{f}, O_{n}} & H_{p_{f}, p_{f}} & H_{p_{f}, S} \\
H_{S, O_{n}} & H_{S, p_{f}} & H_{S, S}
\end{array}\right)=\left(\begin{array}{ccc}
-2 b & 0 & 0 \\
0 & -\frac{\gamma^{2}}{\theta} & 0 \\
0 & 0 & -2 c_{n}
\end{array}\right)
$$

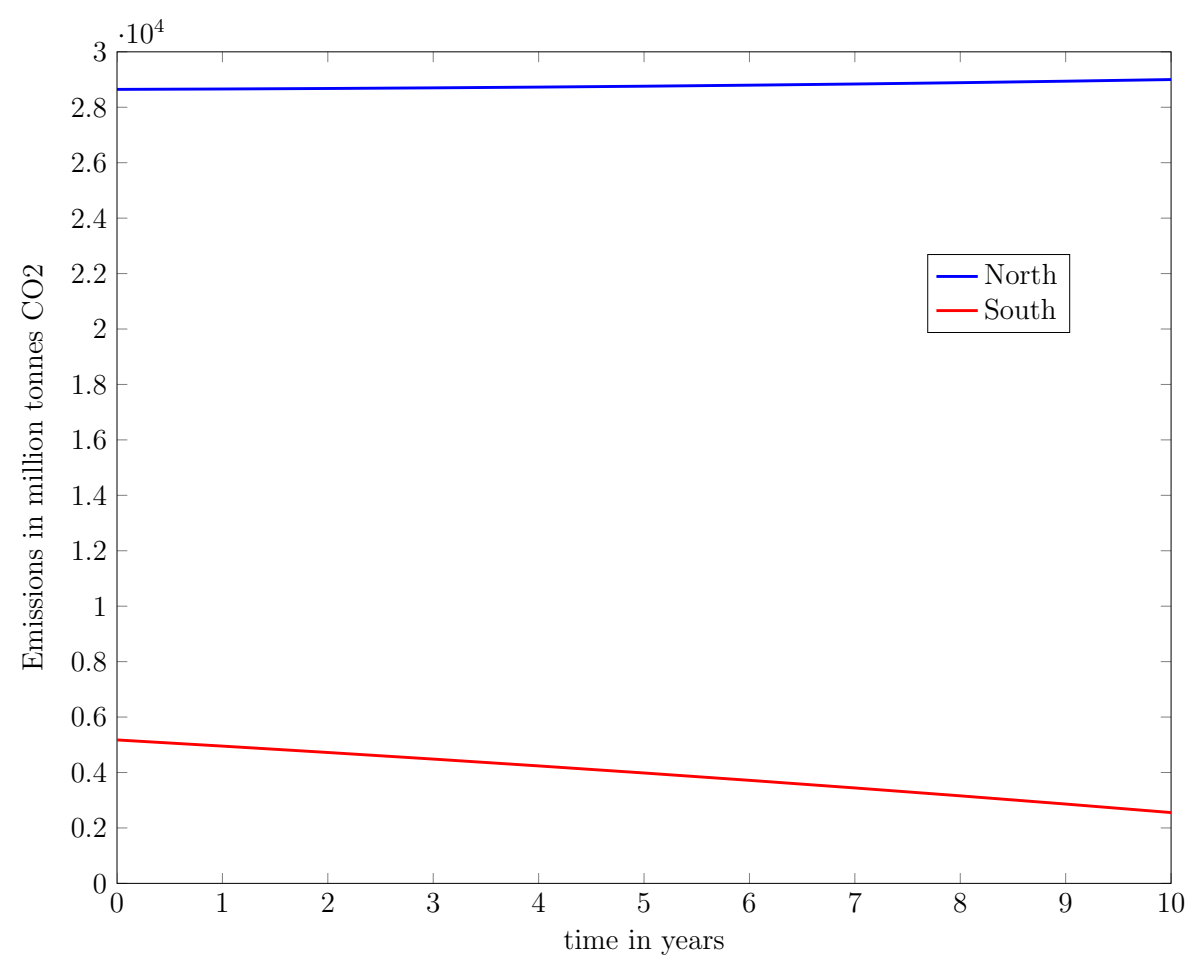

Figure 3.4: Emissions in the fund-based REDD scenario

As it can be seen in Figure 3.4, the shape of the optimal emission paths is similar to the 
two previous cases.

Also, the price that the north offers for reduced deforestation evolves similarly to the price in market equilibrium, where it declines by roughly $25 \%$ over the time horizon regarded (see Figure 3.5).

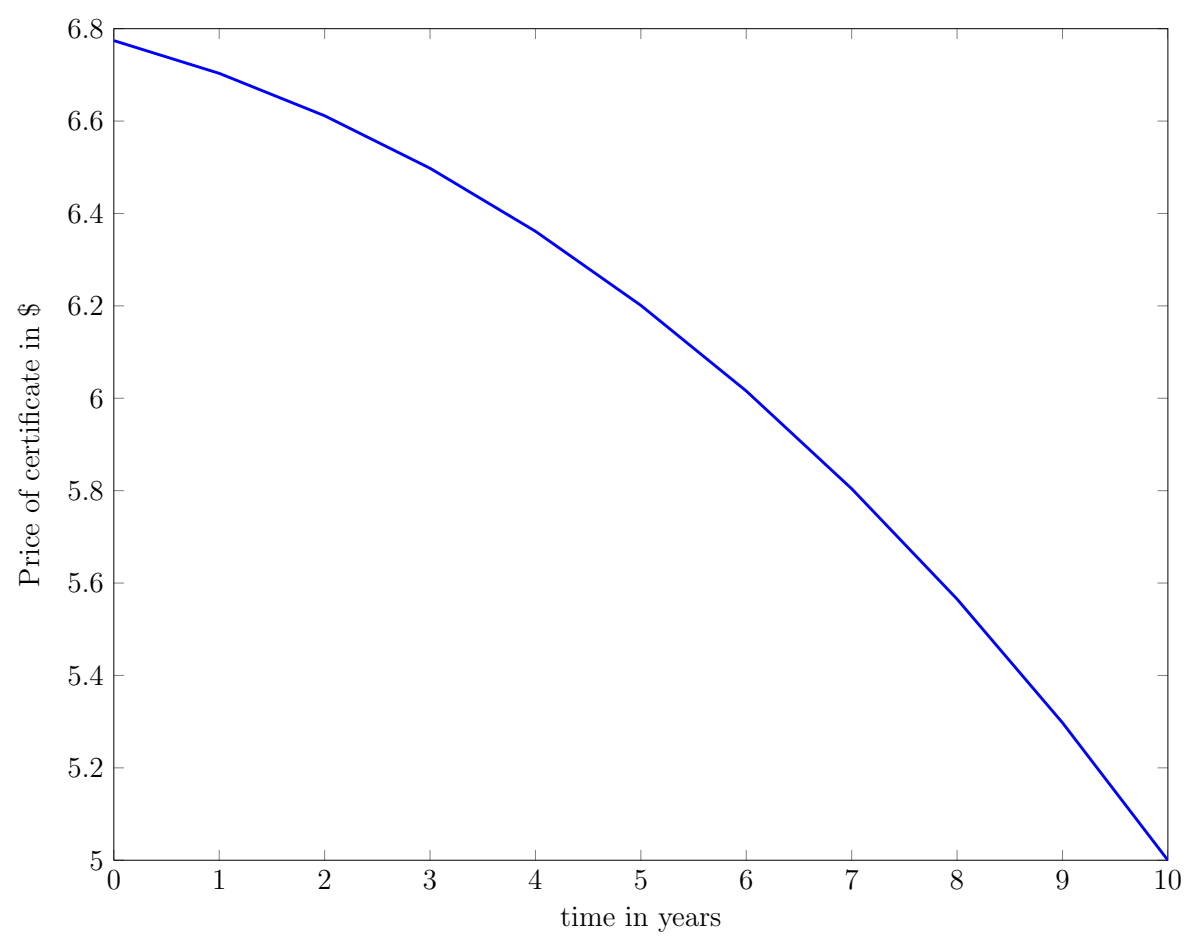

Figure 3.5: Price of reduced deforestation in the fund-based REDD scenario

\subsubsection{Comparison of the different scenarios}

In this section the optimal behaviour in the two different REDD mechanisms will be analysed and compared to each other as well as to the baseline scenario.

Figure 3.6 shows that the introduction of a market-based as well as a fund-based REDD mechanism leads to a significant decline in deforestation. In the market-scenario deforestation decreases on average by $30 \%$. A fund leads to approximately $25 \%$ less deforestation. It is in line with theory that a market-based REDD mechanism leads to a sharper decline in deforestation, because the north has more incentive to buy certificates than to donate money.

This fact is also affirmed by Figure 3.7. The price that the north is willing to pay for reduced deforestation is higher in the market-based scenario, because the certificates can be used towards the north's emission targets. 


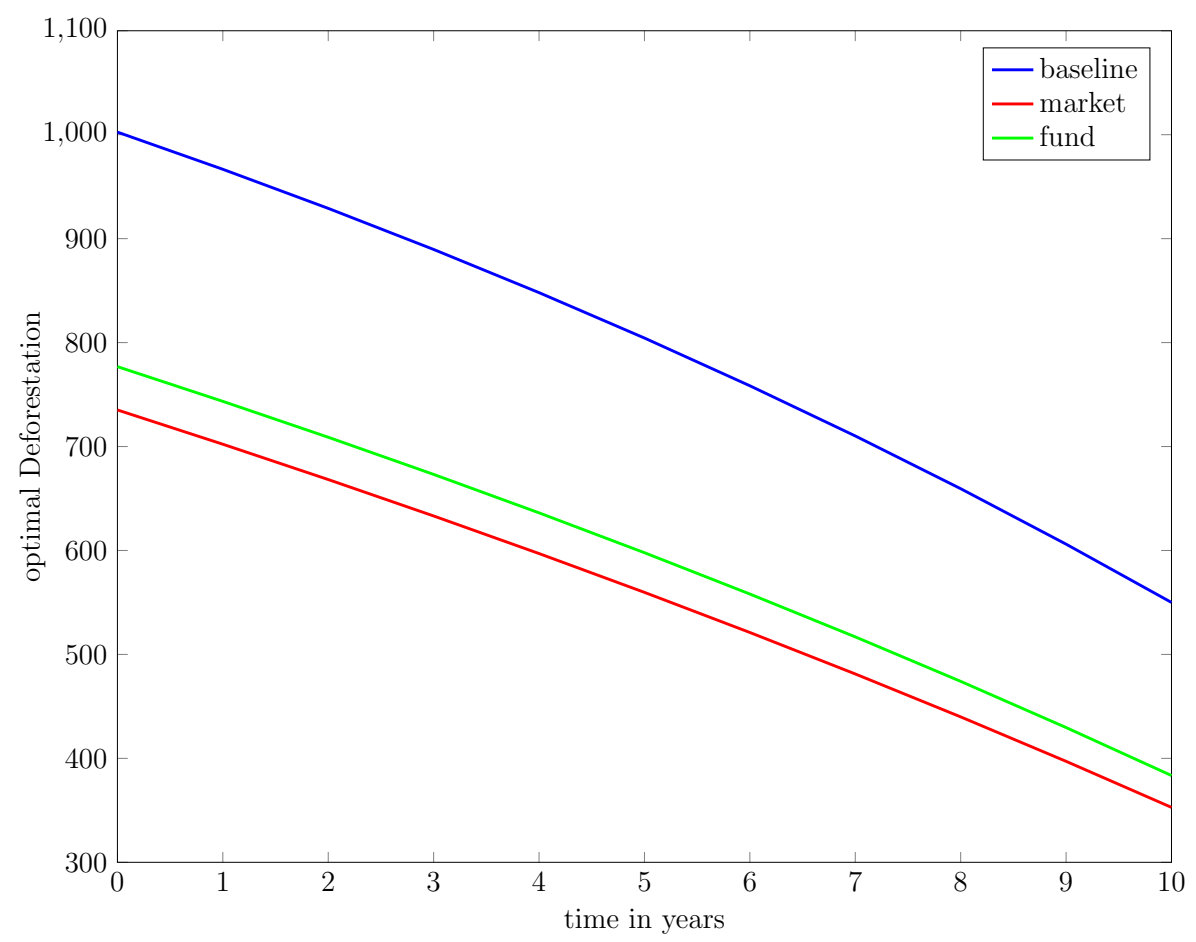

Figure 3.6: Deforestation in three different scenarios

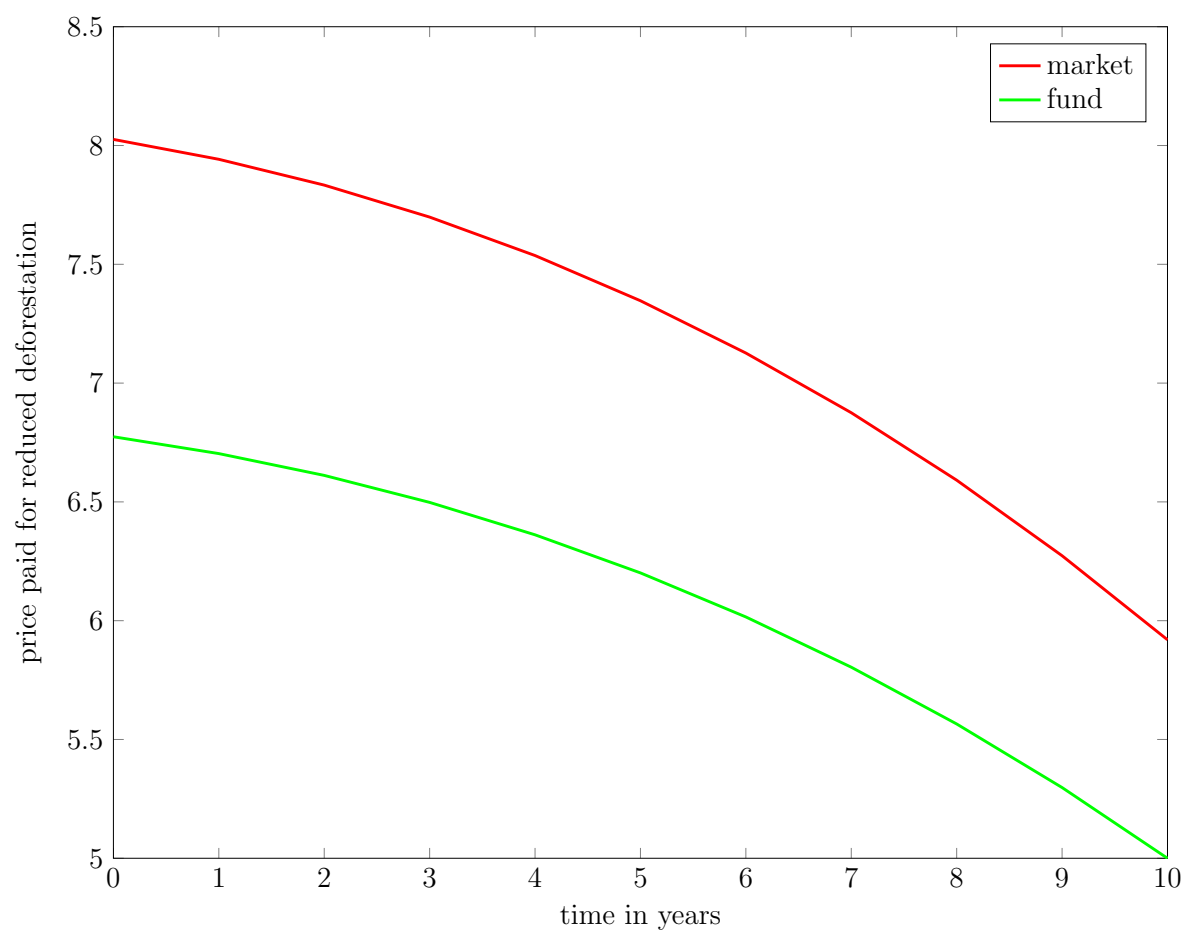

Figure 3.7: Price of reduced deforestation in both REDD scenarios 
In contrast to the purely positive effects of REDD on deforestation, the effects on the emissions of the north are ambiguous. Actual emissions of the north do not decrease in any of the REDD scenarios relative to the baseline (see Figure 3.8). Critics thus claim that REDD helps the north to buy its way out of responsibility. In the market-based approach emissions of the north even increase significantly.

However, as expected, in the market scenario the north agrees on lower emission caps than in the fund scenario (and also than in the baseline, see Figure 3.8) but is only able to comply with the caps by purchasing large quantities of certificates from the south.

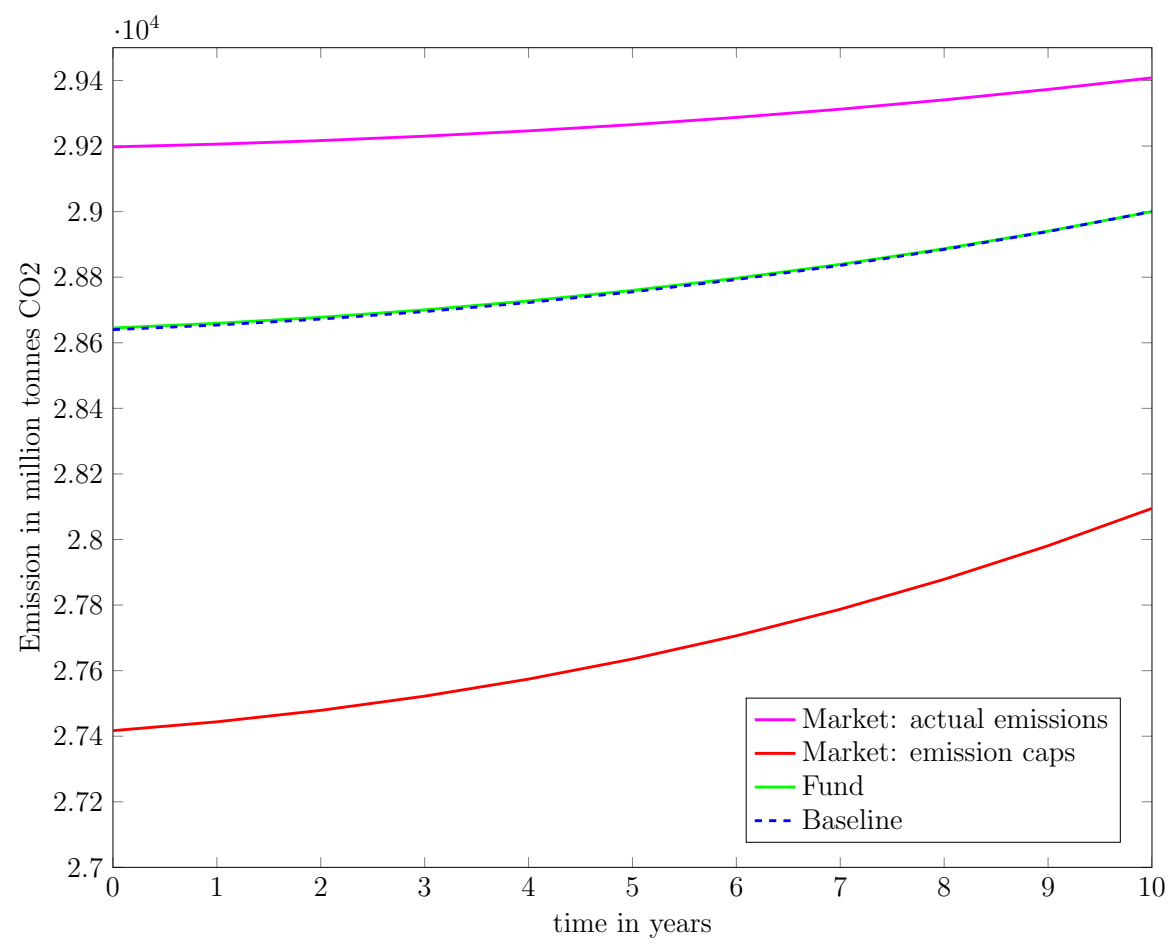

Figure 3.8: Emissions of the north in three different scenarios

The remaining question, which of these contrary effects prevails, is answered in Figure 3.9 .

It shows that both REDD mechanisms can lead to a decline in global total emissions. However, the fund-based approach is able to reduce emissions more effectively than the market-based approach.

The additional reductions beyond the obligations in the fund-based solution is thus more substantial than the fact that more emissions through deforestation are avoided in the market-based approach. 


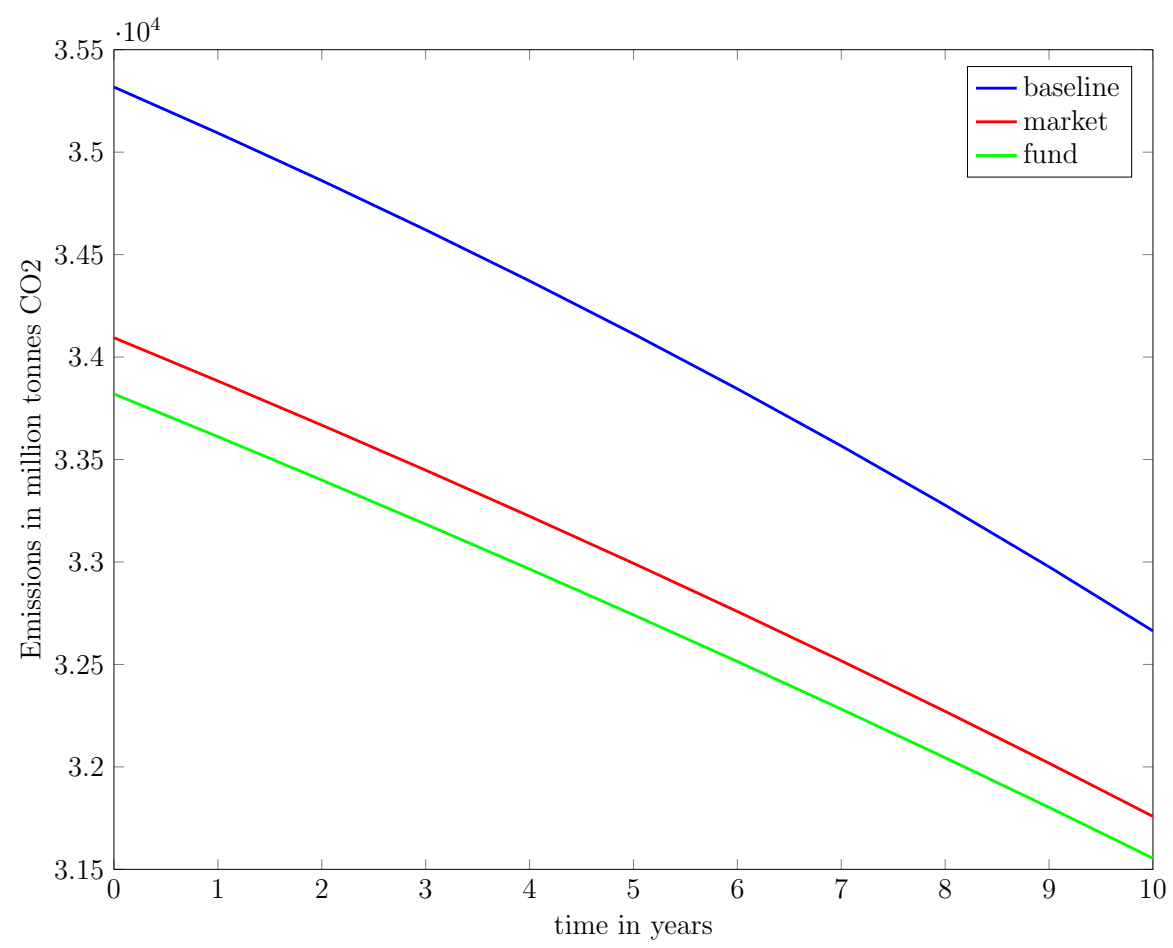

Figure 3.9: Total global emissions in three different scenarios

However, the chances that an agreement becomes implemented rather depend on the benefit that the involved parties derive from it than on the benefit for the environment. Figure 3.10 shows that both regions benefit from the introduction of any REDD mechanism. For the south, the welfare gains are larger in the case of market-based REDD. This reproduces the fact that most rainforest countries favour the financing of REDD through carbon trading (Dooley et al. 2008]).

For the north, fund-based REDD results in a higher welfare gain. The EU officially does not prefer any of the two mechanisms. However, Norway and Germany already started paying into a REDD-like fund (Amazon-Fund).

The reason for the results displayed in Figure 3.10 might be that in a fund-based approach the north, as the donor, can set the price of reduced deforestation whereas in a market scenario, the price results from supply and demand. 


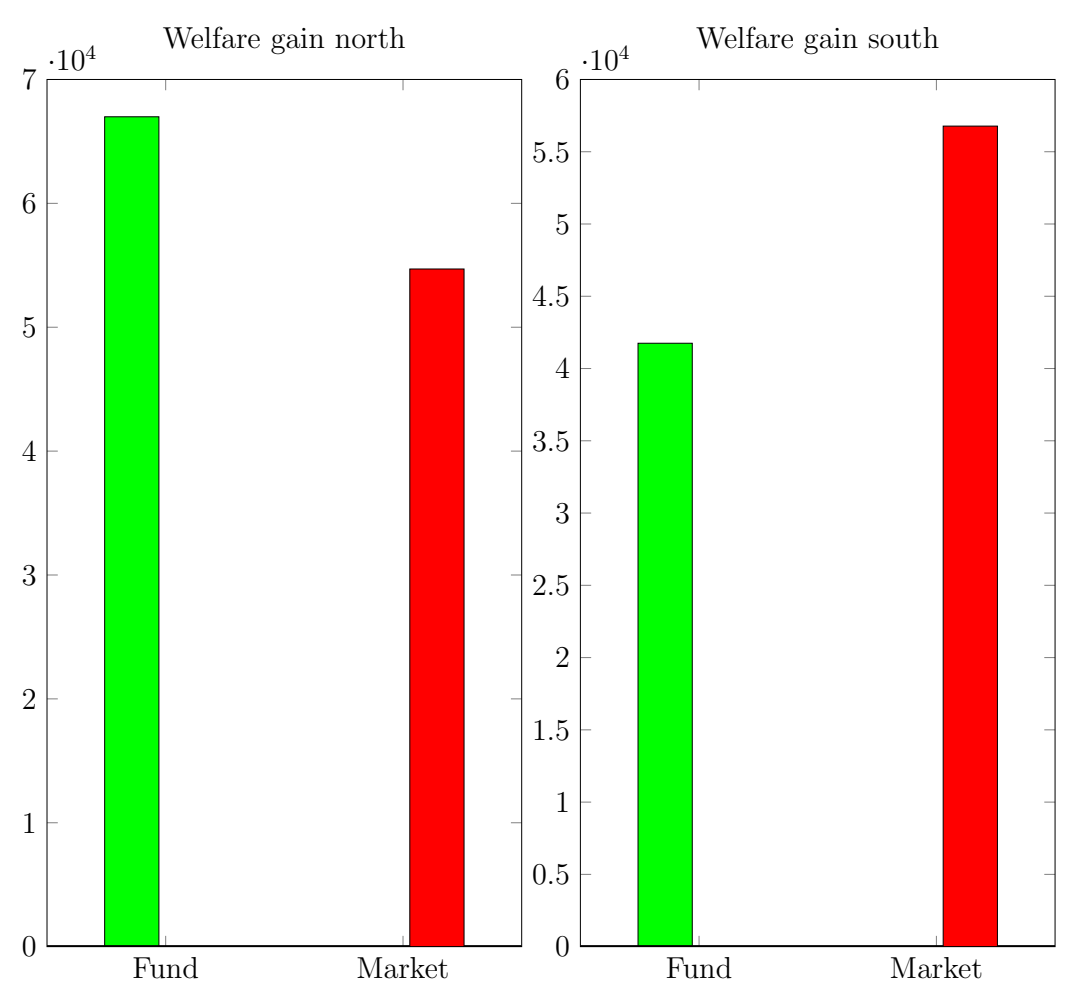

Figure 3.10: Aggregated gain in welfare after ten years

\subsection{Sensitivity Analysis}

In this section it is analysed how parameter changes affect the key figures, which are reduced deforestation, reduced total global emissions and welfare gain through REDD in both scenarios. These effects of parameter changes have been analysed for all parameters that are listed in Table 3.1. At first, by way of example, the findings for variation in environmental awareness and the price for agricultural goods is discussed in detail. Subsequently, the sensitivity analyses for all parameters are briefly summarised.

\subsubsection{Variation in environmental awareness}

At first, changes in parameter $c_{n}$, that weighs the damages caused by climate change, are explored. Variation in this parameter might be caused by awareness campaigns, public debate or shifts in political power.

The case $c_{n}=5 \cdot 10^{-7}$ is the one used for the analysis in Section 3.3.

Figure 3.11 shows rather similar behaviour for fund-based and market-based REDD. Increased environmental awareness leads to more transfers to the south and thus to more 

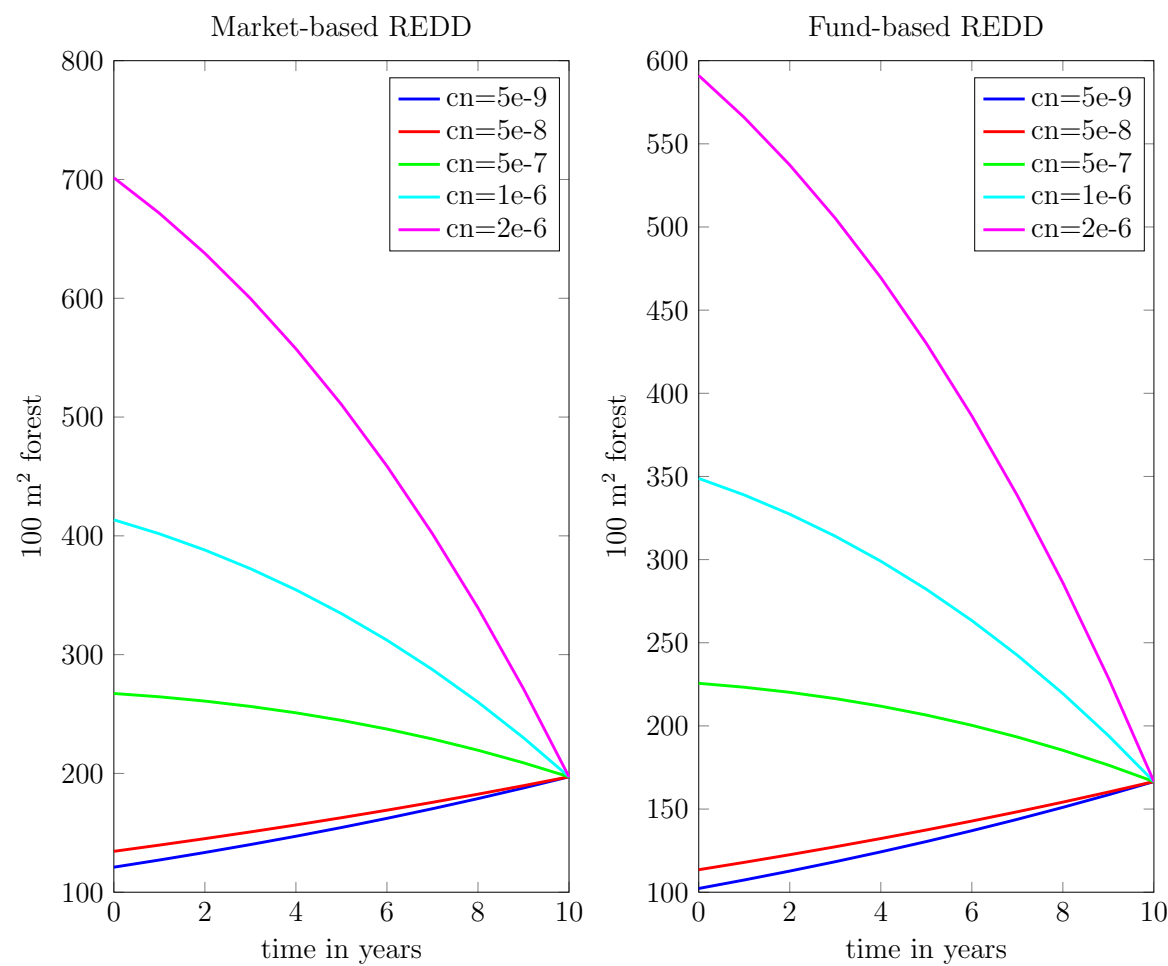

Figure 3.11: Reduced deforestation: variation in environmental awareness
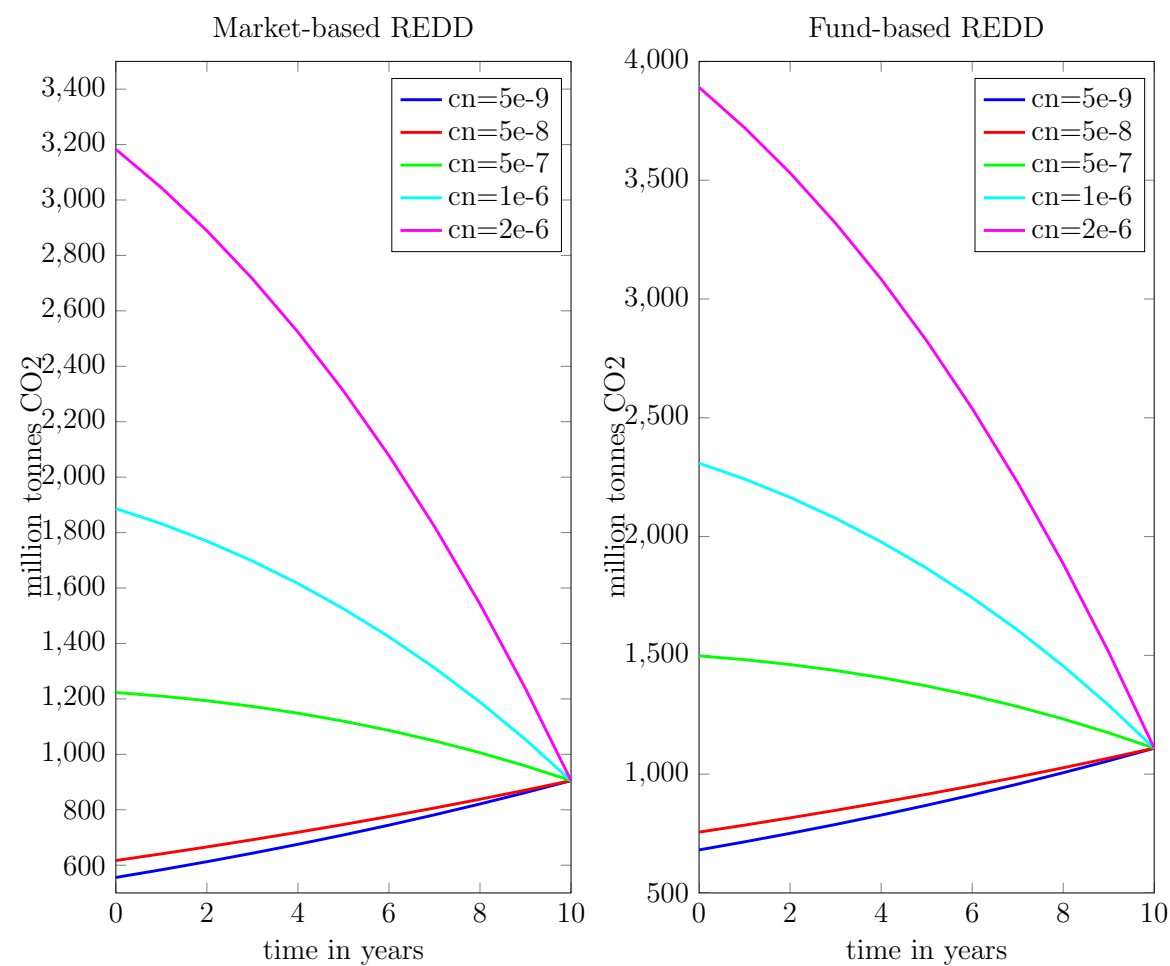

Figure 3.12: Reduced total global emissions: variation in environmental awareness 
avoided deforestation.

Very roughly speaking, doubling the baseline value of $c_{n}$ leads to approximately $50 \%$ more reduced deforestation, whereas dividing $c_{n}$ through ten results in $50 \%$ less avoided deforestation. Dividing baseline $c_{n}$ by 100 causes an only slightly further reduction in reduced deforestation. It is furthermore interesting to note that a value of $c_{n}$ above $3 \cdot 10^{-6}$ leads to the implausible result that the north becomes too environmentally friendly to accept any deforestation at all.

A very similar result can be observed in Figure 3.12 where reduced total global emissions are plotted. That avoided global total emissions increase as well with increased environmental awareness is solely due to increasing avoided deforestation. Actual emissions of the north are higher after the introduction of REDD (only significantly in the case of market-based REDD) and in fact these additional emissions even increase when $c_{n}$ increases. At first this might seem paradoxical. If environmental awareness increases in the north, it obviously wants to reduce global emissions. But the economically optimal way to do so is to save much more rain forest and allow slightly more domestic emissions.

In both figures the results at $T=10$ are not altered by changes in $c_{n}$. This is due to the fact that parameter $\psi$ which weighs the damage in the salvage value function, is not varied.

The gain in welfare that results from the introduction of a REDD mechanism naturally increases with increasing environmental awareness. For the north, this is due to the fact that it becomes more important to be able to reduce the $20 \%$ emissions that result from deforestation, and for the south because the north offers higher transfers.

Figures 3.13 and 3.14 furthermore show that if environmental awareness is already very small, further decreases have hardly any impact.

Another interesting question is whether the statements from Section 3.3.4. still hold true when $c_{n}$ is varied. This is the case for the statements about deforestation and emissions. To be more specific, regardless of the choice of parameter $c_{n}$, market-based REDD still leads to less deforestation and fund-based REDD still results in less global emissions (cf. Figures 3.11 and 3.12 .

The statement about welfare gain, however, is not independent of the choice of $c_{n}$. For the north, a fund only results in more profit gain as long as environmental awareness is below a threshold. For $c_{n}=10^{-6}$ and above, market-based REDD becomes more profitable 


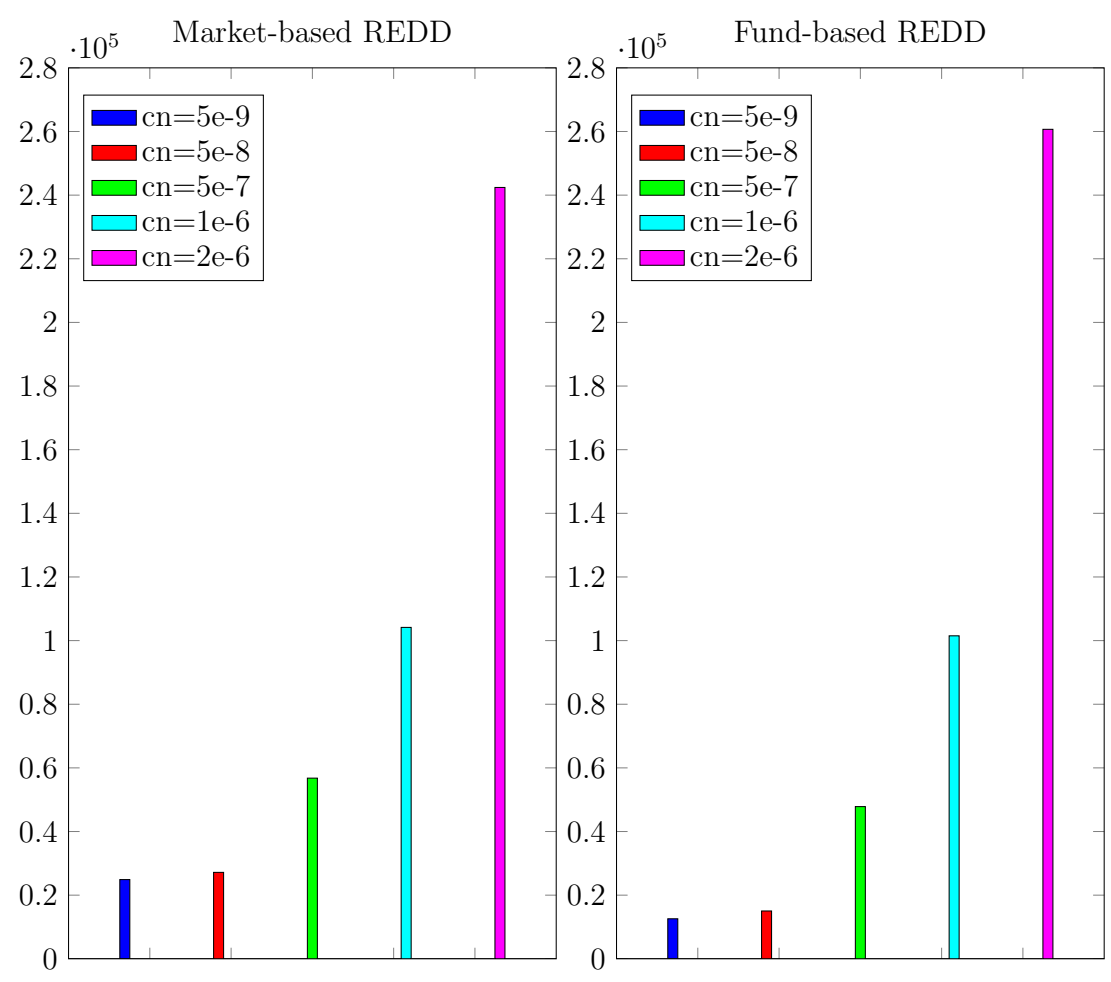

Figure 3.13: Aggregated gain in welfare for south: variation in environmental awareness

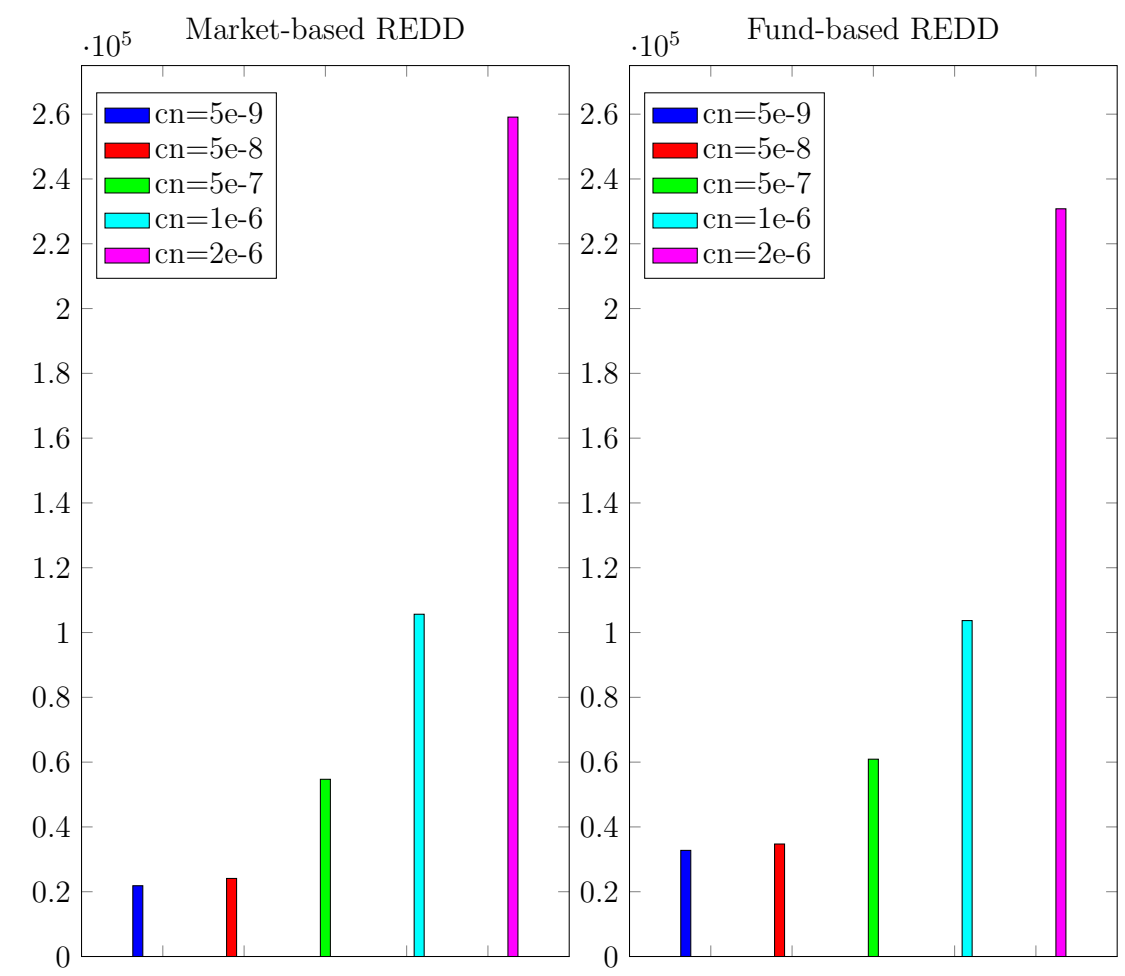

Figure 3.14: Aggregated gain in welfare for north: variation in environmental awareness 

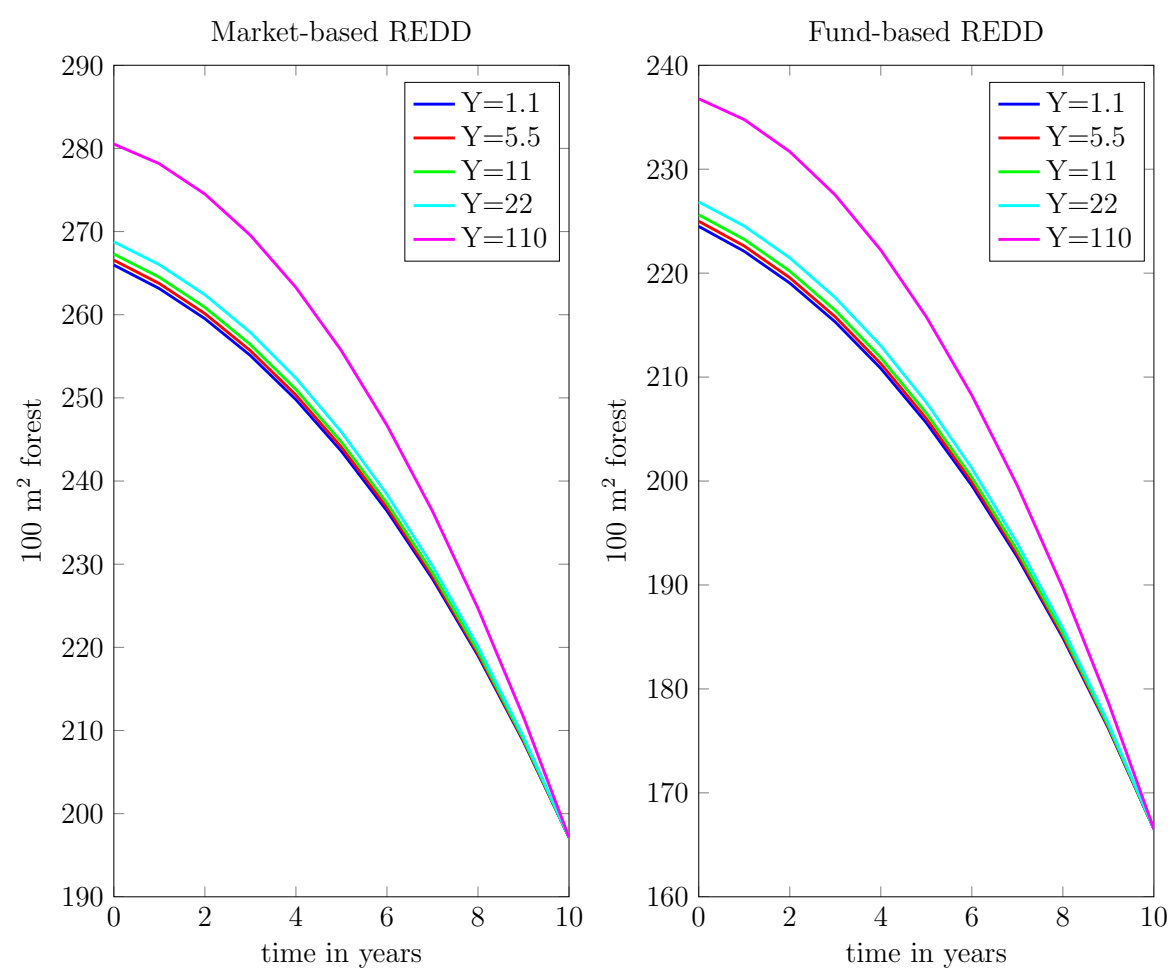

Figure 3.15: Reduced deforestation: variation in agricultural yield

(Figure 3.14). For the south it is the other way round. If the north's environmental awareness is relatively high $\left(c_{n}=5 \cdot 10^{-6}\right)$, the south prefers a fund, whereas in all other cases a market is favoured (Figure 3.13).

\subsubsection{Variation in price for agricultural goods}

Agricultural use of clear-felled areas is the main driving factor for deforestation. Therefore it is interesting to analyse how variation in the yield of agricultural goods affects the key figures of REDD.

The baseline value for the yield used in Section 3.3 is $Y=11$.

At first sight, the results in Figure 3.15 do not seem plausible, because if the yield of agricultural goods increases, avoiding deforestation becomes more expensive. Thus avoided deforestation should decrease. But this only holds true in terms of percentage. Rising $Y$ leads to such a strong increase in $\bar{D}(t)$ (deforestation in the baseline scenario) that avoiding a smaller percentage of it leads to more avoided deforestation in absolute terms.

It is also interesting to note that doubling the baseline yield, dividing it by two or ten, 

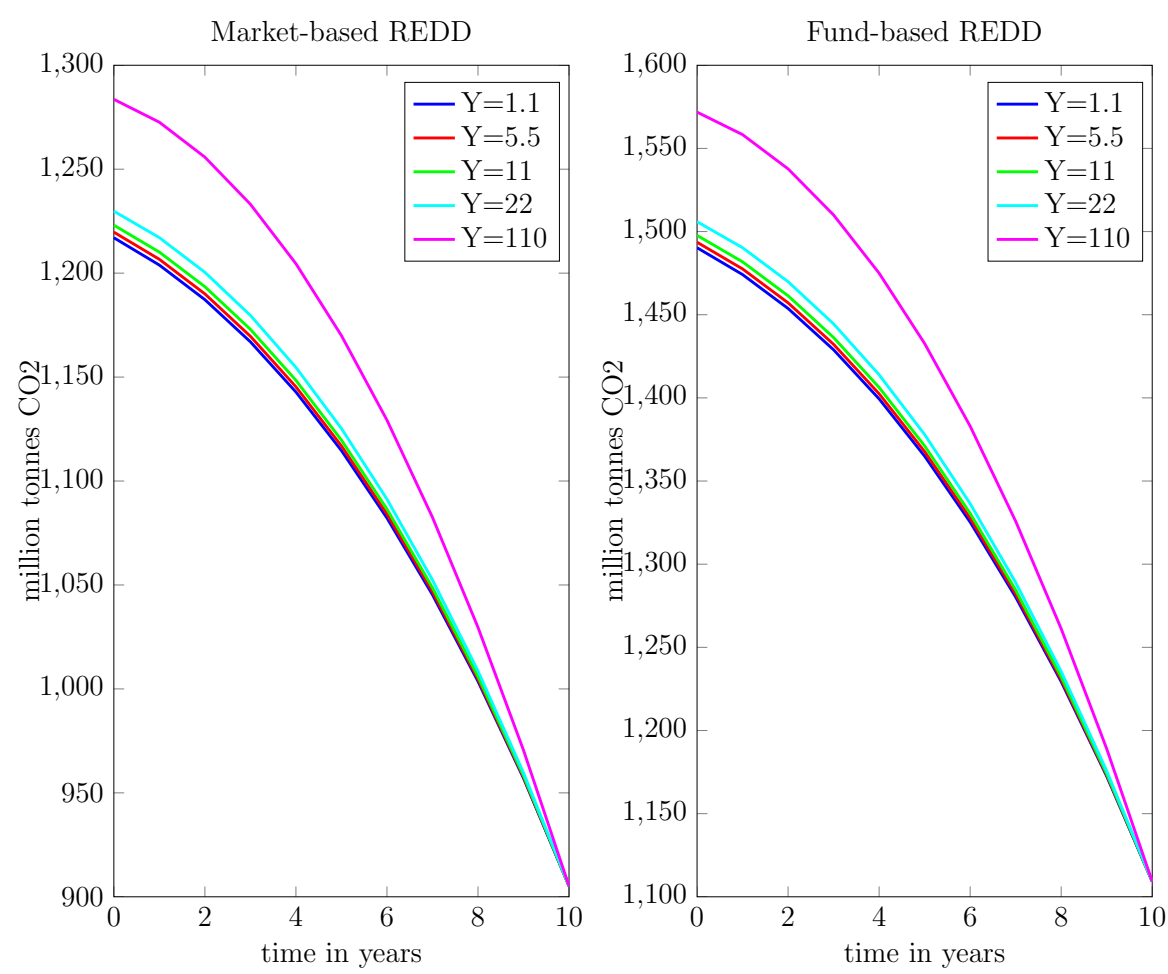

Figure 3.16: Reduced total global emissions: variation in agricultural yield

does not change avoided deforestation significantly. Tenfolding it, however, leads to a relatively strong increase.

As it can be seen in Figure 3.16, also reduced total global emissions increase with rising $Y$. Again, this results only from increasing avoided deforestation. In both REDD scenarios additional actual emissions of the north are the higher the larger $\mathrm{Y}$ is. This effect is particularly strong in the case of market-based REDD.

The observation that additional emissions of the north increase with $Y$ might be explained in the following way: Even when agricultural prices rise it is still cheaper to reduce emission in the south than restricting domestic production. However, with high agricultural prices larger amounts of money have to be transferred to the south. In order not to behave too environmentally friendly, domestic production is raised.

According to Figures 3.17 and 3.18, welfare gains do not vary significantly except for the case of tenfolding $Y$. Even though the changes are not too big, it is clear that welfare gains grow with increasing $Y$. This results from increasing avoided deforestation and emissions. 


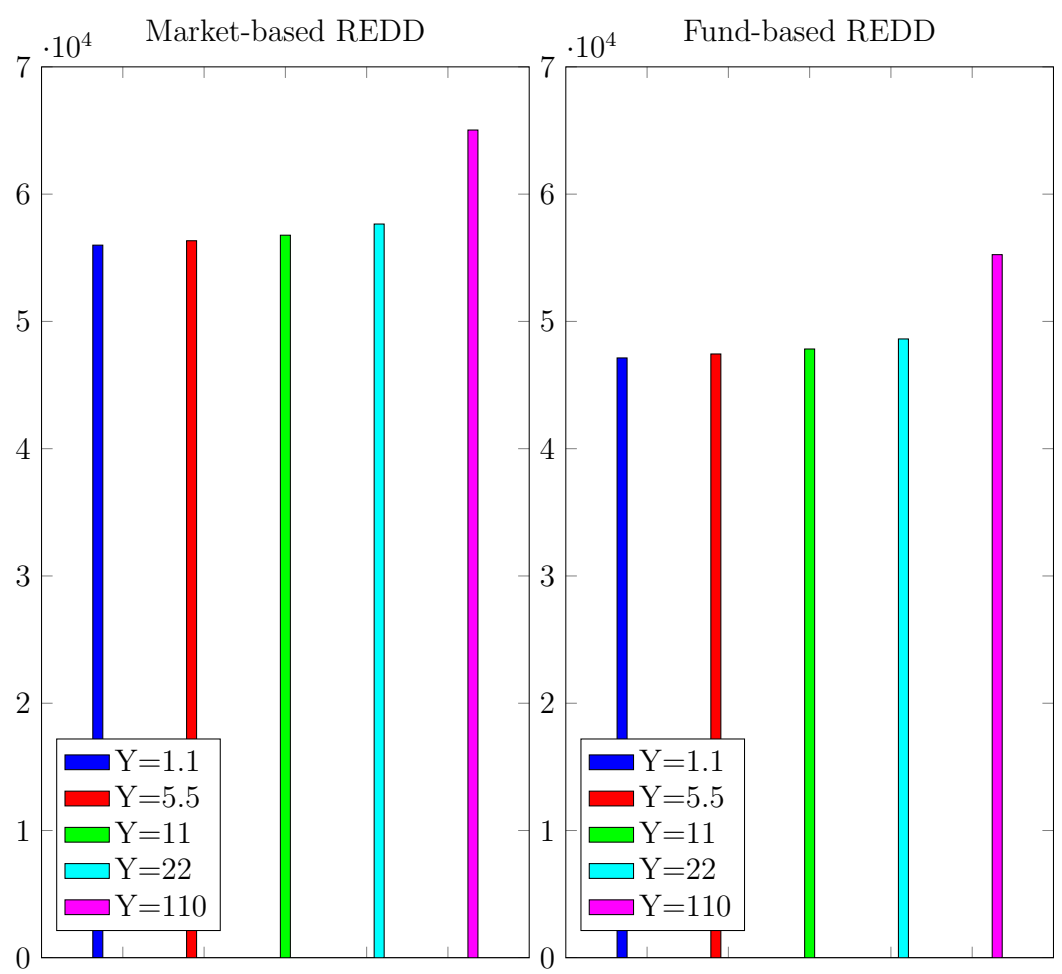

Figure 3.17: Aggregated gain in welfare for south: variation in agricultural yield

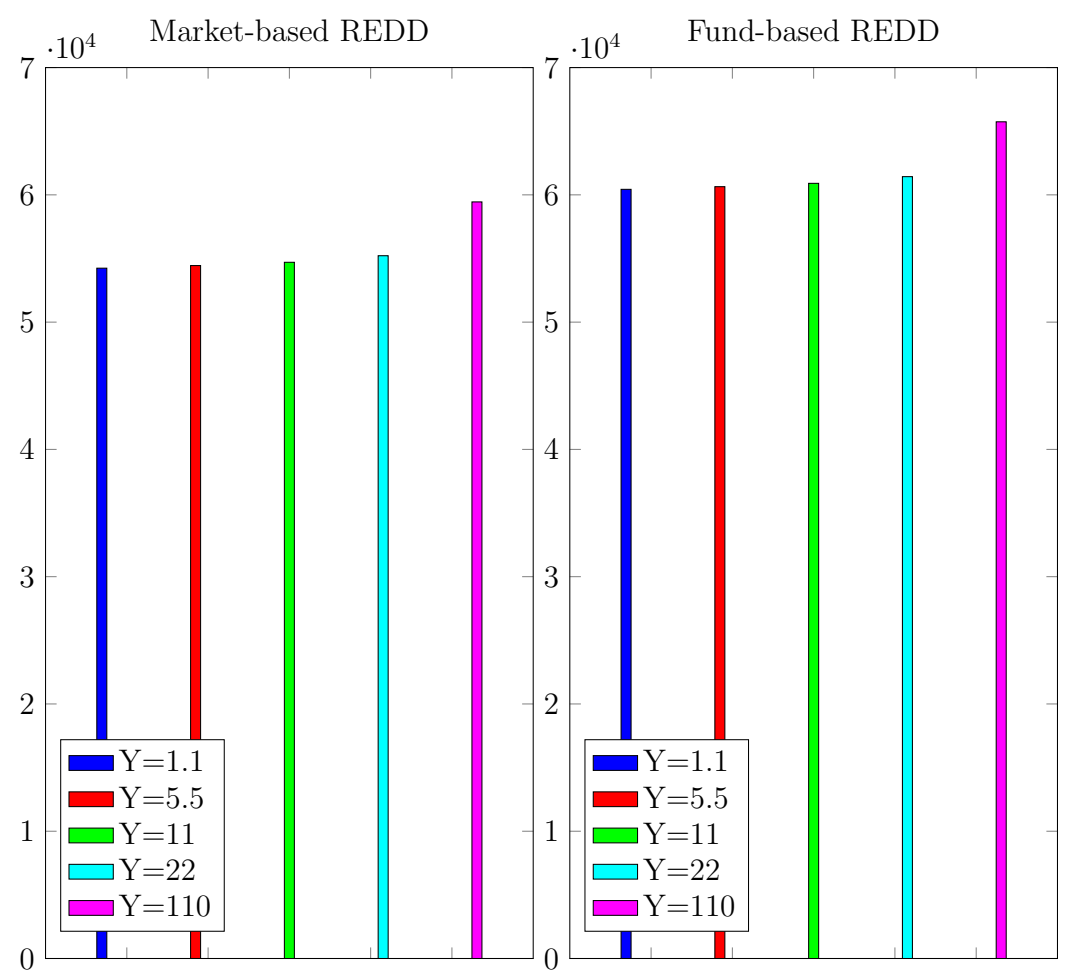

Figure 3.18: Aggregated gain in welfare for north: variation in agricultural yield 
Unlike variations of $c_{n}$, variations of $Y$ do not change any part of the outcome of Section 3.3.4.

Regardles of the choice of $Y$, market-based REDD leads to less deforestation (Figure 3.15) and higher welfare gains for the south (Figure 3.17). Also independently of $Y$, fund-based REDD is preferred by the north (Figure 3.18) and results in less global emissions (Figure 3.16.

\subsubsection{Summary for all parameters}

As in the two examples above, also in all other sensitivity analyses the model reacts plausibly. Furthermore, for all considered combinations of parameters, market-based REDD continues to lead to less deforestation while fund-based REDD keeps resulting in less total global emissions. It can also be said in general that the sensitivity of the key figures reduced deforestation, reduced total global emissions and welfare gain through REDD does not essentially depend on the specific REDD scenario. Thus, the parameters can rather easily be grouped by their influence on the key figures.

Here, four groups of parameters are discerned: Parameters with more than proportional, proportional, less than proportional and very low influence on key figures.

To be exact, only the sensitivity of avoided deforestation is used for this classification, as the sensitivity of other key figures does not differ significantly. Proportional influence here means, that a change in the parameter by $10 \%$ results in a corresponding change in avoided deforestation by approximately 10\%, respectively that doubling a parameter or dividing in half results in doubled / halved avoided deforestation. More than proportional influence can, e.g. be attributed to a parameter if a $10 \%$ variation causes a $20 \%$ change in avoided deforestation. Very low influence means that doubling a parameter causes, say, only a $1 \%$ change.

It is also necessary to mention that those figures refer to avoided deforestation in the beginning of the regarded period, as the results are most sensitive then.

Table 3.2 sums up the findings:

\begin{tabular}{|c|c|c|c|}
\hline more than proportional & proportional & less than proportional & very low influence \\
\hline$S_{0}, \underline{S}$ & $\gamma, \theta$ & $a, b, c_{n}, r_{n}, \psi, T$ & $\bar{P}, F_{0}, Y, \phi, r_{s}$ \\
\hline
\end{tabular}

Table 3.2: Influence of parameter changes on avoided deforestation 




\section{Chapter 4}

\section{Fairness Aspects}

The starting point for this chapter is the often-heard criticism that REDD, in the modality as modelled in the previous chapter, is unfair, as countries are rewarded for originally high deforestation rates. This alludes to the specification of the model, that transfers to the south depend on $\bar{D}(t)-D_{R E D D}(t)$ (i.e. the difference between the deforestation in the baseline scenario and in one of the REDD scenarios). Thus, according to critics, countries with high initial deforestation receive more money from the north.

This facet cannot be addressed in the above model as there the south is represented as one block. Therefore, in this chapter the model is adapted to describe the behaviour of three players: North, South with low deforestation and South with high deforestation.

To do so, it is close at hand to think about possible underlying reasons for different deforestation rates. In the following chapter, three possible explanations are offered, and in each scenario fairness aspects are analysed.

\subsection{Differing parameters}

Different parameter specifications for two agents with rainforests can explain differing deforestation in the baseline scenario. One possible explanation could e.g. lie in different agricultural yields $Y$ on clear-felled areas. Either because the soil is more or less fertile in different regions or because costs are higher in regions with less developed infrastructure. Another reason might be differing preferences for the conservation of rainforests, which are represented by the parameter $\phi$, or different discount rates $r_{s}$.

Variations of different parameters lead to very similar fairness results, therefore only vari- 
ation in $Y$ is considered here.

\subsubsection{The adapted model}

\section{The baseline scenario}

The rainforest owner with a high agricultural yield faces the following optimisation problem:

$$
\begin{gathered}
\max _{D_{h}(t)} \int_{0}^{T} e^{-r_{s} t}\left\{\left[\bar{P}-\theta\left(D_{h}(t)+D_{l}(t)\right)\right] D_{h}(t)+Y_{h}\left[F_{0, h}-F_{h}(t)\right]\right\} d t+e^{-r_{s} T} \phi F_{h}(T) \\
\text { s.t. } \quad \dot{F}_{h}(t)=-D_{h}(t), \quad F_{h}(0)=F_{0, h}
\end{gathered}
$$

The problem for low-yield rainforest owner is given by:

$$
\begin{gathered}
\max _{D_{l}(t)} \int_{0}^{T} e^{-r_{s} t}\left\{\left[\bar{P}-\theta\left(D_{h}(t)+D_{l}(t)\right)\right] D_{l}(t)+Y_{l}\left[F_{0, l}-F_{l}(t)\right]\right\} d t+e^{-r_{s} T} \phi F_{l}(T) \\
\text { s.t. } \quad \dot{F}_{l}(t)=-D_{l}(t), \quad F_{l}(0)=F_{0, l}
\end{gathered}
$$

From the perspective of one agent, the only difference to the specification (3.1) is that timber price does not only depend on the agent's own deforestation activities but also on the other one's. The two optimisation problems are thus linked and the Nash equilibrium solution can be obtained similarly to the solution in 4.2.1.

Let $\overline{D_{h}}(t)$ and $\overline{D_{l}}(t)$ denote the respective solutions. With the definition

$$
\bar{D}(t)=\overline{D_{h}}(t)+\overline{D_{l}}(t)
$$

the north again faces the optimisation problem (3.6).

\section{Market-based REDD}

Only the modelling of the second stage, that describes carbon trading when $O_{n}(t)$ is already known, has to be slightly modified.

From the perspective of the north the optimisation problem does not change and is given by (3.8). 
The two groups with rainforests simultaneously optimise the following problems:

$$
\begin{gathered}
\max _{D_{h}(t)} \int_{0}^{T} e^{-r_{s} t}\left\{R_{h}\left(D_{h}(t)\right)\right\} d t+e^{-r_{s} T} \phi F_{h}(T) \\
R_{h}\left(D_{h}(t)\right)=\left[\bar{P}-\theta\left(D_{h}(t)+D_{l}(t)\right)\right] D_{h}(t)+Y_{h}\left[F_{0, h}-F_{h}(t)\right]+p_{z}(t) \gamma\left[\overline{D_{h}}(t)-D_{h}(t)\right] \\
\text { s.t. } \quad \dot{F}_{h}(t)=-D_{h}(t), \quad F_{h}(0)=F_{0, h} \\
\max _{D_{l}(t)} \int_{0}^{T} e^{-r_{l} t}\left\{R_{l}\left(D_{l}(t)\right)\right\} d t+e^{-r_{s} T} \phi F_{l}(T) \\
R_{l}\left(D_{l}(t)\right)=\left[\bar{P}-\theta\left(D_{h}(t)+D_{l}(t)\right)\right] D_{l}(t)+Y\left[F_{0, l}-F_{l}(t)\right]+p_{z}(t) \gamma\left[\overline{D_{l}}(t)-D_{l}(t)\right] \\
\text { s.t. } \quad \dot{F}_{l}(t)=-D_{l}(t), \quad F_{l}(0)=F_{0, l}
\end{gathered}
$$

The equilibrium market price is the price that results from

$$
Z_{n}(t)=\gamma\left(\overline{D_{h}}-D_{h}(t)+\overline{D_{l}}-D_{l}(t)\right)
$$

Using this price function, in the first stage the north again faces problem (3.11).

\section{Fund-based REDD}

In the second stage $O_{n}(t)$ and the prices $p_{h}(t)$ and $p_{l}(t)$ are already known. It is important to note here that the prices $p_{h}(t)$ and $p_{l}(t)$, assigned to avoided deforestation in different regions, can theoretically differ, as the north who acts as a leader and donor does not have to offer the same compensation to each country.

The two players with rainforests simultaneously face:

$$
\begin{gathered}
\max _{D_{h}(t)} \int_{0}^{T} e^{-r_{s} t}\left\{R_{h}\left(D_{h}(t)\right)\right\} d t+e^{-r_{s} T} \phi F_{h}(T) \\
R_{h}\left(D_{h}(t)\right)=\left[\bar{P}-\theta\left(D_{h}(t)+D_{l}(t)\right)\right] D_{h}(t)+Y_{h}\left[F_{0, h}-F_{h}(t)\right]+p_{h}(t) \gamma\left[\overline{D_{h}}(t)-D_{h}(t)\right] \\
\text { s.t. } \quad \dot{F}_{h}(t)=-D_{h}(t), \quad F_{h}(0)=F_{0, h} \\
\max _{D_{l}(t)} \int_{0}^{T} e^{-r_{l} t}\left\{R_{l}\left(D_{l}(t)\right)\right\} d t+e^{-r_{s} T} \phi F_{l}(T) \\
R_{l}\left(D_{l}(t)\right)=\left[\bar{P}-\theta\left(D_{h}(t)+D_{l}(t)\right)\right] D_{l}(t)+Y_{l}\left[F_{0, l}-F_{l}(t)\right]+p_{l}(t) \gamma\left[\overline{D_{l}}(t)-D_{l}(t)\right] \\
\text { s.t. } \quad \dot{F}_{l}(t)=-D_{l}(t), \quad F_{l}(0)=F_{0, l}
\end{gathered}
$$


Using the resulting functions $D_{h}\left(p_{h}(t), p_{l}(t), t\right)$ and $D_{l}\left(p_{h}(t), p_{l}(t), t\right)$, the north can optimise in the first stage, similarly as in (3.14), but now with three control variables:

$$
\begin{gathered}
\max _{O_{n}(t), p_{h}(t), p_{l}(t)} \int_{0}^{T} e^{-r_{n} t}\left[a O_{n}(t)-b O_{n}(t)^{2}-p_{h}(t) \gamma\left\{\overline{D_{h}}(t)-D_{h}\left[p_{h}(t), p_{l}(t), t\right]\right\}\right. \\
\left.-p_{l}(t) \gamma\left\{\overline{D_{l}}(t)-D_{l}\left[p_{h}(t), p_{l}(t), t\right]\right\}-c_{n}[S(t)-\underline{S}]^{2}\right] d t-e^{-r_{n} T} \psi S(T) \\
\text { s.t. } \quad \dot{S}(t)=O_{n}(t)+\gamma\left[D_{h}\left(p_{h}(t), p_{l}(t), t\right)+D_{l}\left(p_{h}(t), p_{l}(t), t\right)\right]
\end{gathered}
$$

\subsubsection{Results}

For the computation of results $Y_{h}=9, Y_{l}=5$ and $F_{0, h}=F_{0, l}=\frac{3,952,000,000}{2}$ is chosen. All other parameters remain as set in Table 3.1 .

Figures 4.1 and 4.2 summarise the main results. Even though the player with high agricultural yield deforests more in all three scenarios, the amount of avoided deforestation is always the same as for the agent with low agricultural yield. As also the prices offered for reduced deforestation are the same for both players, both receive exactly the same transfer from the north.

Therefore, if different initial deforestation is due to differing parameters, both REDD mechanisms can be regarded as absolutely fair.

\subsection{Stackelberg Competition}

Another explanation for differing deforestation rates is that the two agents with rainforests do not choose their quantities simultaneously, but there is a market leader and a follower (Stackelberg [1934).

\subsubsection{The adapted model}

The model for this case in the baseline scenario, market- and fund-based REDD, is exactly the same as in Section 4.1. with $Y_{l}=Y_{h}=Y$.

Let subscript $h$ denote the variables of the leader and subscript $l$ the ones of the follower, as the leader will deforest more. 


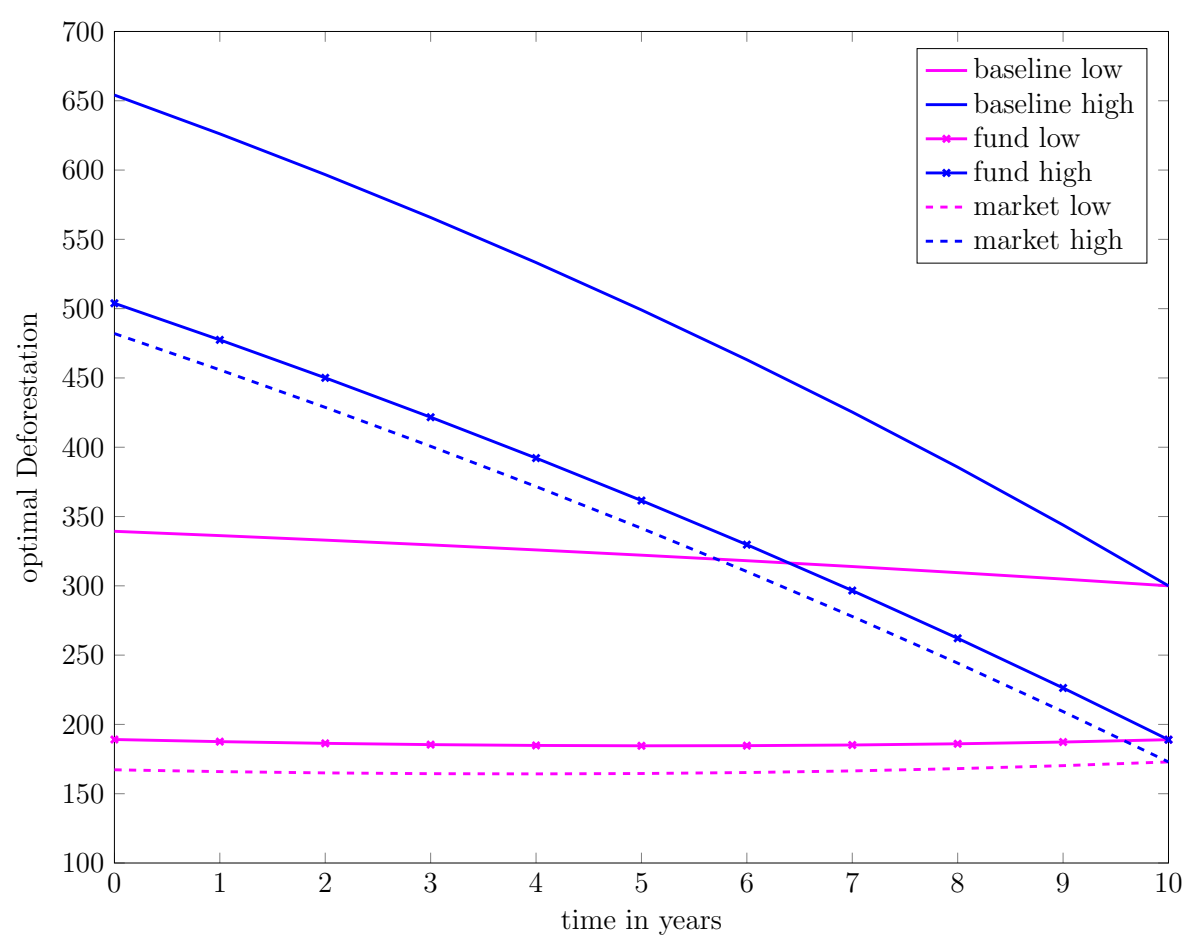

Figure 4.1: Deforestation of two players with differing agricultural yield in three scenarios
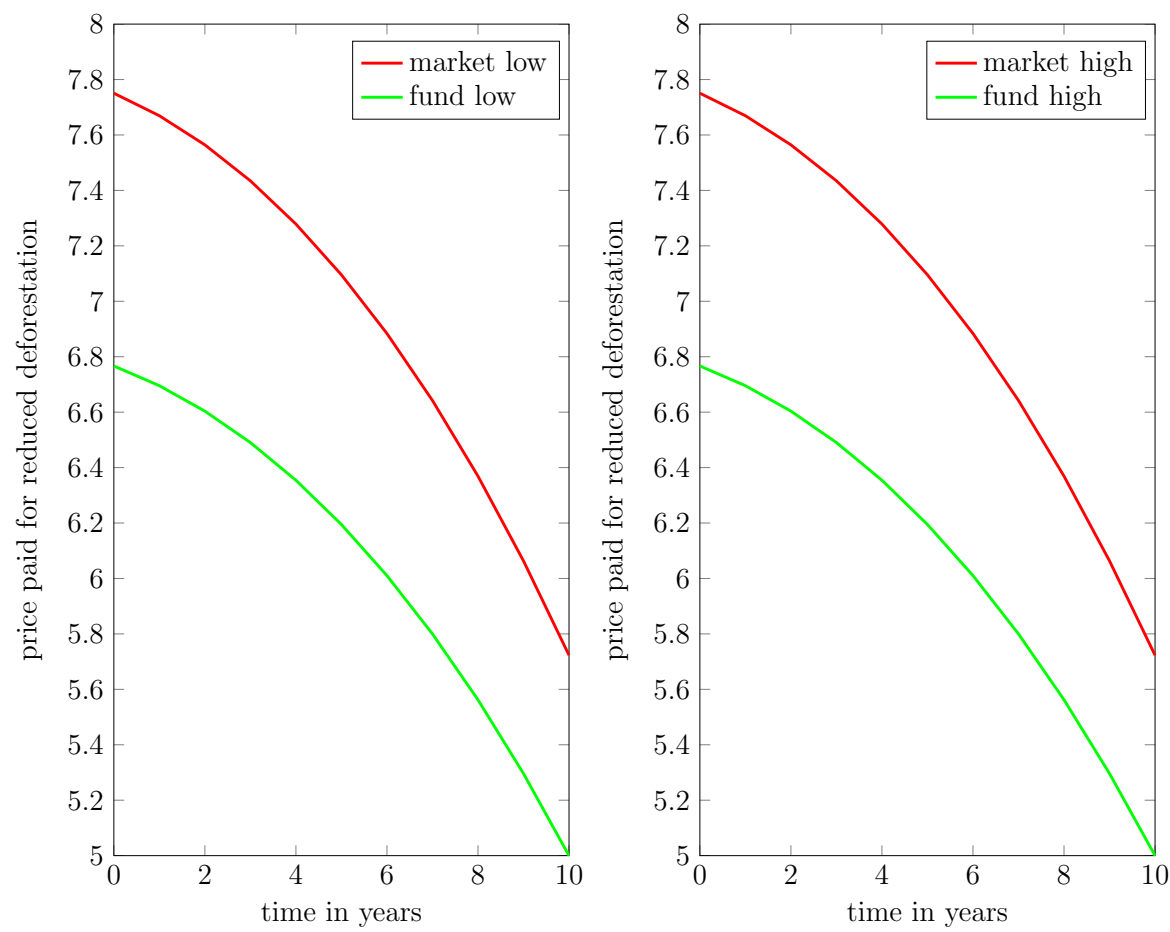

Figure 4.2: Prices of reduced deforestation received by two players with differing agricultural yield in both REDD scenarios 
It is assumed that when choosing her optimal deforestation the follower takes the amount of deforestation of the leader $D_{h}(. ., t)$ as given. The leader then uses the resulting $D_{l}\left(D_{h}(\ldots, t), . ., t\right)$ to optimise her choice of deforestation.

\subsubsection{Results}

For the following figures, parameters are chosen as stated in Table 3.1.

The effects of the asymmetric market-power assumption can be seen in Figure 4.3. In market-based as well as in fund-based REDD the leader is able to avoid more than the follower.

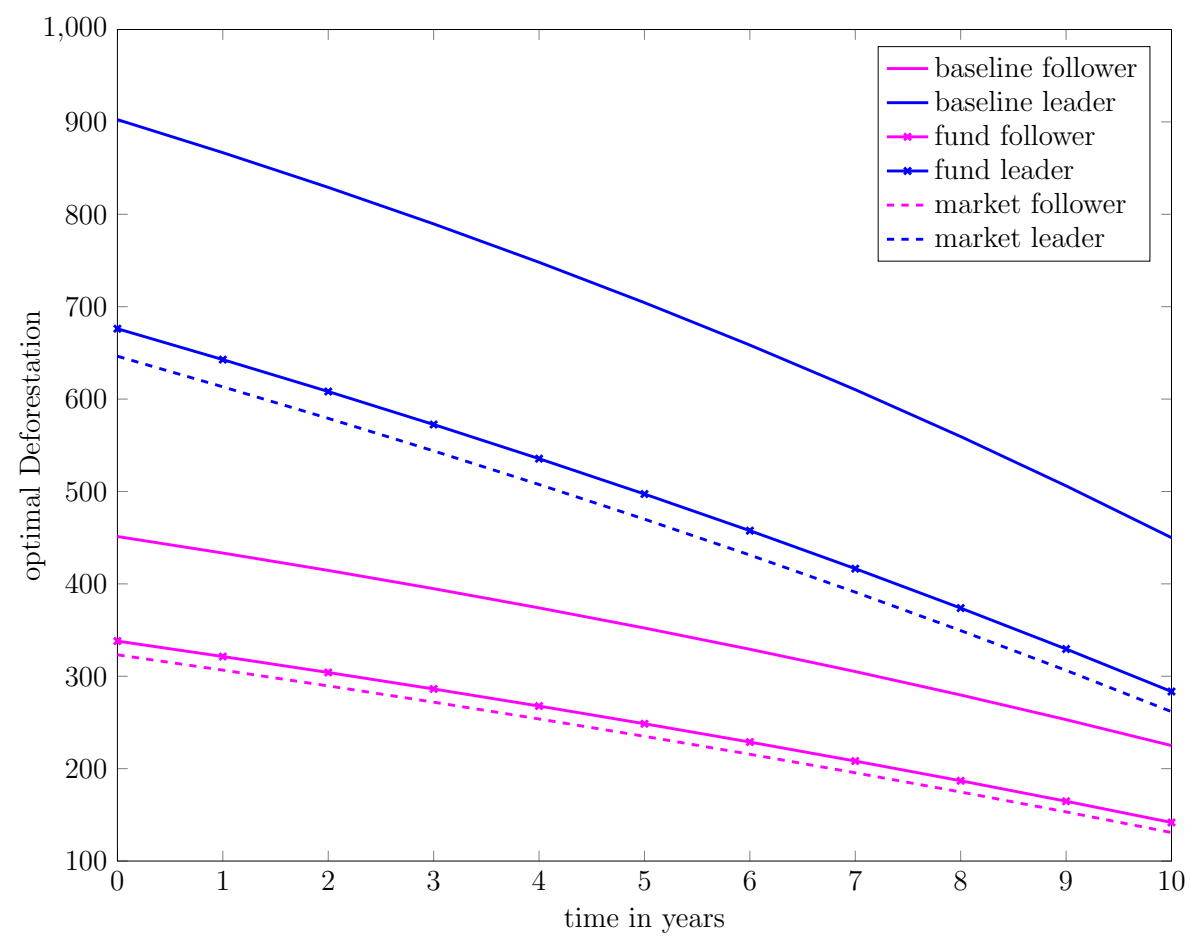

Figure 4.3: Deforestation of two players with differing market power in three scenarios

As a result, the transfer that the leader receives from the north is approximately twice as big as the compensation payments to the follower (see Figure 4.4). This can be regarded as unfair.

However, some kind of fairness is still retained, as the prices offered for reduced deforestation are the same for both agents with rainforest (see Figure 4.5). 

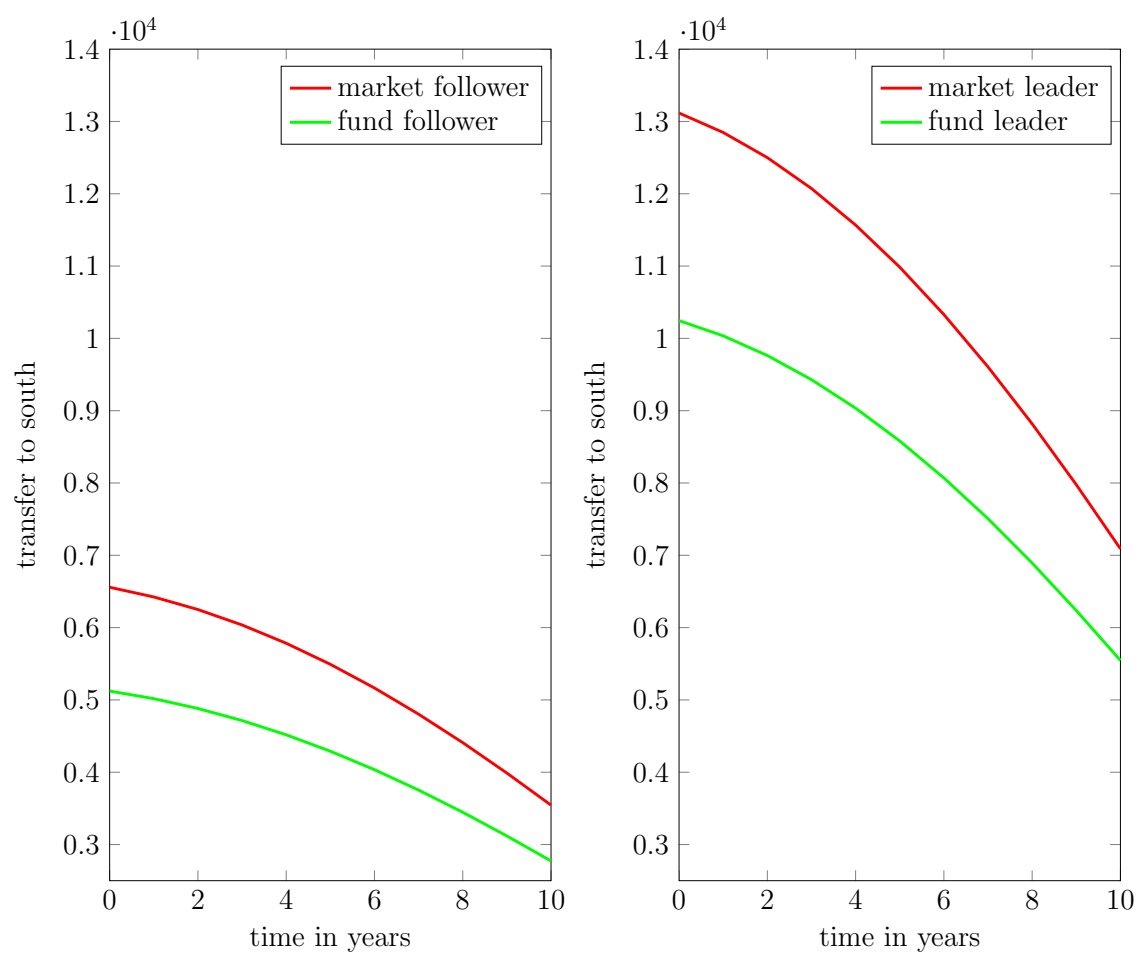

Figure 4.4: Tranfers received by two players with differing market power in two scenarios

\subsection{Separate markets}

The aim of this section is to show that in fund-based REDD under rather strong assumptions, it can happen that heterogeneous agents with rainforest receive different prices for their avoided deforestation. This could then be seen as the most unfair form of REDD.

It is assumed that one of the agents with rainforest only cuts down timber for sale and does not pursue agriculture on cleared areas. This agent will be called timber seller. The other southern agent will be called farmer and is only interested in agricultural production, which she increases through slash-and-burn land clearance.

\subsubsection{The adapted model}

\section{The baseline scenario}

The timber seller faces the following problem, which is straightforward to solve:

$$
\left.\max _{D_{t}(t)} \int_{0}^{T} e^{-r_{s} t}\left\{\left[\bar{P}-\theta D_{t}(t)\right] D_{t}(t)\right]\right\} d t+e^{-r_{s} T} \phi F_{t}(T)
$$



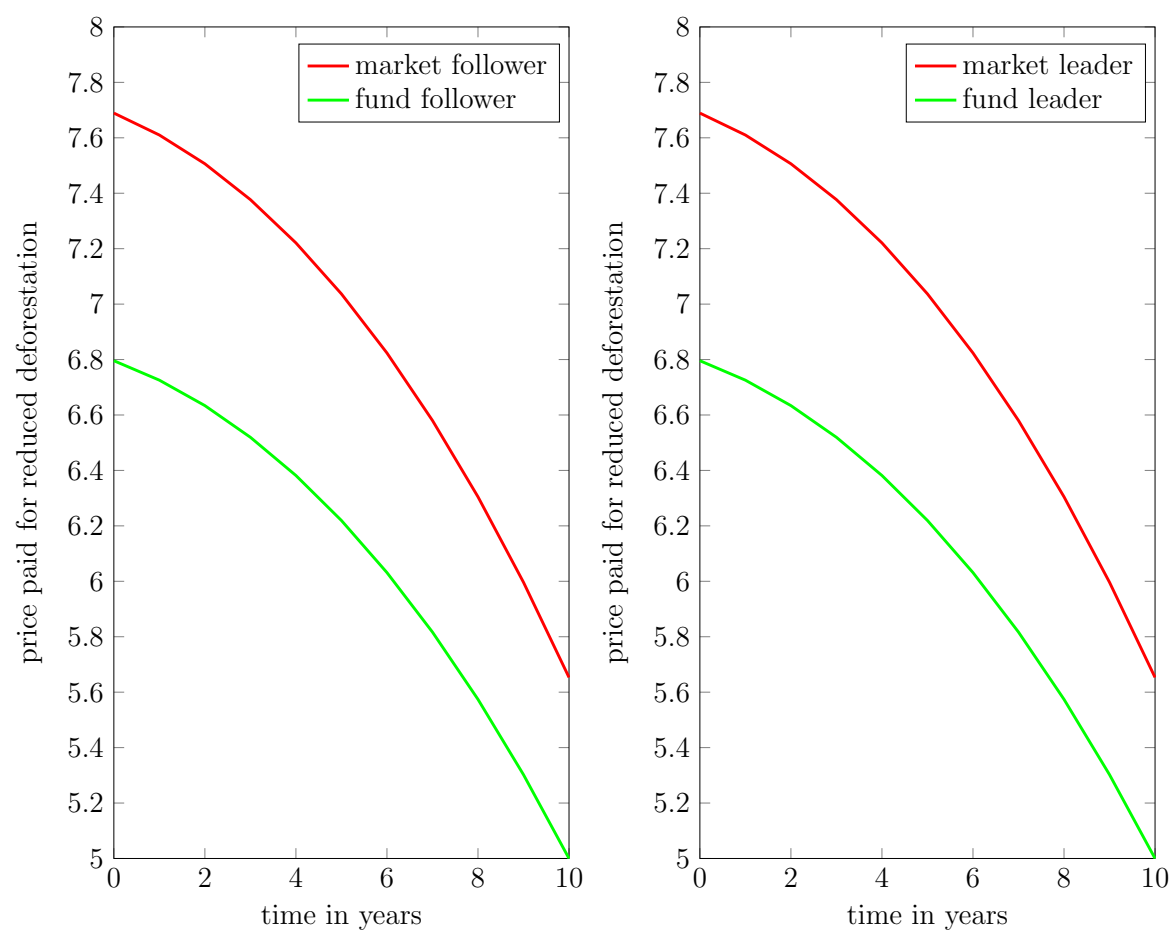

Figure 4.5: Prices of reduced deforestation received by two players with differing market power in both REDD scenarios

$$
\text { s.t. } \quad \dot{F}_{t}(t)=-D_{t}(t), \quad F_{t}(0)=F_{0, t}
$$

The problem for the farmer is given by

$$
\begin{gathered}
\max _{D_{f}(t)} \int_{0}^{T} e^{-r_{s} t}\left\{Y\left[F_{0, f}-F_{f}(f)\right]\right\} d t+e^{-r_{s} T} \phi F_{f}(T) \\
\text { s.t. } \quad \dot{F}_{f}(t)=-D_{f}(t), \quad F_{f}(0)=F_{0, f} .
\end{gathered}
$$

This problem is linear in the control variable $D_{f}(t)$. Therefore the farmer will deforest at a maximal rate $D_{\max }$ as long as the costate variable $\lambda_{f}(t)$ is negative, and switch to $D_{\min }$ when $\lambda_{f}(t)$ becomes positive.

A minimal deforestation rate of zero seems logical and $D_{\max }$ is set to 650 , in order to correspond to the deforestation levels in Chapter 3.

After denoting the solutions as $\overline{D_{t}}(t)$ and $\overline{D_{f}}(t)$ and defining $\bar{D}(t)=\overline{D_{t}}(t)+\overline{D_{f}}(t)$ the north can again face the problem stated in 3.6 . 


\section{Fund-based REDD}

In the second stage emission caps $O_{n}(t)$ as well as the price offers for the timber seller $p_{t}(t)$ and the farmer $p_{f}(t)$ are given.

The timber seller optimises the following problem:

$$
\begin{gathered}
\max _{D_{t}(t)} \int_{0}^{T} e^{-r_{s} t}\left\{\left[\bar{P}-\theta D_{t}(t)\right] D_{t}(t)+p_{t}(t) \gamma\left[\overline{D_{t}}(t)-D_{t}(t)\right]\right\} d t+e^{-r_{s} T} \phi F_{t}(T) \\
\text { s.t. } \quad \dot{F}_{t}(t)=-D_{t}(t), \quad F_{t}(0)=F_{0, t}
\end{gathered}
$$

The problem for the farmer is given by

$$
\begin{gathered}
\max _{D_{f}(t)} \int_{0}^{T} e^{-r_{s} t}\left\{Y\left[F_{0, f}-F_{f}(f)\right]+p_{f}(t) \gamma\left[\overline{D_{f}}(t)-D_{f}(t)\right]\right\} d t+e^{-r_{s} T} \phi F_{f}(T) \\
\text { s.t. } \quad \dot{F}_{f}(t)=-D_{f}(t), \quad F_{f}(0)=F_{0, f} .
\end{gathered}
$$

Let $\lambda_{f}$ again denote the costate variable of the farmer. Then the optimal behaviour of the farmer is to deforest at a maximal rate $D_{\max }$ as long as $\lambda_{f}(t)+\gamma p_{f}(t)<0$. However, the farmer will stop deforesting entirely if the price offered by the north is large enough, more precisely if

$$
p_{f}(t)>\frac{-\lambda_{f}(t)}{\gamma}=\frac{Y-e^{r_{s}(t-T)}\left(Y-\phi r_{s}\right)}{\gamma r_{s}} .
$$

At the first stage, the north optimally chooses $O_{n}(t), p_{t}(t)$ and $p_{f}(t)$ :

$$
\begin{aligned}
\max _{O_{n}(t), p_{t}(t), p_{f}(t)} & \int_{0}^{T} e^{-r_{n} t}\left[a O_{n}(t)-b O_{n}(t)^{2}-p_{t}(t) \gamma\left\{\overline{D_{t}}(t)-D_{t}\left[p_{t}(t), p_{f}(t), t\right]\right\}\right. \\
& \left.-p_{f}(t) \gamma\left\{\overline{D_{f}}(t)-D_{f}\left[p_{t}(t), p_{f}(t), t\right]\right\}-c_{n}[S(t)-\underline{S}]^{2}\right] d t-e^{-r_{n} T} \psi S(T) \\
\text { s.t. } \quad & \dot{S}(t)=O_{n}(t)+\gamma\left[D_{t}\left(p_{f}(t), p_{t}(t), t\right)+D_{f}\left(p_{t}(t), p_{f}(t), t\right)\right]
\end{aligned}
$$

The optimality conditions for $O_{n}(t)$ and $p_{t}(t)$ can be derived as in 4.2.3.

The choice of $p_{f}(t)$ can be deduced a bit differently. In particular, at every point in time $t$ the north will either choose $p_{f}(t)=0$ or $p_{f}(t)=\frac{-\lambda_{f}(t)}{\gamma}+\epsilon$. A price between 0 and $\frac{-\lambda_{f}(t)}{\gamma}$ does not have any deforestation-mitigating effect. However, as soon as the price is slightly over $\frac{-\lambda_{f}(t)}{\gamma}$, the farmer-agent is ready to stop all deforestation. Significantly higher price 
offers than $\frac{-\lambda_{f}(t)}{\gamma}$ cannot lead to even less deforestation but would cause higher costs for the north.

From a strictly mathematical point of view, a choice $p_{f}(t)=\frac{-\lambda_{f}(t)}{\gamma}+\epsilon$ cannot be optimal, as $p_{f}(t)=\frac{-\lambda_{f}(t)}{\gamma}+\frac{\epsilon}{2}$ leads to the same amount of deforestation but lower costs. However, one can at least analyse, if it is better for the north to always offer a price $\frac{-\lambda_{f}(t)}{\gamma}+\epsilon$, never to offer a price high enough to avoid deforestation of the farmer, or to offer $p_{f}(t)=\frac{-\lambda_{f}(t)}{\gamma}+\epsilon$ at some points in time and $p_{f}(t)=0$ at others.

\subsubsection{Results}

With $D_{\max }=650, \epsilon=10^{-5}$ and all other parameters set as specified in Table 3.1 , the two first-mentioned strategies and 500 versions of the last-mentioned one were tested. In all test runs the strategy $p_{f}(t)=\frac{-\lambda_{f}(t)}{\gamma}+\epsilon, \quad \forall t \in[0, T]$ resulted in the highest welfare for the north.

Figure 4.6 shows the resulting deforestation pattern. The farmer would initially deforest much more than the timber seller but stops all deforestation activities due to the introduction of REDD. The timber seller only halves her deforestation activities.

The price that the timber seller receives for avoided deforestation is slightly decaying with time. The price offered to the farmer is much higher in the beginning but sharply declines as the costate $\lambda_{f}(t)$ increases (Figure 4.7). In other words, at the end of the regarded period, turning forests into fields yields significantly less gain for the farmer than in the beginning. Therefore the compensational payment can be decreased strongly.

Altogether, except for the last two periods, transfers to the farmer are much higher than payments to the timber seller. This and the differing prices offered by the north can be regarded as unfair. 


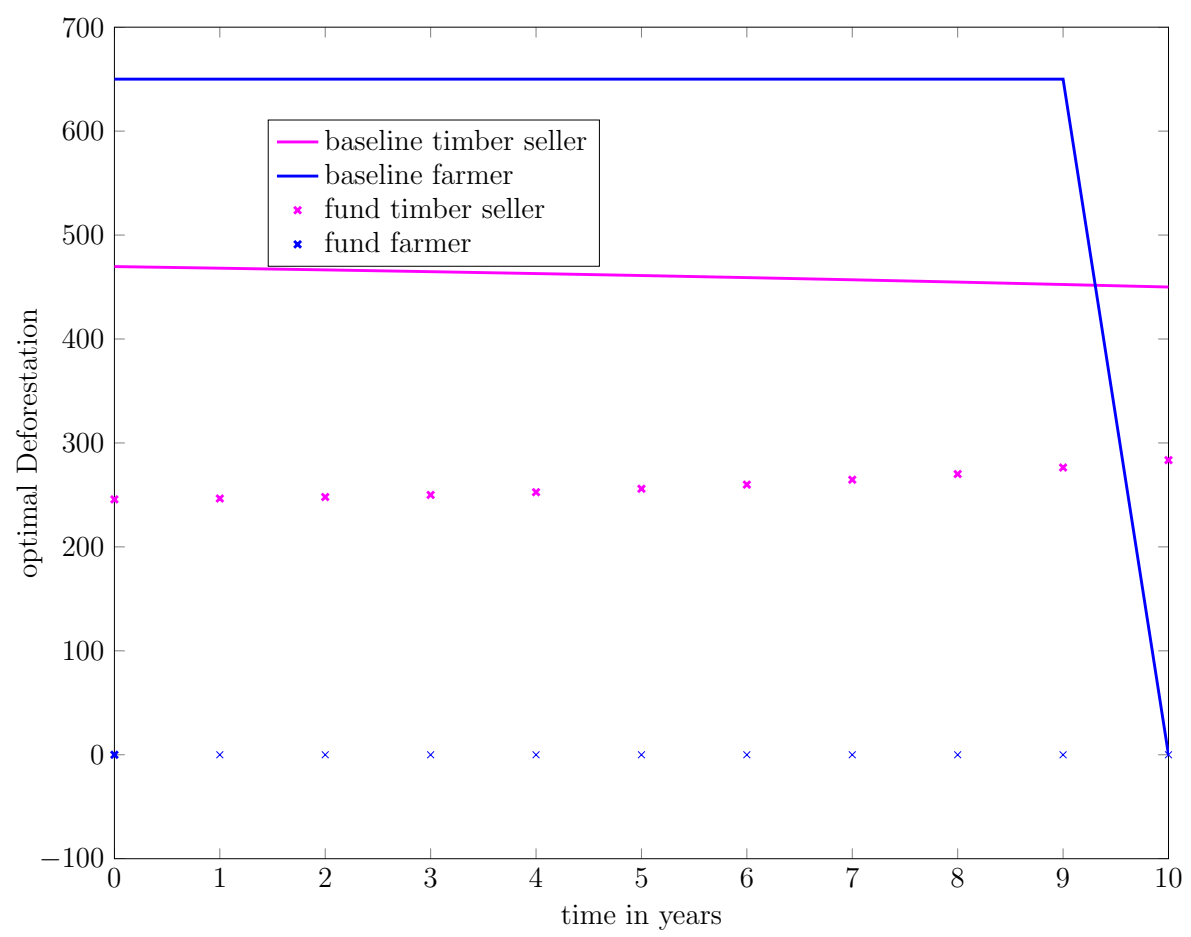

Figure 4.6: Deforestation of two players with differing market segments in two scenarios
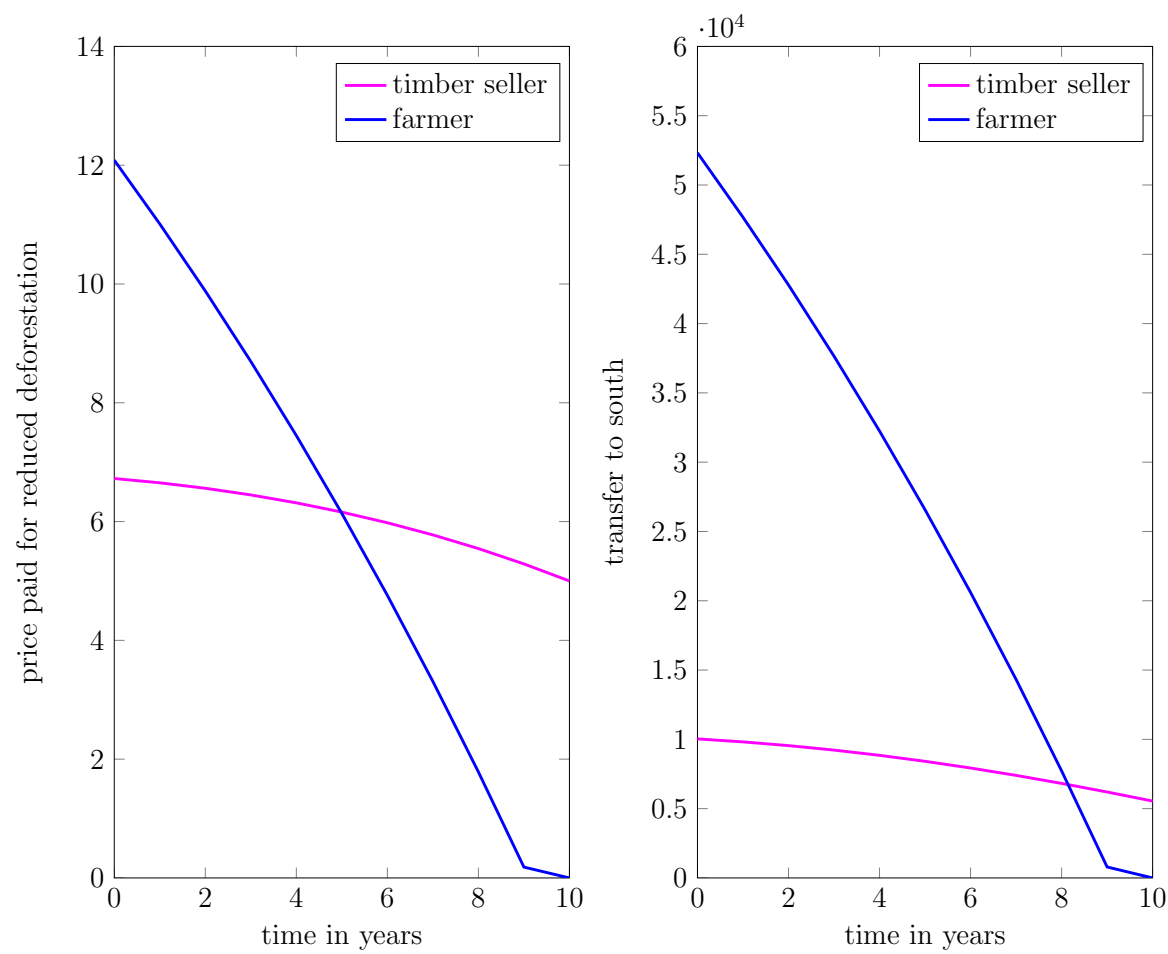

Figure 4.7: Prices of reduced deforestation and transfers offered to two players with differing market segments in two REDD scenarios 



\section{Chapter 5}

\section{Sustainability Aspects}

Another common criticism against REDD is that due to the transfers, the south becomes even more dependent on the north and does not grow sustainably. This criticism already found its way into international negotiations: In the Bali Roadmap 2007 the parties agreed that REDD should simultaneously contribute to climate change mitigation and poverty alleviation.

A first step towards this goal is the already ongoing cooperation between Norway and Guyana: Norway transfers money into the Guyana REDD+ Investment Fund which will invest into low-carbon development (see GRIF). A key element of a REDD mechanism that leads to sustainable growth in the south is thus to invest transfers rather than consuming them.

Ring-fencing payments for investment into low-carbon sectors of the economy is more easily enforceable in the case of fund-based REDD than in a scenario with carbon trading. A benefactor can determine what the recipient is supposed to do with the money. To order a permit seller at an international carbon market how she has to use the sales revenue might be less accepted, nevertheless it is also possible.

Therefore, and for completeness, both REDD-scenarios will be analysed under the premise of ring-fenced payments.

\subsection{The adapted model}

It is assumed that the south can not only derive economic utility from deforestation but also from a green sector. While deforestation results in emissions, output of the green 
sector is generated without causing $\mathrm{CO}_{2}$ emissions. Of course it is hard to imagine absolutely carbon-free economic activities, but it can be argued that those emissions are negligible.

For simplicity it is further assumed that this green branch of economy can be modelled with an AK-production function (Rebelo [1991]) and Solow-type capital accumulation (Solow [1956]). Hence, in absence of a REDD mechanism, the output of this green sector can be modelled as

$$
Y(t)=A K(t)
$$

where $A$ is a positive constant describing the level of technology and $K(t)$ denotes the capital stock in time $t$, which evolves according to

$$
\dot{K}(t)=s A K(t)-\delta K(t), \quad K(0)=K_{0} .
$$

In this capital accumulation equation, $\delta$ represents the constant rate of depreciation. The investments into the capital stock are a constant fraction of the output ,and this savings rate $s$ is exogenously given. The remaining fraction of the output

$$
C(t)=(1-s) A K(t)
$$

can be consumed and directly yields utility.

In the baseline scenario the south thus faces the following optimisation problem:

$$
\begin{aligned}
& \max _{D(t)} \int_{0}^{T} e^{-r_{s} t}\left\{[\bar{P}-\theta D(t)] D(t)+Y\left[F_{0}-F(t)\right]+(1-s) A K(t)\right\} d t+e^{-r_{s} T}[\phi F(T)+\tilde{\phi} K(T)] \\
& \text { s.t. } \dot{F}(t)=-D(t), \quad F(0)=F_{0} \\
& \dot{K}(t)=s A K(t)-\delta K(t), \quad K(0)=K_{0}
\end{aligned}
$$

The salvage value function here also contains a term for the capital stock at the end of the observed period, and the capital stock is weighed with $\tilde{\phi}$.

As $s$ is exogenously given, this modification changes the utility of the south but not the optimal choice of deforestation in the baseline scenario, $\bar{D}(t)$.

In both REDD scenarios the first two lines of the optimisation problem remain the same 
but the capital accumulation equation has to be modified to

$$
\dot{K}(t)=s A K(t)-\delta K(t)+p(t) \gamma[\bar{D}(t)-D(t)], \quad K(0)=K_{0} .
$$

The transfer $p(t) \gamma[\bar{D}(t)-D(t)]$ which was consumed directly in the original model is now invested into the capital stock of the green sector. A growing capital stock leads to higher production in this sector and thus indirectly to higher utility.

The modelling of the optimisation problems of the north does not have to be modified.

\subsection{Solving the adapted model}

\subsubsection{The second stage}

In the second stage, taking $O_{n}(t)$ and $p(t)$ as given, the optimal reaction of the south is to choose the following deforestation:

$$
\begin{aligned}
D(p(t), t)= & \frac{1}{2 \theta}\left(\bar{P}+\frac{Y-e^{r_{s}(t-T)}\left(Y+\phi r_{s}\right)}{r_{s}}\right) \\
& -\frac{p(t) \gamma\left[(1-s) A+e^{\left(r_{s}+\delta-s A\right)(t-T)}\left(\tilde{\phi}\left(\delta+r_{s}-s A\right)-(1-s) A\right)\right]}{2 \theta\left(\delta+r_{s}-s A\right)} \\
= & \bar{D}(t)-\frac{p(t) \gamma\left[(1-s) A+e^{\left(r_{s}+\delta-s A\right)(t-T)}\left(\tilde{\phi}\left(\delta+r_{s}-s A\right)-(1-s) A\right)\right]}{2 \theta\left(\delta+r_{s}-s A\right)}
\end{aligned}
$$

In the case of fund-based REDD the second stage is now completed, in the case of marketbased REDD the amount of certificates offered by the south is thus given by

$$
Z_{s}(t)=\gamma \frac{p(t) \gamma\left[(1-s) A+e^{\left(r_{s}+\delta-s A\right)(t-T)}\left(\tilde{\phi}\left(\delta+r_{s}-s A\right)-(1-s) A\right)\right]}{2 \theta\left(\delta+r_{s}-s A\right)} .
$$

The demand of the north remains to be

$$
Z_{n}(t)=\frac{a-p(t)}{2 b}-O_{n}(t)
$$

Therefore in market equilibrium a price of

$p(t)=\left(a-2 b O_{n}\right)\left\{2 b\left[\frac{\left((1-s) A+e^{\left(r_{s}+\delta-s A\right)(t-T)}\left(\tilde{\phi}\left(\delta+r_{s}-s A\right)-(1-s) A\right)\right) \gamma^{2}}{2 \theta\left(\delta+r_{s}-s A\right)}+\frac{1}{2 b}\right]\right\}^{-1}$

arises. 
Comparing this result and results from previous chapters shows that the price function as well as the function $D(p(t), t)$ has become more complex (cf. (3.16) and (3.18)). This makes solving the optimisation problems in the first stage more difficult.

\subsubsection{The first stage}

In the case of market-based REDD, in the first stage the north again faces (3.11). Therefore, the system of differential equations

$$
\begin{aligned}
& \dot{\lambda}(t)=r_{n} \lambda(t)+2 c_{n}(S(t)-\underline{S}), \quad \lambda(T)=\phi \\
& \dot{S}(t)=O_{n}(t)+\gamma \bar{D}(t), \quad S(0)=S_{0}
\end{aligned}
$$

has to be solved. $O_{n}(t)$ in turn has to be chosen to optimise the Hamiltonian and is a function of $\lambda(t)$. In contrast to previous calculations, however, the coefficients of $\lambda(t)$ in $O_{n}(\lambda(t))$ are not constant anymore. (Displaying the functional form of $O_{n}(\lambda(t))$ is omitted because of the complexity and length of the term.)

Therefore, it is no longer possible to obtain an analytical result using the Matlab toolbox Symbolic. Instead, the numerical ODE solver ode 45 is used. This solver can only treat initial value problems, but for $\lambda(t)$ the terminal and not the initial value is fixed.

Hence a shooting method is employed which uses various initial values $\lambda_{0}$ until the required terminal value $\phi$ is reached.

In the case of fund-based REDD, the north can choose $O_{n}(t)$ and $p(t)$, but the system of differential equations looks only slightly different:

$$
\begin{aligned}
& \dot{\lambda}(t)=r_{n} \lambda(t)+2 c_{n}(S(t)-\underline{S}), \quad \lambda(T)=\phi \\
& \dot{S}(t)=O_{n}(t)+\gamma D(p(t), t), \quad S(0)=S_{0}
\end{aligned}
$$

As in the market scenario, $O_{n}(t)$ now depends on $\lambda(t)$ in a more complex way. Here $D(p(t), t)$ also directly appears in the second differential equation, and the coefficient of $p(t)$ in $D(p(t), t)$ is not time-invariant anymore.

Therefore also the fund-based scenario is solved by ode 45 and a shooting method. 


\subsection{Parametrisation}

As the optimal decisions of both players in the baseline scenario do not change, the model does not need to be calibrated again and the parameters from Table 3.1 can be reused. However, five new parameters have to be chosen.

$K_{0}$ :

The choice of the initial stock of clean capital only effects the level of utility but not the optimal decisions of the agents. Therefore $K_{0}$ is simply set to zero, reflecting that the green sector is not yet highly developed in the south.

$s:$

According to the World Bank (World-Bank) savings rates of countries with rainforests approximately range between $10 \%$ and 30\%. (E.g. Brazil 15\%, Guyana 11\%, Ghana 30\%, Mozambique $12 \%$, Indonesia $31 \%$ and Malaysia $32 \%$.) Therefore, $20 \%$ will be used if not stated otherwise, but variation between $10 \%$ and $30 \%$ will also be analysed.

$\delta:$

To my knowledge, depreciation rates between $5 \%$ and $15 \%$ are widely used in the literature (see e.g. $\operatorname{Sax} 2004$ ). This range of rates will be investigated, while in general the average value of $10 \%$ will be used.

A:

For this parameter the fewest reference values can be found. Thus this problem is approached in the following way: In absence of a REDD mechanism, the growth rate of the capital stock is given by $s A-\delta$. If zero growth and, as mentioned above, $s=0.2$ and $\delta=0.1$ are assumed, then $A=0.5$ is required. This will serve as the basis value but also variations of A will be analysed.

$\tilde{\phi}:$

The salvage value of the capital stock is set to 1 as $K$ already measures the value of the capital stock in monetary units.

Table 5.1 summarises the basis choice of parameters. 


\begin{tabular}{|ccccc|}
\hline$K_{0}$ & $s$ & $\delta$ & $A$ & $\tilde{\phi}$ \\
\hline 0 & 0.2 & 0.1 & 0.5 & 1 \\
\hline
\end{tabular}

Table 5.1: New parameters used in the following sections

\subsection{Results}

Figure 5.1 shows that with the above mentioned choice of parameters, investing REDDtransfers leads to much more avoided deforestation than directly consuming them. The difference between deforestation under REDD in this model and the original model from Chapter 3 is particularly strong in the beginning of the observed period, whereas in $t=10$ no difference is visible anymore. This means that the south prefers to avoid more deforestation in the beginning because early transfers increase the capital stock early and then the south can benefit from a higher capital stock in more following periods.

As in Chapter 3, market-based REDD leads to less deforestation than fund-based REDD and the gap is even bigger.
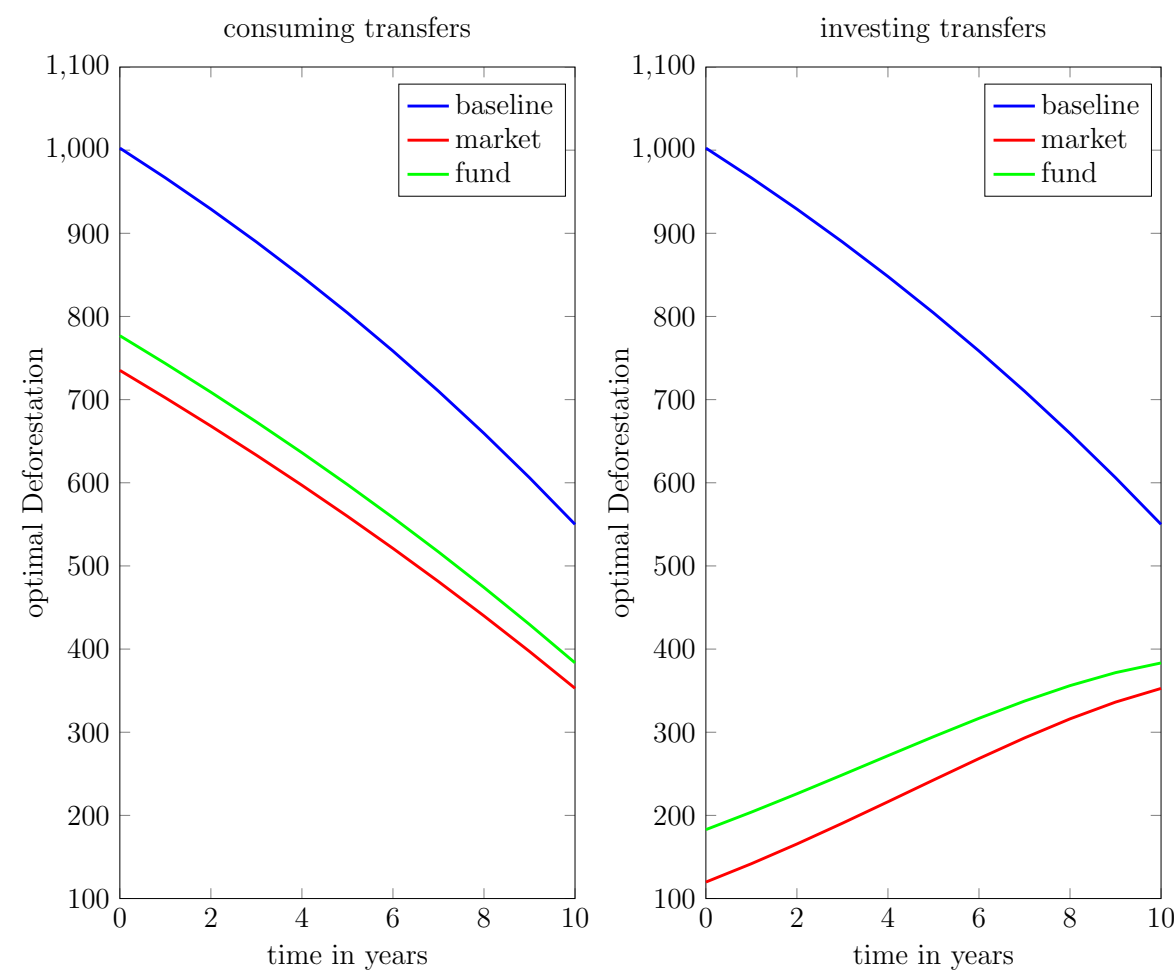

Figure 5.1: Deforestation in the original (1.) and the adapted (r.) model in three different scenarios

Also for the prices paid for avoided deforestation the main result that they are higher 

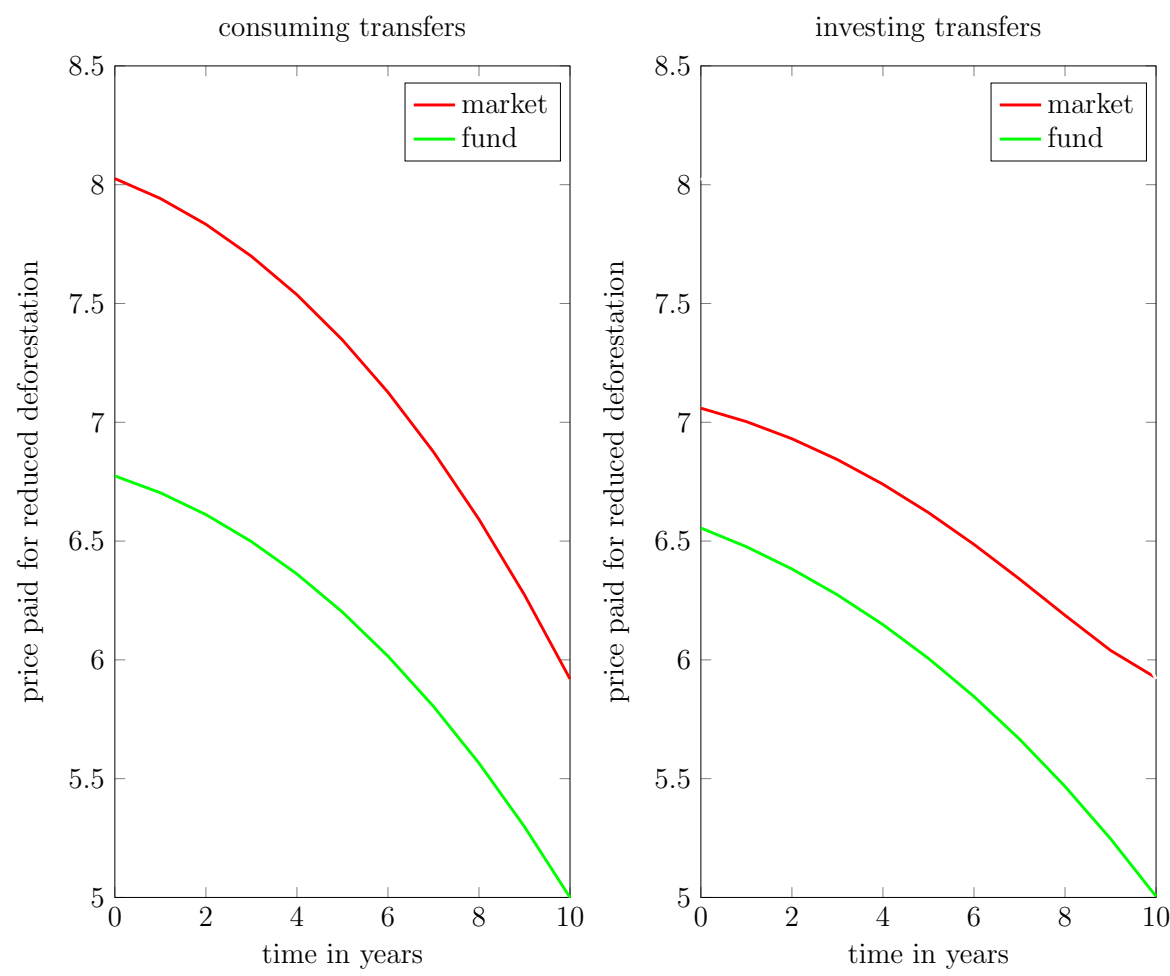

Figure 5.2: Prices of reduced deforestation in the original (l.) and the adapted (r.) model in both REDD scenarios

in market-based REDD, remains intact (see Figure 5.2). The price curves nevertheless become flatter and lower except for the end of the period. Lower prices can be paid because the long-term utility generated by a certain compensation payment is higher and therefore the offer curves of the south are shifted upwards.

Figure 5.3 shows that actual emissions of the north slightly increase in both REDD scenarios, relative to the original model. From the perspective of the north, the south already avoids enough emissions, therefore the north can emit a bit more. This effect however is not very big. The more striking effect of investing transfers is that in market-based REDD the north now accepts much lower emissions caps which it fulfils only through buying carbon certificates.

As a result of sharply declining deforestation and only slightly increasing emissions of the north, total global emissions decrease more substantially than in the original model (see Figure 5.4), but fund-based REDD still leads to less total global emissions than REDD with carbon trading.

All these results are also reflected in Figure 5.5. For the south, market-based REDD is still 

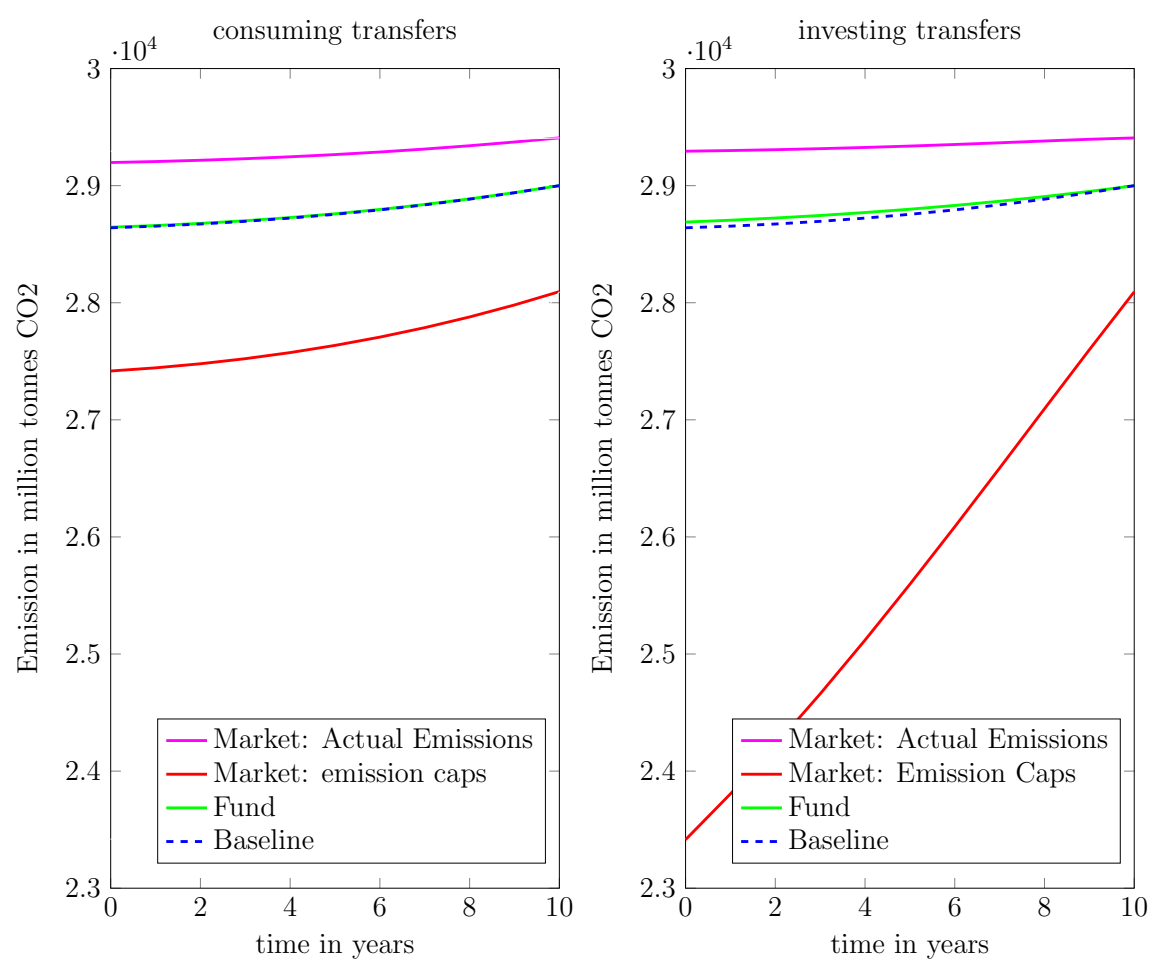

Figure 5.3: Emissions of the north in the original (l.) and the adapted (r.) model in three scenarios
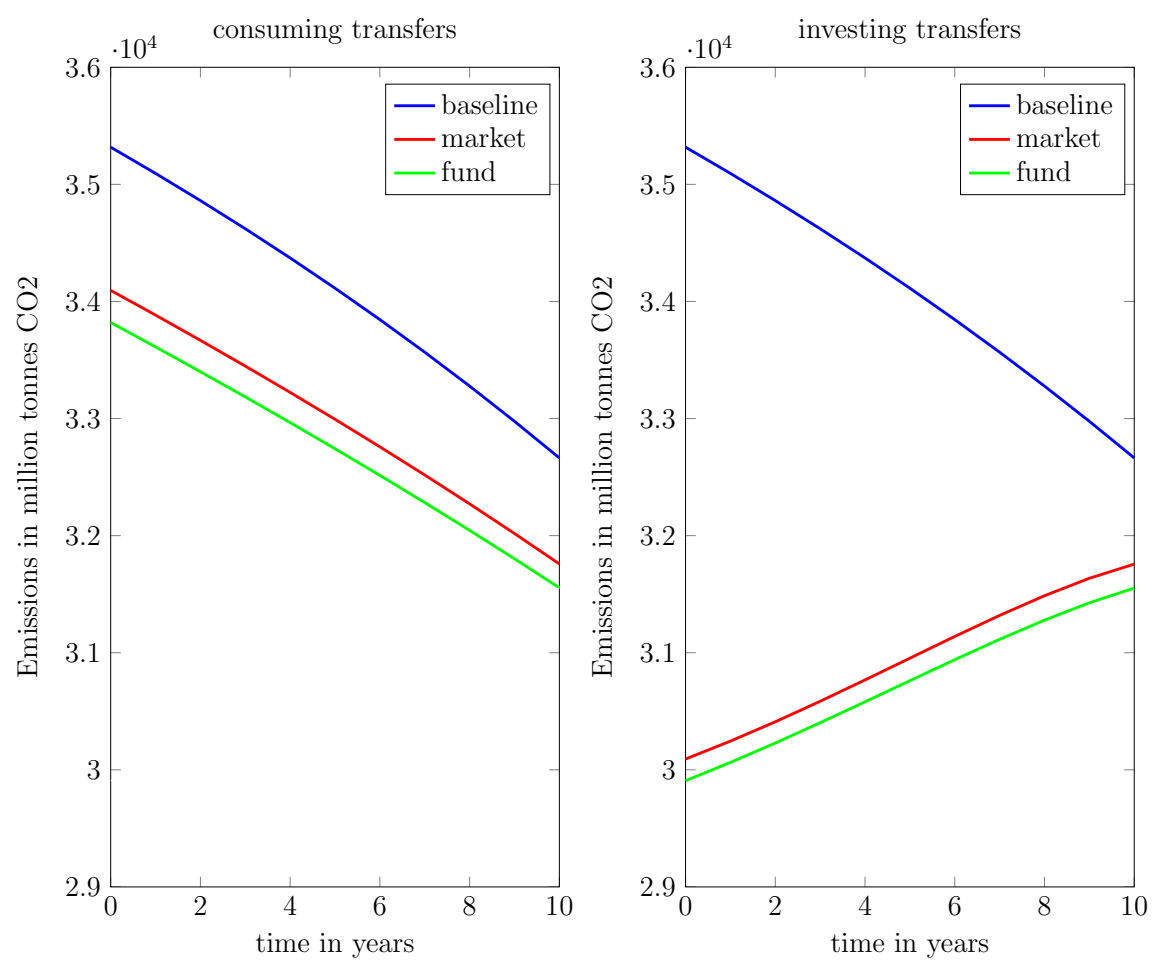

Figure 5.4: Total global emissions in the original (l.) and the adapted (r.) model in three scenarios 
more profitable, whereas the north still prefers a fund. The welfare gain in both scenarios for the south is about ten times larger than in the original model, as invested transfers lead to higher income more sustainably. For the north the welfare gain also increases significantly. This is due to less emissions and lower prices of avoided deforestation in this scenario.
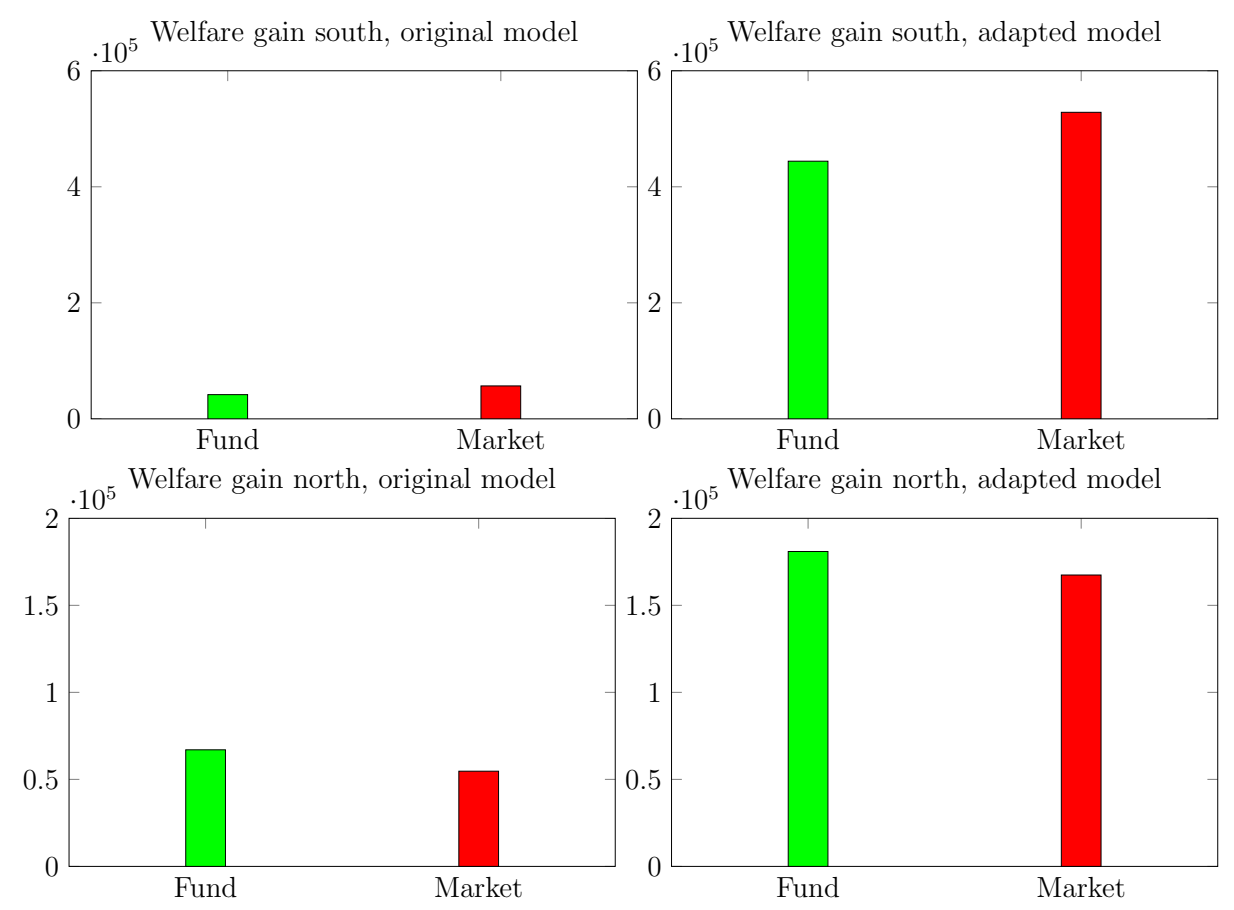

Figure 5.5: Aggregated welfare gain in the original (1.) and the adapted (r.) model in both REDD scenarios

\subsection{Sensitivity Analysis}

In this section the effects of varying parameters $A, s$ and $\delta$ on total global emissions are investigated. Sensitivity plots for optimal deforestation or other target variables do not yield much further insight and are therefore omitted.

If not stated explicitly otherwise, parameters are chosen as in Table 5.1.

As expected, the choice of parameter $A$ has a large influence on total global emissions. Figure 5.6 shows how optimal emissions decrease with increasing $A$ because investment in the green sector becomes more and more attractive for the south. However, if $A$ is chosen 0.1 or below, emissions are higher in the adapted model than in the original model from Chapter 3. In that case, the output-capital ratio is too small to provide enough incentive 

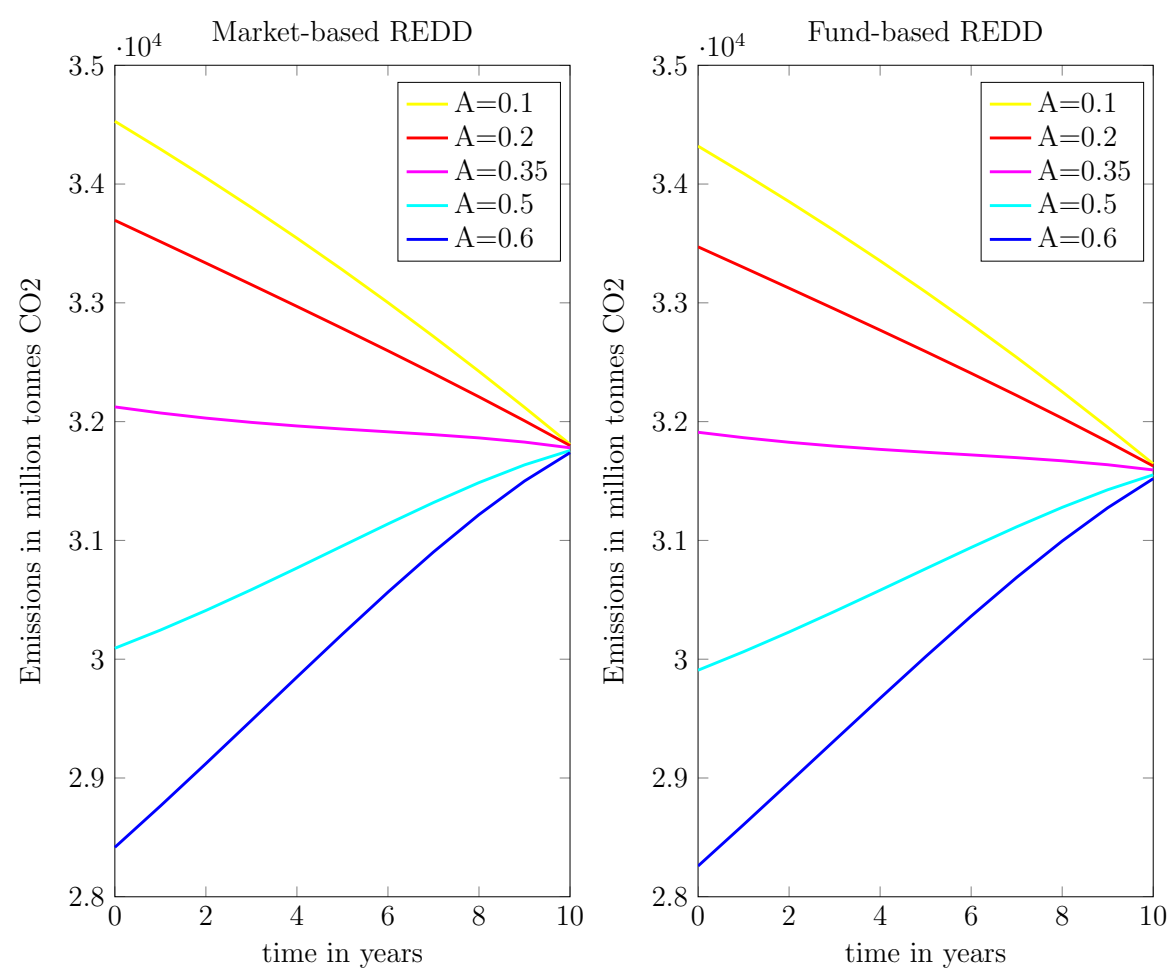

Figure 5.6: Total global emissions: variation in output-capital ratio $A$

to reduce more deforestation than in the original model.

The effect of different savings rates $s$ on total global emissions is more ambiguous. The south consumes in time $t$ the share $(1-s) A K(t)$ of the output. An increasing savings rate thus decreases the direct utility of a REDD-transfer and therefore also decreases avoided emissions from avoided deforestation. A high savings rate, however, also leads to faster capital accumulation, which indirectly increases consumption. Apparently this effect prevails (see Figure 5.7) and global emissions mainly decrease with increasing $s$.

Interestingly, in fund-based REDD there is a point in time when the emissions-curve for $s=0.3$ intersects the curves for lower savings rates. After this point in time the accumulation of capital is not that important anymore and the direct effect predominates.

The implications of varying $\delta$ are then again straightforward to interpret (Figure 5.8). The higher the rate of capital depreciation, the less utility can be derived from investing in it and the less incentive the south has to avoid emissions through deforestation.

Neither regarded variation in $s$ nor in $\delta$ leads to results where the adapted model is less effective in reducing global emissions than the original one. 

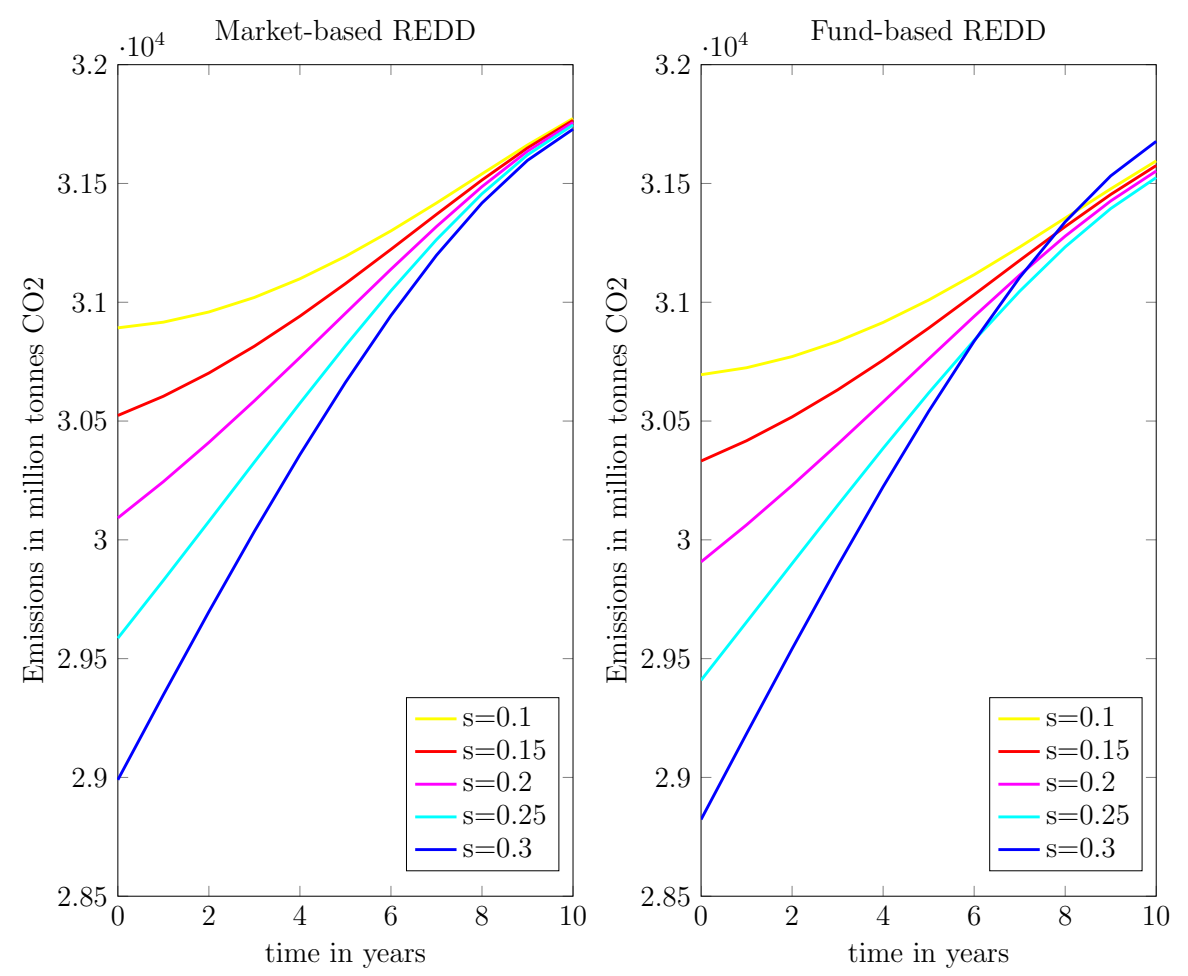

Figure 5.7: Total global emissions: variation in savings rate $s$
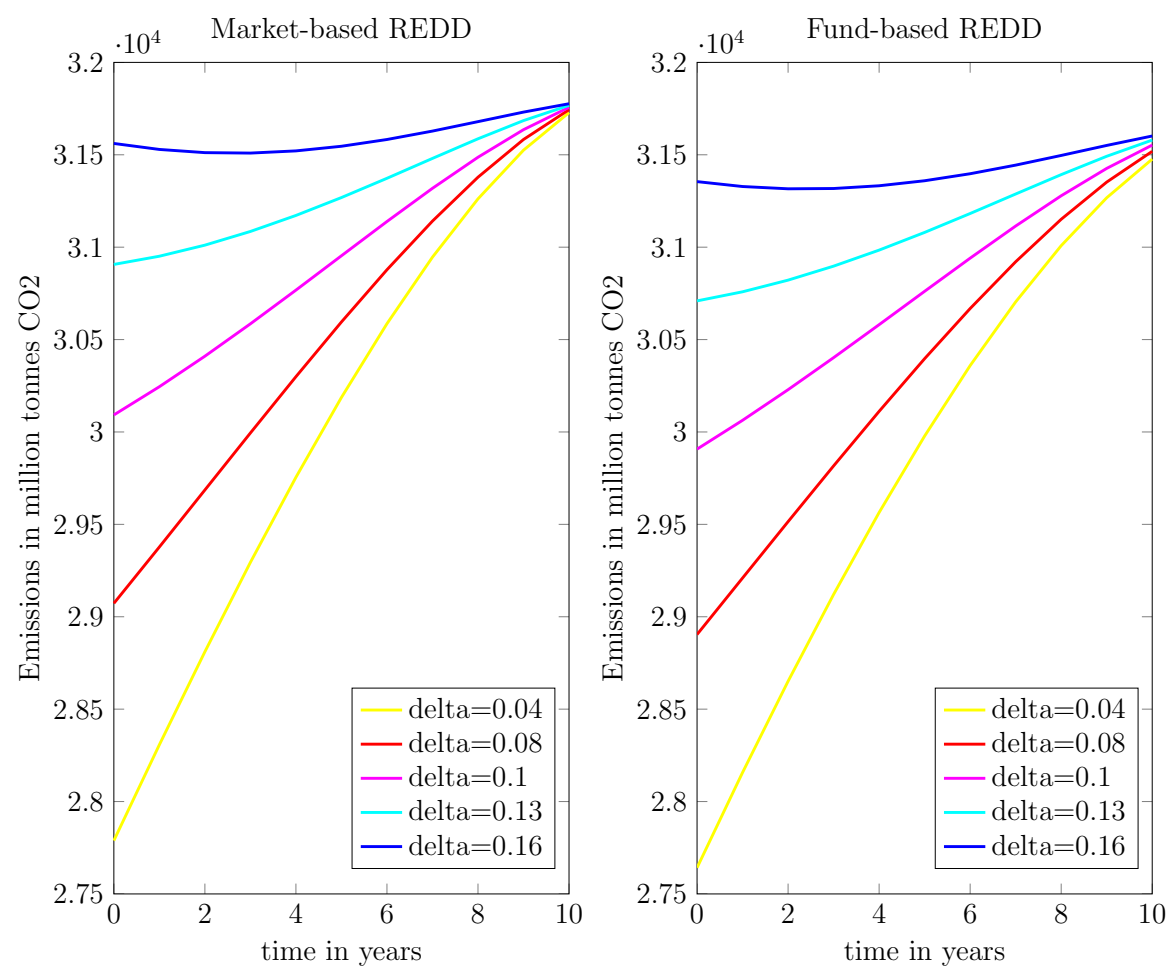

Figure 5.8: Total global emissions: variation in depreciation rate $\delta$ 



\section{Chapter 6}

\section{Conclusion}

The starting point of this thesis is to analyse the main distinguishing features of marketbased and fund-based REDD. For that purpose, a model that reproduces the main ideas of both REDD mechanisms is developed and the results are analysed. As the question, which approach can reduce global emissions more effectively, cannot be analysed independently from the reduction obligations for industrialised countries, also the optimal choice of emission caps is modelled.

It is shown that the introduction of any of the two mechanisms leads to less deforestation and less global emissions, and can thereby be a valuable contribution in the battle against climate change.

As widely believed in the real discussion, also the model shows that market-based REDD can reduce deforestation more effectively and industrialised countries are willing to pay higher compensation payments. However, also as assumed in public discussion, the therewith avoided emissions are partly compensated by increasing emissions of the industrialised countries. In fund-based REDD, industrialised countries hardly increase their emissions, because in this scenario it is not possible to use the avoided emissions from avoided deforestation towards their own emissions-reductions compliance targets. This effect is strong enough to offset the upside of the market-based approach, and total global emissions are lower in the fund-based approach than in the market-scenario.These results are robust with respect to parameter changes as well as small adaptions of the model as shown in Chapters 4 and 5.

As the chances that a REDD mechanism is implemented rather depend on the utility that agents derive from it than on its benefit for the environment, the aggregated gains in utility are analysed as well. It appears that rainforest countries favour a market-based 
approach, while industrialised countries prefer a fund. These results are again compatible with real political initiatives. This outcome is also robust to small adaptions of the model as shown in Chapters 4 and 5 and with respect to changes in agricultural yield. However, there is a threshold for environmental awareness of industrialised countries, above which preferences are exactly the other way round.

After finding these basic statements in Chapter 3, more specific aspects of REDD are highlighted in Chapters 4 and 5. These chapters can also be seen as reactions to oftenheard criticism against REDD.

In particular, Chapter 4 focuses on fairness aspects. It is found that the fairness of a REDD-mechanism depends on the underlying reason for heterogenous behaviour of agents with rainforests. If there are structural differences between the optimisation problems of the southern agents, REDD can be seen as unfair, because the bigger climate sinner, who initially deforests more, receives higher transfers from the north, or even higher prices per unit of avoided deforestation. If, however, different levels of initial deforestation are only due to different parameters, then both southern agents receive the same transfer and avoid the same amount of deforestation. To assess, which of the above attempted explanations corresponds closest to the real situation, is beyond the scope of this thesis.

In Chapter 5 it is modelled how poverty alleviation, to which REDD should also contribute according to the Bali Roadmap 2007, can be made more sustainable. The approach there is to invest REDD transfers directly into green projects rather then just letting rainforest countries consume them. It is found that as long as the output-capital ratio of the project is above a certain threshold, this new model specification is more beneficial for rainforests, climate, and both actors.

If I had to recommend one of the two REDD-scenarios, given my current understanding I would advocate a fund-based mechanism. Firstly, it leads to lower global emissions in all model specifications and for all regarded parameter sets . Furthermore, I think that scenarios where compensation payments are invested in green projects, as indicated in Chapter 5, are more likely realizable in fund-based REDD.

According to the model, industrialised countries prefer a fund and act as leaders in this game. It is therefore conceivable that industrialised countries start a fund, even though rainforest countries favour a carbon market. Once the fund is installed, rainforest countries have an incentive to generate money from that fund and will cooperate.

However, much more research can be done to put suggestions of this sort on a sound 
scientific basis.

A first future extension of the model could be to add the damage caused by climate change to the utility function of the south. This significantly raises the complexity of the model but might yield interesting results. Another adaption could affect the modelling of the green economic sector, which is quite schematic in Chapter 5. There, e.g. the savings rate could be endogenized. A structural modification of the model could be to analyse the behaviour of at least four heterogenous agents (i.e., two industrial countries and two rainforest countries). The heterogeneity might stem from differing environmental awareness or differing economic framework conditions and lead to new insights. 



\section{Bibliography}

A. D. Amato and E. Valentini. A Note on International Emissions Trading with Endogenous Allowance Choices. Economics Bulletin, 31(2):1451-1462, 2011.

Amazon-Fund. URL http://www.amazonfund.gov.br/FundoAmazonia/fam/site_en/ Esquerdo/doacoes/. Internet Platform of the Amazon Fund, accessed on 03.10.2014.

P. Andrés-Domenech, G. Martín-Herrán, and G. Zaccour. An empirical differential game for sustainable forest management. submitted, 2008.

H. Benchekroun and N. V. Long. On the multiplicity of efficiency-inducing tax rules. Economics Letters, 76:331-336, 2002.

V. Bosetti, E. Massetti, and M. Tavoni. The WITCH Model. Structure, Baseline, Solutions. Social Science Research Network Electronic Paper Collection, 2007.

V. Bosetti, R. Lubowski, A. Golub, and A. Markandya. Linking Reduced Deforestation and a Global Carbon Market: Impacts on Costs, Financial Flows, and Technological Innovation. BC3 Working Paper Series, 2009.

M. Breton, G. Zaccour, and M. Zahaf. A differential game of joint implementation of environmental projects. Automatica, 41:1737-1749, 2005.

M. Chiroleu-Assouline, J-C. Poudou, and S. Roussel. North / South Contractual Design through the REDD+ Scheme. CES Working Papers, 2013.

E. J. Dockner and N. V. Long. International Pollution Control: Cooperative versus Noncooperative Strategies. Journal of Environmental Economics and Management, 24: 13-29, 1993.

K. Dooley, I. Leal, and S. Ozinga. An overview of selected REDD proposals, 2008. URL http://www.fern.org/sites/fern.org/files/media/documents/ document_4314_4315.pdf. accessed on 04.05.2014. 
S. Ehui, P. Hertel, and P. Preckel. Forest resource depletion, soil dynamics, and agricultural productivity in the tropics. Journal of Environmental Economics and Management, 18(2):136-154, 1990.

M. Eriksson. The Role of the Forest in an Integrated Assessment Model of the Climate and the Economy. CERE Working Paper, 2013.

FAO. Global Forest Resources Assessment 2010 of the Food and Agriculture Organization of the United Nations. 2010.

T. Fatheuer. Rettet der Markt den Wald? Lateinamerika Nachrichten, 414, 2008.

C. Figuières and E. Midler. Avoiding deforestation efficiently and fairly: a mechanism design perspective, 2011. Paper presented at 18th Annual Conference of the European Association of Environmental and Resource Economists.

GRIF. URL http://www.guyanareddfund.org/. Internet Platform of the Guyana REDD+ Investment Fund, accessed on 03.10.2014.

C. Helm. International emissions trading with endogenous allowance choices. Journal of Public Economics, 87:2737-2747, 2003.

V. Holloway and E. Giandomenico. The History of REDD Policy. Carbon Planet White Paper, Carbon Planet, Adelaide, 2009.

F. Karima, G. Martín-Herrán, and G. Zaccour. Slowing deforestation pace through subsidies: a differential game. Automatica, 40:301-309, 2008.

G. Kindermann, M. Obersteiner, B. Sohngen, J. Sathaye, K. Andrasko, E. Rametsteiner, B. Schlamadinger, S. Wunder, and R. Beach. Global cost estimates of reducing carbon emissions through avoided deforestation. Proceedings of the National Academy of Sciences of the United States of America, 105(30):10302-10307, 2008.

C. Le Quéré, M. R. Raupach, J. G. Candell, and G. Marland. Trends in the sources and sinks of carbon dioxide. Nature Geoscience, 2:831-836, 2009.

G. Martín-Herrán, P. Cartigny, E. Motte, and M. Tidball. Deforestation and foreign transfers: a Stackelberg differential game approach. Computers $\&$ Operations Research, 33:386-400, 2006.

W. D. Nordhaus and J. Boyer. Warming the World: Economic Models of Global Warming. MIT Press, Cambridge Mass., 2000. 
J. G. J. Olivier, G. Janssens-Maenhout, M. Muntean, and J. A.H.W. Peters. Trends in global CO2 emissions: 2013 Report. PBL Netherlands Environmental Assessment Agency, 2013.

H. Ollivier. Growth, deforestation and the efficiency of the REDD mechanism. Journal of Environmental Economics and Management, 64:312-327, 2012.

S. Rebelo. Long-Run Policy Analysis and Long-Run Growth. The Journal of Political Economy, 99(3):500-521, 1991.

C. Sax. Wohlstand ohne Wachstum? Die Hintergrundberichte, chapter Solow Residuen im Vergleich. Bodmer, F. and Borner, S., 2004.

S. Solomon, G.-K. Plattner, R. Knutti, and P. Friedlingstein. Irreversible climate change due to carbon dioxide emissions. Proceedings of the National Academy of Sciences of the United States of America, 106(6):1704-1709, 2009.

R. M. Solow. A Contribution to the Theory of Economic Growth. Quarterly Journal of Economics, 6:65-94, 1956.

H. F. v. Stackelberg. Marktform und Gleichgewicht. 1934.

N. Stern. The economics of climate change: Stern review. Camebridge University Press, 2007.

M. Tavoni, V. Bosetti, and B Sohngen. Forestry and the Carbon Market Response to Stabilize Climate. Social Science Research Network Electronic Paper Collection, 2007.

theredddesk. URL http://theredddesk.org. Internet Platform of the The Global Canopy Programme, accessed on 01.10.2014.

D. Van Soest and R. Lensink. Foreign transfers and tropical deforestation: What terms of conditionality? American Journal of Agricultural Economics, 82:389-399, 2000.

World-Bank. URL http://data.worldbank .org/indicator/NY.GNS. ICTR.ZS. Internet Platform of the World Bank, accessed on 08.11.2014. 